\title{
LA-10294-MS
}

LA--10294-MS

DE86 007591

UC-41

Issued: January 1986

\section{A Guide to \\ Radiological Accident Considerations for Siting and Design of DOE Nonreactor Nuclear Facilities}

\author{
J. C. Elder \\ J. M. Graf \\ J. M. Dewart \\ T. E. Buhi \\ W. J. Wenzel \\ L. J. Walker \\ A. K. Stoker
}

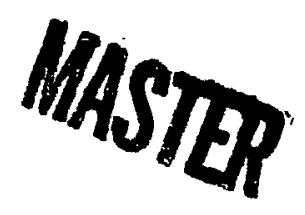

\section{DISCLAIMER}

This report was prepared as an account of work sponsored by an agency of the United Siates Government. Ne ither the United States Government nor any agency thereof, nor any of their employees, make: any warranty, express or implied, or assumes any legal liability or responsitility for the accuracy, completeness, or usefulness of any information, apparatus, product, or process disclused, or represents that its use would not infringe privately owned rights. Reference herein to any specific commercial product, process, or service by trade name, trademark, manufacturer, or otherwise does not necessarily constitute or imply its endorsement, recommendation, or favoring by the United States Government or any agency thereof. The views and opinions of authors expressed herein do not necessarily state or reflect those of the United Siater Government or any agency thereof. 
ABSTRACT $\ldots \ldots \ldots \ldots \ldots \ldots \ldots \ldots \ldots \ldots \ldots \ldots \ldots \ldots \ldots \ldots \ldots$

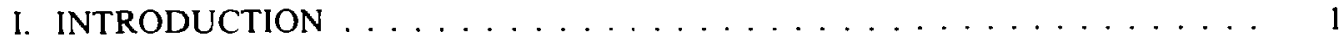

A. Need for the Guide . . . . . . . . . . . . . . . . . .

B. Status of the Guide . . . . . . . . . . . . . . . . . . . 2

C. Features of DOE Nuclear Facilities . . . . . . . . . . . . 2

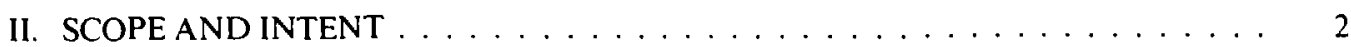

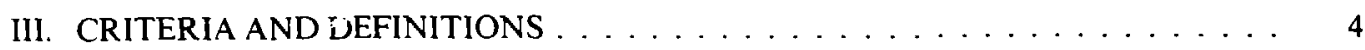

A. DOE Orders .......................... 4

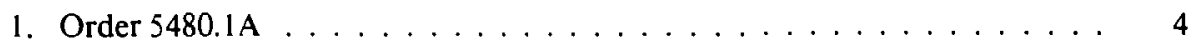

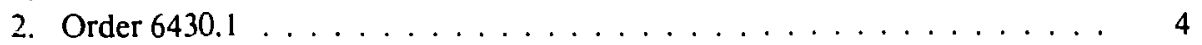

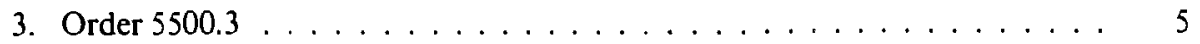

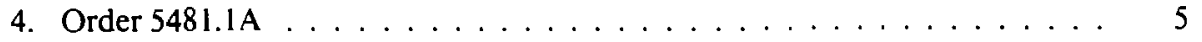

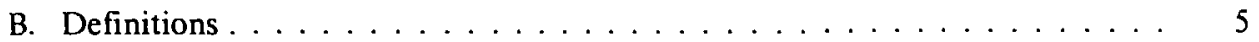

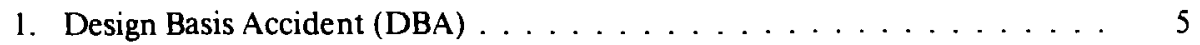

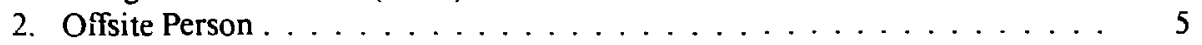

3. Population Dose . . . . . . . . . . . . . . . . . . 6

4. Population Center Distance . . . . . . . . . . . . . . . . . 6

5. Effective Dose Equivalent . . . . . . . . . . . . . . . 6

6. Risk Analysis and Risk Assessment. . . . . . . . . . . . . . . . 6

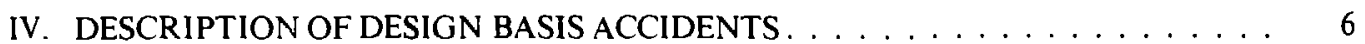

A. Operational Accidents. . . . . . . . . . . . . . . . 7

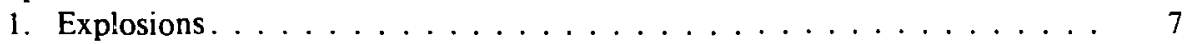

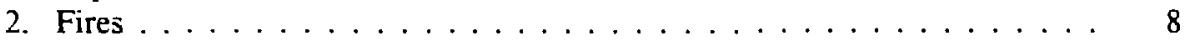

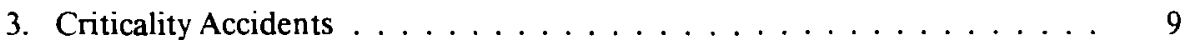

4. Leaks to the Atmosphere. . . . . . . . . . . . . . . . . . . 11

5. Leaks to the Aquatic Environment . . . . . . . . . . . 11

B. Natural Phenomena Events. . . . . . . . . . . . . . . . . 11

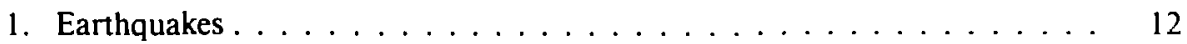

a. Site Selection . . . . . . . . . . . . . . . . . 12

b. Structural Adequacy. . . . . . . . . . . . . . . 12

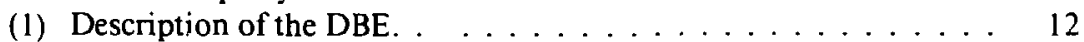

(2) Static Response Method . . . . . . . . . . . . . . 12

(3) Dynamic Analysis Method. . . . . . . . . . . . . . . . 13

(4) Determination of Damping . . . . . . . . . . . . . 13

(5) Strength Analysis (Combined Response) . . . . . . . . . . . 13

c. Component Adequacy. . . . . . . . . . . . . . . 13

d. Damage Estimation and Release Fraction. . . . . . . . . . . . . . 14

2. Tornadoes and Extreme Winds . . . . . . . . . . . . . . . . 14

a. Site Selection . . . . . . . . . . . . . . . . . 14

b. Structural Adequacy . . . . . . . . . . . . . . . 14

c. Component Adequacy. . . . . . . . . . . . . . . . . . . 14

d. Damage Estimation $c$ nd Release Fraction . . . . . . . . . . . . 15

e. Dispersion Assumptions . . . . . . . . . . . . . . 15

3. Other Natural Phenomena . . . . . . . . . . . . . . . . 15

C. Accidents with External Origins . . . . . . . . . . . . . . 15

1. Pipelines, Tankers, Barges, or Rail Cars Carrying Hazardous

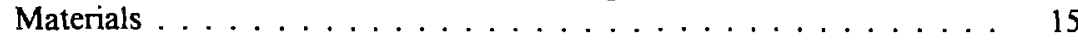

2. Aircraft and Airports . . . . . . . . . . . . . . . . . . . 16

3. Gther Nuclear Facilities or Reactors . . . . . . . . . . . . . . 16

4. Large Dams . . . . . . . . . . . . . . . . . . . . . 16

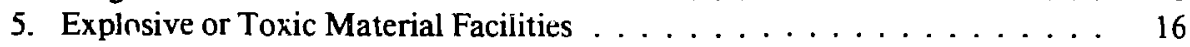

D. Accidents with Higher Probability . . . . . . . . . . . . . 16 


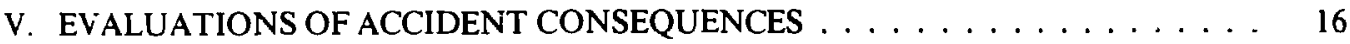

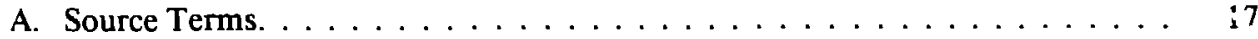

1. Radionudides. . . . . . . . . . . . . . . . . . 17

2. Radionuclide Quantities . . . . . . . . . . . . . . . . . 18

B. Release Fractions . . . . . . . . . . . . . . . . . . . . . 19

C. Reduction and Removal Factors. . . . . . . . . . . . . . . . . 21

D. Release Duration . . . . . . . . . . . . . . . . . . 23

E. Meteorological Analysis and Dispersion. . . . . . . . . . . . . . . . 24

1. Gaussian Dispersion Model . . . . . . . . . . . . . . . . . . . 24

2. Dispersion Parameters/Stability Classifications . . . . . . . . . . . . . 24

3. Release Effects . . . . . . . . . . . . . . . . . . 24

a. Plume Rise . . . . . . . . . . . . . . . . . . . . . . 24

b. Stack and Building Wake Effects . . . . . . . . . . . . . 24

4. Dispersion Effects. . . . . . . . . . . . . . . . . . . 24

a. Radioactive Decay. . . . . . . . . . . . . . 25

b. Inversion Lid. . . . . . . . . . . . . . . . . . . 25

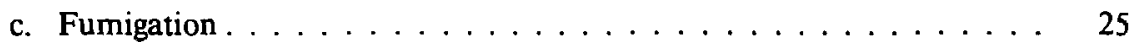

d. Terrain . . . . . . . . . . . . . . . . . 25

e. Dry Deposition. . . . . . . . . . . . . . . . . . 25

5. Meteorclogy . . . . . . . . . . . . . . . . . . . 25

6. Population Dose . . . . . . . . . . . . . . . . . . 25

F. Radiological Dose . . . . . . . . . . . . . . . . . . . . . 25

1. Inhalation Dose. . . . . . . . . . . . . . . . . . 25

2. Direct Irradiation from Cloud Immersion . . . . . . . . . . . . . 26

3. Ingestion Dose . . . . . . . . . . . . . . . . . . 26

G. Other Consequences to be Considered. . . . . . . . . . . . 26

1. Environmental Contamination . . . . . . . . . . . . . . . 26

2. Population Dose . . . . . . . . . . . . . . . 27

3. Public Health Effects . . . . . . . . . . . . . . . . . 27

ACKNOWLEDGMENTS $\ldots \ldots \ldots \ldots \ldots \ldots \ldots \ldots \ldots \ldots$

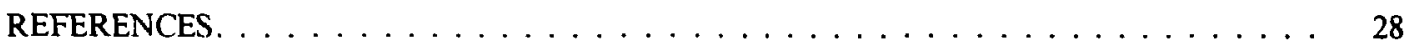

APPENDICES

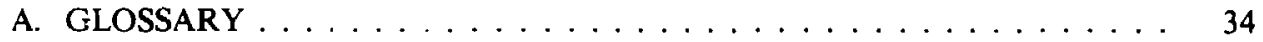

B. RADIATION DOSE AND HEALTH EFFECTS. . . . . . . . . . . . . 39

C. RISK ASSESSMENT METHODS. . . . . . . . . . . . . . . . . 43

D. DISPERSION CALCULATION METHODS . . . . . . . . . . . 46

E. DOSE METHODS . . . . . . . . . . . . . . . . . . . 52

F. DOSE CODE COMPARISON . . . . . . . . . . . . 58

G. ENVIRONMENTAL CONTAMINATION CONCERNS . . . . . . . . 61

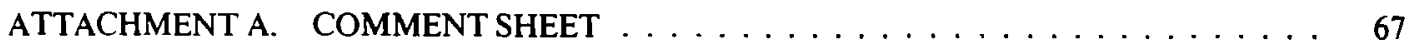

TABLES

I. SUMMARY OF NONREACTOR NUCLEAR FACILITY TYPES . . . . . . . . . 3

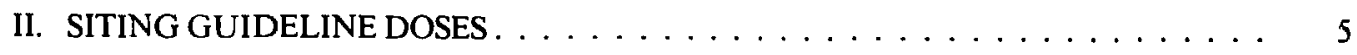

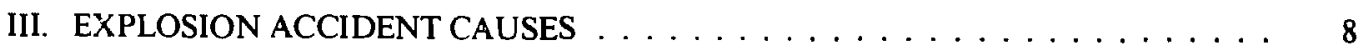

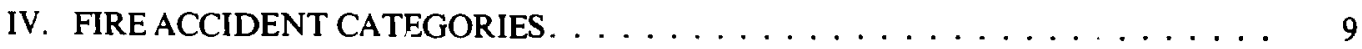


V. CRITICALITY ACCIDENT FISSION YIELDS . . . . . . . . . . . 10

VI. POTENTIAL RADIOLOGICAL DOSE GUIIDELINES FOR ACCIDENT

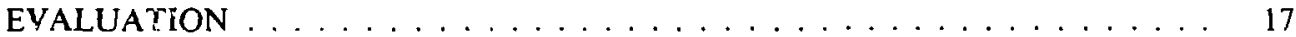

VII. IMPORTANT RADIONUCLIDES FOR ORGAN DOSE CALCULATIONS . . . . 20

VIII. SAFETY ANALYSIS PARAMETERS SUMMARY－RELEASE ERACTIONS . . . 22

IX. SAFETY ANALYSIS PARAMETERS SUMMARY - REDUCTION AND REMOVAL

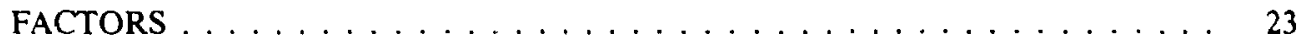

B-I. LIFETIME RISK OF DYING OF A RADIATION-INDUCED CANCER . . . . . . . 41

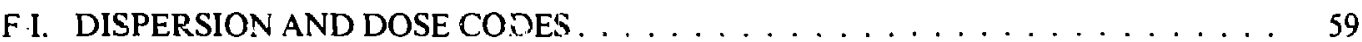

F-II $\quad$ SUMMARY OF RESULTS $\ldots \ldots \ldots \ldots \ldots \ldots \ldots \ldots \ldots$

G-I. DECONTAMINATION FACTORS FOR $\mathrm{PuO}_{2} \ldots \ldots \ldots \ldots \ldots$

G-II. FCPULATION DENSITY AND LAND USE FRACTIONS FOK AGRICULTURAL,

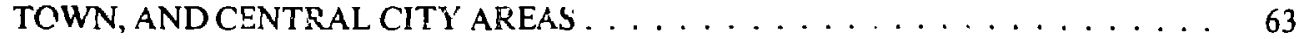

G-III. BUILDING AND DWELLING PARAMETER ESTIMATES . . . . . . . . . . 63

G-IV BUILDING TYPE AND LAND USE AREA FRACTION ESTIMATES . . . . . . . 64

G-V. DECON TAMINATION METHODS AND COSTS (1981 DOLLARS) FOR AGRICULTURAL, SiJBURBAN, AND COMMERCIAL AREAS FOR $\mathrm{PuO}_{2} \ldots \ldots 65$

G.VI. TOTAL, DECONTAMINATION CCST SUMMARY ESTIMATES . . . . . . . 66

\section{FIGURES}

Figure 1. Earthquake analysis steps. . . . . . . . . . . . . . . 13

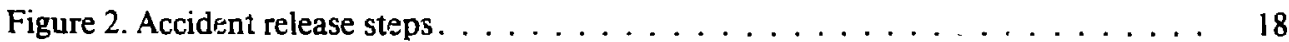

Figure 3. Accident consequence steps . . . . . . . . . . . . . . . . 19 


\title{
A GUIDE TO RADIOLOGICAL ACCIDENT CONSIDERATIONS FOR SITING AND DESIGN OF DOE NONREACTOR NUCLEAR FACILITIES
}

\author{
by \\ J. C. Elder, J. M. Graf, J. M. Dewart, T. E. Buhl, \\ W. J. Wenzel, L. J. Walker, and A. K. Stoker
}

\begin{abstract}
This Guide was prepared to provide the experienced safety analyst with a zcident analysis guidance in greater detail than is possible in Department of Energy (DOE) Orders. The Guide audresses analysis of postulated serious accidents considered in the siting and selection of major design features of DOE nuclear facilities. Its scope has been limited to radiological accidents at nonreactor nuclear facilities. The analysis steps addressed in the Guide lead to evaluation of radiological dose to exposed persons for comparison with siting guideline doses. Other possible consequences considered are environmental contamination, population dose, and public health effects. Choices of models and parameters leading to estimation of source terms, release fractions, reduction and removal factors, dispersion and dose factors are discussed. Although requirements for risk analysis have not been established, risk estimates are finding increased use in siting of major nuclear facilities and are discussed in the Guide.
\end{abstract}

\section{INTRODUCTION}

\section{A. Need for the Guide}

A DOE guide in the area of postulated radiological accident analysis at nonreactor nuclear facilities was provided to supply more detail than that practical in the DOE Orders. Further, collection of related information in a guide of this type was considered useful for conducting radiological accident analysis within the DOE complex.

Major requirements for the siting and design of nuclear facilities as formulated by the Nuclear Regulatory Commission (NRC) and DOE are found in the Code of Federal Regulations (CFR, Title 10) and DOE Orders respectively and are stated in terms of radiation dose (or effective dose equivalent) calculated at a specified location. Although the siting criteria doses may be unambiguous, the many models, parameters, and assump- tions necessary for the intermediate calculational steps between the postulated accident and the resultant dose are not specified. The NRC addresses this situation by issuing supplementary guidance such as teclınical information documents, safety guides, and regulatory guides. This supplementary information is available to and has been appropriately used by DOE safety analysts; however, it is specific to the types of facilities licensed by NRC, particulariy light-water reactors (LWRs). That the DOE should apply reactor-based criteria to nonreactor facilities has been implied in DOE Orders. However, applying criteria intended for LWR power plants to DOE facilities that may be "first of a kind," located remotely on a DOE reservation, and already subject to strict regulatory control is often not appropriate. Recognition that a numerical limit should be accompanied by guidance for its application led to the preparation of this Guide. Its scope is limited to accidental release of radioactive material from nonreactor nuclear facilities. 


\section{B. Status of the Guide}

This Guide should be regarded only as a guide, not as a regulation or standard or as a statement of DOE policy. DOE Orders remain the primary source of requirements related to nuclear facility siting, design, and safety analysis. The status of the Guide as a substantial document useful to the safety analyst has been enhanced by an effort to obtain careful pcer review. Following the suggestions contained in this Guide should lead to compliance with applicable DOE Orders.

The extent to which the Guide will receive continuing review and revision has not been determined. This will depend on its usefulness, the extent of its utilization by field offices and contractors, and the feedback received during the first year or two after its issue.

A comment sheet has been included as Attachment A to encourage the user to provide the authors with input as the need arises.

\section{Features of DOE Nuclear Facilities}

DOE nonreactor nuclear facilities house a broad variety of processes, a number of which contain radiological hazards with potential for onsite and offsite consequences in the event of a major accident. These potential hazards are generally of lower magnitude than those associated with nuclear reactor facilities because of a lower inventory of radicnuclides and lower levels of dispersive energy. However, careful analysis of potential accidents in nuciear facilities is required to assure that the combination of proper siting and design of safety features would provide a high degree of safety for members of the public. This is accomplished by considering siting criteria and safety features described in later sections.

Nonreactor nuclear facilities are defined in DOE Order 5480.1A, Chapter V, "Safety of Nuclear Facilities," as

Nuclear Facility. A facility whose operations involve radioactive materials in such form and quantity that a significant nuclear hazard potentially exists to the employees and the general public. Included are facilities that (1) produce, process, or store radioactive liquid or solid waste, fissionable materials, or tritium; (2) conduct separations operations; (3) conduct irradiated materials inspection, fuel fabrication, decontamination, or recovery operations; (4) conduct fuel enrichment operaticns. Incidental use of radioactive materials in a facility operation (e.g., check sources, radioactive sources, and $x$-ray inachines) does not necessarily require the facility to be included in this definition.

Nuclear facilities are further categorized in DOE Order 6430.1, Chapter IV, as either critical or noncritical facilities (DOE 1983A). Critical facilities are those for radioactive material handling, processing, or storage, and other facilities having vital importance to DOE programs or high dollar value [such as plutonium processing, tritium processing, weapon assembly $(\mathrm{HE} / \mathrm{Pu})$, and certain storage facilities]. Noncritical tàcilities are other facilities that meet the definition of nuclear facilities (above).

The major categories of DOE nonreactor nuclear facilities and a summary of processes, prominent radionuclides, dispersive energy potential, and accident types most likely to be the design basis accident (DBA) are presented in Table I. The entries in Table I are discussed in greater detail in the Standards and Criteria Guide (Brynda 1981). There may be other nuclear facility types which require analysis of a DBA.

\section{SCOPE AND INTENT}

The Guide focuses on the implementation of DOE Order 5480.1A, Chapter V, DOE Order 5500.3, and DOE Order 6430.1, "General Design Criteria Manual." It also has illcidental application to DOE Order 5481.1A, "Safety Aralysis and Revieu System." Its most direct application is to DOE Order 6430.1, which contains guidance on siting anó major cesign features of nuclear facilities. Order 6430.1 discusses gene1al requirements, largely leaving the choice of analysis method and parameters to the analyst. The large number of analysis methods available have resulted in variations among analysts seeking to answer the basic questions:

- Does the proposed site meet the siting guidclire doses?

- Is the proposed site more suitable than alternative sites, based on consideration of other potential consequences of an accident, such as population dose, environmental contamination, or public health effects?

- Can ernergency planning requirements be inet at the proposed site?

- Can an existing aacility safely house a new process? 


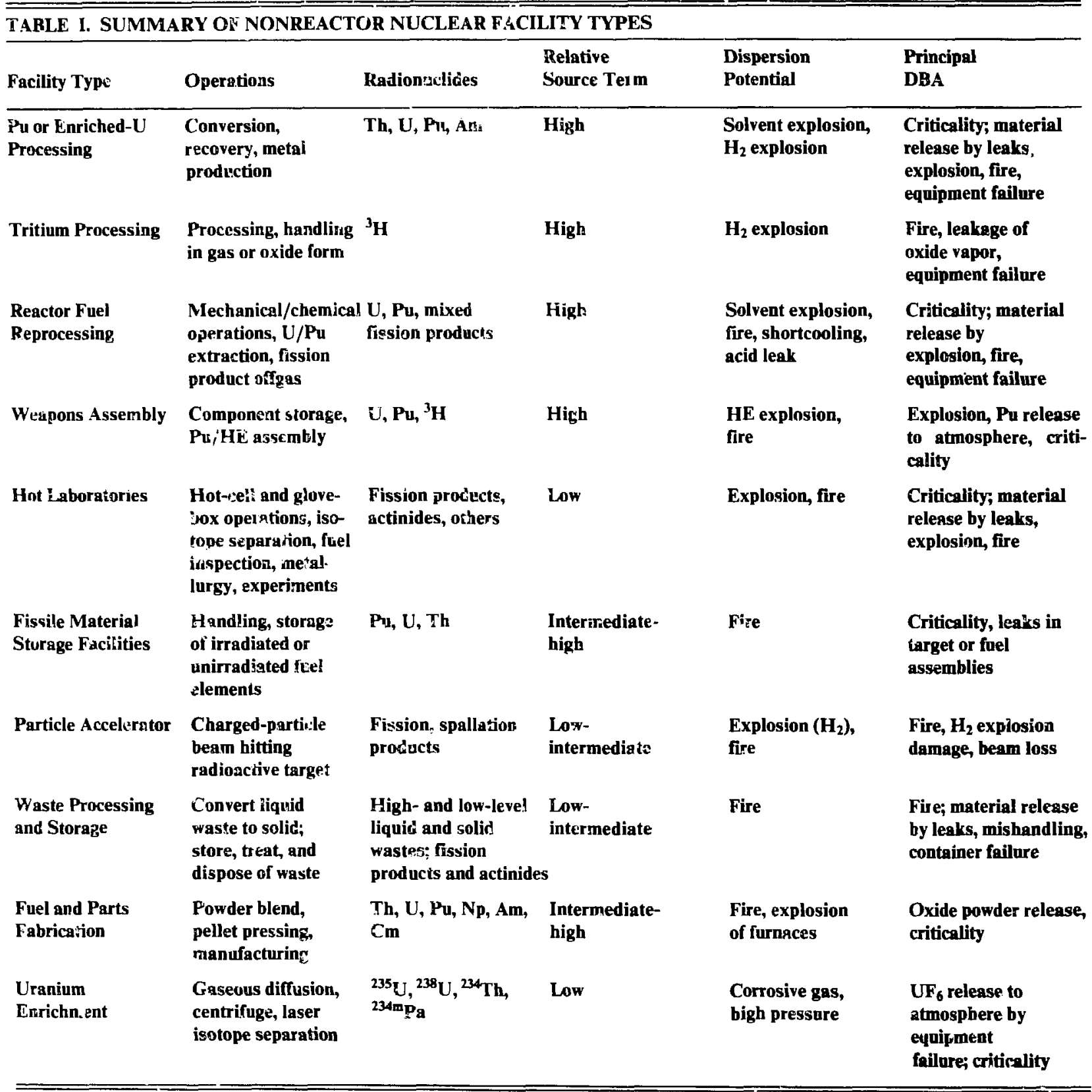


The Guide has been compiled to aid experienced analysts in applying analysis techniques consistently to all accidents with major potential for radiological consequences. It is not intended as a tutorial document or as a guide to writing safety analysis reports (SARs). The Guide should be useful anywhere postulated accident analysis is required, that is, for SARs, design analysis, environmental documentation, emergency planning, etc. Its primary utility will probably be as a tool for the analyst and will contain useful information and quality references. Areas either vague or not covered by experimental data are identified, and in some cases, specific assumptions are suggested.

Covering all aspects of radiological accident analysis was not considered possible or practical. The analyst should not assume all areas of accident dnalysis have been covered in the Guide, although an attempt has been made to deal with all important issues.

\section{CRITERIA AND DEFINITIONS}

\section{A. DOE Orders}

1. Environmental Protection, Safety, and Health Protection Program for DOE Operations (Order 5480.1A). DOE Order 5480.1A, Chapter I (DOE 1981A), "Environmental Protection, Safety, and Health Protection Standards," provides as a recommended standard for nuclear facility safety "appropriate portions of Reactor Site Criteria" (10 CFR 100, revised, CFR 1962). DOE Order 5480.1A, Chapter V (DOE 1981 B), "Safety of Nuclear Facilities," establishes safety procedures and requirements for nuclear facilities (reactors and accelerators are exceptions in Chapter V) to assure

... that nuclear facilities are sited, designed, constructed, modified, operated, maintained, and decommissioned in accordance with generally uniform standards, guides, and codes that are consistent with those applied to comparable licensed nuclear facilities.

Although the $10 \mathrm{CFR} 100$ site criteria were issued specifically for siting stationary pressurized-water and boiling-water reactors, they have represented for over 20 yr the only authoritative siting guidance and have been applied to nonreactor facilities by NRC and DOE (or previously by the Atomic Energy Commission (AEC) or Energy Research and Develonment Administration
(ERDA)]. More recent guidance has been proposed for use within DOE in DOE Order 6430.1, as discussed in tie following sections.

DOE Order $5480.1 \mathrm{~A}$ also requires that adequate consideration be given to environmental protection, safety, and health protection matters throughout the life of a nuclear facility, including its siting. Its operation must not create undue environmental protection, safety, or health protection risks. Evaluation methods applied to accident effects in these areas are addressed in the Guide.

2. General Design Criteria (Order 6430.1). The DOE implements radiological accident guidance for siting and major design features in DOE Order 6430.1, "General Design Criteria Manual" (DOE 1983A). DOE policy stated in Order 6430.1 requires that "DOE facilities be designed and constructed to be reasonable and adequate for their intended purpose and consistent with health, safety, and environmental protection requirements."

Dose guidelines proposed for inclusion in Chapter I of DOE Order 6430.1 to limit a one-time accidental dose from a major credible accident are as shown in Table II. The proposed guideline doses for whole body and thyroid are purposely consistent with existing siting criteria in 10 CFR 100. Bone surface and lung doses are based on ratios of ICRP weighting factors $(0.03$ for bone surfaces, 0.12 for lungs) to the thyroid weighting factor (0.03) (ICRP 1977). This rationale was developed by NRC in the Clinch River Breeder Reactor site suitability decision (NRC 1977A). Determination of effective dose equivalent is discussed in Section III.B.6.

The following caveat should accompany each publication of the guidelines to aid in keeping dose guidelines in proper perspective (CFR 1962):

The use of these guideline doses is not intended to imply that these doses constitute acceptable limits for emergency doses to the public under accident conditions. Rather, these values are reference values to be used in the evaluation of facility sites with respect to potential accidents of exceedingly low probability of occurrence and low risk of public exposure to radiation. They do not apply to facility operations under normal or emergency status, nor to emergency dose guidelines that might be appropriate for the general public should an accident occur. 
TABLE II. SITING GUIDELINE DOSES ${ }^{a}$

\begin{tabular}{lcl}
\hline & \multicolumn{2}{c}{ Dose } \\
\cline { 2 - 3 } Organ & (rem) & (Sv) \\
\hline Whole body & 25 & 0.25 \\
Thyroid & 300 & 3.0 \\
Bone surface & 300 & 3.0 \\
Lungs & 75 & 0.75 \\
Effective dose equivalent & 25 & 0.25 \\
\hline
\end{tabular}

Assuming a 50-yr committed dose equivalent.

The radiological guidelines in DOE Order 6430.1, Chapter I, require consideration also be given to onsite personnel when the site and major design features are selected. Consideration of the onsite person is stated in DOE Order 6430.1, Chapter I, to be "prudent measures associated with the radiological protection of onsite personnel and in conjunction with onsite emergency planning, as required through implementation of DOE Order 5500.3." The guidanise on dose methodology provided herein is considered useful in meeting the requirements of DOE 5500.3 related to emergency radiological response plans.

3. Nuclear Facility Emergency Planning, Preparedness, and Response Programs (Order 5500.3). This order requires emergency actions to respond to the onsite and offsite consequences of a radiological emergency and to assure protection of onsite personnel, public health and safety, and the environment.

4. Safety Analysis and Review System (Order 5481.1A). Postulated accident considerations are discussed in appropriate detail in DOE Order 5481.1A in terms of safety analysis (DOE 1981C). Accident-related topics to receive analysis or be addressed are

- identification of hazards,

- potential accidents,

- probability of occurrence,

- physical design features and administrative controls to prevent or mitigate potential accidents, and

- predicted consenuences.

Various DOE field offices have prepared parallel orders to implement DOE Order 5481.1A. These orders are generally more specific to the operational needs of contractor activities under a field office and might not be applicable across the DOE complex.

\section{B. Definitions}

The glossary of the Guide (Appendix A) contains definitions of many terms used in the Guide. Definitions needing further elaboration and discussion are included in this section.

1. Design Basis Accident (DBA). All credible accidents are evaluated for the purpose of cstablishing the s.eed for certain design features in a nuclear facility and approving its siting. The DBA is that accident causing the most severe consequences ano is compared with the guideline doses.

Credibility of a potential accident is based on the annual frequency at which the accident is expected to occur. Accident-frequency data to support a probability estimate may be lacking. In this case, a deterministic approach similar to TIL-14844 (AEC 1962) may be applied. Assumptions should contain a suitable level of conseryativism. Credibility limits in the range of $10^{-8}$ to $3 \times 10^{-5}$ occurrences per year have been used within the DOE and elsewhere (Lucas 1981, Clemens 1982, ALO 1982, ANSI 1976, NRC 1983). This Guide suggests an approximate annual frequency of $10^{-6}$ be used to establish the credibility of potential DBAs. The selection of $10^{-6} / \mathrm{yr}$ is based primarily on a general consensus among risk analysts to consider a frequency of $10^{-5} / \mathrm{yr}$ as a frequency which should cause concern if the accident consequence is high; conversely, a frequency lower than $10^{-7} / \mathrm{yr}$ is considered so low as to be almost indeterminate or nonsensical. Therefore, any postulated major accident which has an estimated annual frequency approaching $10^{-6} / \mathrm{yr}$ should be considered credible.

2. Offsite Person. The offsite person is a nember of the exposed offsite population and is assumed to be located at the site boundary. His dose, which may be a whole-body dose, an individual-organ dose, or an effective dose equivalent, is compared with the siting guideline doses proposed for DOE Order 6430.1 (also listed in Section III.A.2). The exposure received by the offsite person should depend on unfavorable, site-specific meteorology data (methods are discussed in Section V.E.5.). As a general rule, the offsite person is assumed to be present at the centerline of the cloud for a period of $2 \mathrm{~h}$ unless cloud passage or evacuation within a shorter time is a reasonable assumption at the proposed site. It may be assumed that any person who might be considered the offsite person is lawfully occupying the location and will consent to evacuation. The offsite person should be assumed to be the individual most affected by the released material. In most cases tikis 
person is characterized by the ICRP reference man (ICRP 1974). A possible exception is a radioiodine exposure in which the dose to an infant's thyroid might result in a higher effective dose equivalent.

3. Population Dose. Population dose is an estimate of total radiation dose received by members of a population group exposed to the radionuclides released by the postulated accident. It can represent a collective wholebody dose, collective dose to a specific organ, or a collective effective dose equivalent. Consideration of population dose may be appropriate under some circumstances, such as the case where several sites are being compared. Population doses may show a decisive advantage of one site over the others.

Estimation of population dose and potential public health effects is addressed in Section V.G.

4. Population Center D'stance. Population center distance is defined as the minimum distance from the proposed nonreactor nuclear facility (structure, not boundary) to the nearest population center. DOE Order 6430.1 does not specify a population center distance other than by indirect reference to 10 CFR 100. A population center is defined in 10 CFR 100 as a densely populated center containing more than about 25000 residents. To establish a minimum distance to a population center, the 10 CFR 100 calculation ( 1.3 times a lowpopulation-zone outer-boundary distance) is suggested, if the release is delayed over $2 \mathrm{~h}$.

Some population center boundaries are vague; that is, sprawling suburbs may approach the proposed site in an irregular pattem, making a single population center distance difficult to choose. Political boundaries are not generally invoked as population boundaries without consideration of actual residences, including the possibility of future expansion bringing residences closer to the facility. It will be necessary to evaluate each siting case on its own particular features and make judgments that may not be always consistent among analysts.

5. Effective Dose Equivalent. Effective dose equivalent is a specialized dose value relating doses received by multiple organs to a single whole-body dose for the nurpose of comparison with sitiing guideline doses. It is based on the ICRP 26 approach that risk of delayed mortality should be the same whether the whole body is irradiated uniformly or whether several organs receive the dose (ICRP 1977). The ICRP 26 approach replaces the critical organ concept, which has been in use for many years. The effective dose equivalent is the sum of doses to each organ receiving dose (including whole body), after each organ dose is multiplied by an organ weighting factor. These weighting factors are based on somatic health effects data derived from many sources. Some organ nsk factors are still in question. Health effects data, the weighting factors that may be derived from them, and related topics are discussed in Appendix B.

6. Risk Analysis and Risk Assessment. Risk is the combination of probability that a serious event will occur (number of events per unit time) and the estimated consequences of that event (commonly cancers or deaths or rem). The common practice of calling risk the product of probability and consequence is not considered sufficiently informative because both components are needed to fully describe the nature of the risk. Risk analysis is considered the specific technique, such as fault or event tree analysis, which is used to perform the broader process of risk assessment. Since the DOE has not specifically adopted a risk assessment method or defined an acceptable level of risk, treatment of this subject in the Guide is limited to discussion of risk assessment methods presently in use by DOE contractors: qualitative (informal) methods and probabilistic (formal) methods. Ongoing activity in this area by DOE and its contractors is encouraged, along with active information exchanges with other safety analysts not presently equipped to perform probabilistic risk assessment. Sources of risk analysis and risk assessment methods are discussed further in Appendix C.

\section{DESCRIPTION OF DESIGN BASIS ACCI- DENTS}

Requirements for identification and description of the DBAs are set forth in DOE Order 6430.1, Chapter I, and other chapters which are facility specific. Proposed nuclear facilities must be sited and designed to provide confinement of radioactive materials under normal operations and DBA conditions. The DBAs are the postrilated accidents and resulting conditions against which the structure, systems, and equipment must meet their functional goals. The analysis of DBAs serves two major purposes: to determine the need during the design phase for engineered safety features (ESFs) and other controls, and to justify that the proposed facility including the ESFs will adequately meet siting guideline doses in the event of the DBA.

Both internal and external initiating events must be considered. Unless the facility is specifically designed to withstand all credible external initiating evenis, some release of radioactive material from these events must be assumed. This release should be estimated and shown to be lower than that which could cause dose in 
excess of the siting guideline doses in DOE Order 6430.1, Chapter I (also in Guide Section III.A.2). The steps involved in evaluation of accident consequences are discussed in Section V.

The processes in the nuclear facility should be carefully reviewed to assure that all potential accidents that could qualify as DBAs have been described and analyzed, both for their probabilities and their consequences. The traditional deterministic method is acceptable as well as some form of risk assessment (a consideration of both probability and consequence). An informal, qualitative approach or a more formal, quantitative approach may be used, if a comprehensive, systematic, well-reviewed, and well-documented analysis is performed. Two general methods of risk assessment (qualitative and quantitative analysis methods) are presently in use within the DCE complex and are discussed in Appendix C.

The depth of analysis should be in some measure proportional to the level of risk at the facility under evaluation. Certainly, critical nuclear facilities (plutonium processing, tritium processing, weapons assembly, and reactor fuel reprocessing) shoul $i$ be subjected to a rigorous formal risk assessment or a deterministic analysis containing a suitable level of conservatism in the estimation of accident consequences. The following assumptions are presented as examples, all or part of which might be included in formulation of DBAs:

- A worst-case release mechaniism is assumed, consistent with credible but conservative selection of physical and chemical parameters of the released material.

- The maximum amount of dispersible material allowed in the facility is assumed available for release.

- Maximum release fraction based on the physical and chemical parameters is assumed.

- Credit for ESFs and administrative controls such as evacuation is based on degraded performance unless they are clearly unaffected by the accident.

- Unfavorable atmospheric or aquatic dispersion conditions are assumed.

- Radiological dose calculations are based on a 50-yr dose accumulation time and selection of breathing rate, particle size, and chemical solubility class, leading to doses which contain a suitable level of conservatism.

\section{A. Operational Accidents}

The DBA could be an operational accident caused caused by an internal event. Direct causes are usually poor design or procedures, operator errors, equipmen' failures, or inadequate technical development (un- knowns) that lead to the accident. The majo: accident categories are explosion, fire, nuclear criticality, leaks to the atmosphere, and leaks to the aquatic environment. Event histories have been prepared that can aid the analyst in deciding what operational accident could be the DBA for the proposed facility (for example, Perkins $1980,1981)$. Several other reports contain useful descriptions of accidents and suggested parameters applicable to many operational DBAs (Selby 1975, Faust 1977, Walker 1978, ANSI 1076, ANSI 1980, and ORNI 1970).

1. Explosions. The processes in the facility must be reviewed for notential energy release by explosion or other uncontrolled reaction that could release radioactive material to the atmosphere or aquatic environment. The major causes of explosions involving radioactive materials are listed in Table III. The list should not be considered all-inclusive but contains a summary of major accident types either noted as actual events in event histories or postulated events considered to be credible through accident analysis.

Experimental or explosion accident investigation data available in the literature have been summarized by Walker (1978); major sources of dispersal information are Selby (1975), Mishima (1966, 1970), and Castleman (1969). In the absence of applicable information, simplifying but conservative assumptions should be made. For example, maximum airborne concentration of respirable particles within the space into which solid particles or liquid droplets are dispersed by an explosion probably will not exceed $100 \mathrm{mg} / \mathrm{m}^{3}$ after the first $10 \mathrm{~min}$ (Selby 1975). Release fractions are discussed further in Section V.B.

For facilities other than a weapons assembly (HE/ru) facility, dispersal beyond the facility structure may be limited by an assumption of structural integrity if blast barriers are provided around conceivable blast locations and engineered safety features are unaffected. In this case, the radioactive material would be discharged through the ventilation system at its normal discharge rate and released at effective stack height. Otherwise, the release should be assumed a puff release at ground level.

$\mathrm{HE} / \mathrm{Pu}$ assembly cells designed to fully contain an $\mathrm{HE}$ detonation may release limited amounts of material through facility peneirations. An analysis method of this case may also be found in the Pantex Environmental Impact Statement (EIS) (DOE 1983B) and supporting documents. A detonation accident at existing $\mathrm{HE} / \mathrm{Pu}$ facilities (weapons assembly cells tinat canrot fully contain a detonation) should be assumed to release $100 \%$ of $\mathrm{Pu}$ present as an aerosol and $20 \%$ as a respirable aernsol. A suggested method of accident analysis in which an elevated cloud of accident debris is dispersed may be found in the Pantex EIS and supporting documents (DOE 1983B). 


\section{TABLE III. EXPLOSION ACCIDENT CAUSES*}

\section{Chemical Processing}

1. $\mathrm{H}_{2}$ explosion- $\mathrm{H}_{2}$ from radiolysis, $\mathrm{Na}-\mathrm{H}_{2}$ reaction, fluoride-zirconium reaction in dissolver or in a reducing furnace.

2. Solvent or red oil explosion-organics in evaporators, concentretors, denitrators.

3. Hydrazoic acid explosion (hydrazine).

4. Ion exchange resin-fire followed by explosion.

5. Unstable co nyounds-silver-nitrogen-halogen compounds, ammonium nitrate, mercury compounds.

Weapon Assembly

1. High-explosives ćetonatiun-uncased $\mathrm{HE} / \mathrm{Pu}$ or $\mathrm{HE} / \mathrm{U}$, during assembly.

\section{General}

1. Powdered metals

2. Hydrogen

3. Acetylene

4. Volatile organic liquiuis

5. Nitrates

6. Peroxides
7. Methane

8. Ozone

9. Picric acid

10. Explosive gas mixtures

11. Fuels, natural gas

'Perkins 1980, Perkins 1981, Selby 1975, Walker 1978.

Frequency of explosions in chemical processing, fuel fabrication, and radioactive material processing plants can be estimated from event histories. A typical approach to estimating accident probability from failure rates and accident frequencies is described by Selby (1975, p. 92). Receni sources of data have been collected by Perkins $(1980,1981)$. Source terms, release fractions, and $E$ valuation of accident consequences are discussed further in Section V.

2. Fires. The processes in the facility must be reviewed for potential release of radioactive material by fire damage. DOE Order 6430.1 specifies design criteria for nuclear facilities (Chapter $\mathrm{X}$ and in specific facility chapters). Fire resistance requirements are stated as a 2 $\mathrm{h}$ minimum fire barrier in the major walls, floors, and ceilings acting as a secontay ur tertiary confinement system. Four-hon- idrriers are required if the potential cost of fire damage exceeds $\$ 75$ million. It may be assumed that the fire does not bieach the structure if proposed fire protection (sprinklers and other systems) and restricted fire loading in the building are such that the fire should be extinguished within $2 \mathrm{~h}$. A plume release at effective release height may be assumed. If breach of the building cannot be excluded, breach of the confinement system followed by ground-level plumemodel release (adjusted for thermal plume rise, if appropriate) should be assumed.

Assumptions regarding fire-caused release of radioactive material from confinement will vary among nuclear facilities and should be substantiated for eack case. The following general statements will usually apply to most facilities:

- All systems designed as critical systems operate normally throughout the event.

- Air cleaning systems operate normaily during the fire if they receive adequate protection from direct nire damage of system components; HEPA filters operate with accident-case efficiencies (stated in Section V.C.) or with higher efficiency if adequate protection is provided by sprinkler systems, demisters, and prefilters.

- Any installed fire protection system functions as designed. 
- Amcunts of flamınable materials and radioactive materials in rolved in the fire are the maximum amounts actually present durine full-capacity operation. Case-specific location of flammable material, separate from radioactive materials, may be used to mitigate the consequences of the fire; otherwise, estimates should include the more conservative assumptions.

- The amount of radicactive material ir the source term includes the total amount of disper sible material normally in process within an area surrounded by a 2 - or 4 -h fire barrier.

Selection of release tractions should be based on appropriate experimental or historical data where possible. Sirice the amount of material released is dependent on the form and vriatility of the material and the air velocity across the material, no single release fraction can be assumed. Source terms, release fractions, and evaluation of accident consequences are discussed further in Section V.

Major potential sources of fires in nuclear facilities are summarized iı Table IV. These major categories are based on analysis of event histories and accident analyses (Perkins 1980, 1981). The probability of fires with a potential for release of radioactive materiai may be estimated from event histories. An approach to estimating fire frequencies tas been drawn from fire statistics in the chemical industry (Selby 1975).

3. Criticality Accidents. A criticality event is in many cases a local event without offsite impact; however, the processes in the facility should be reviewed for potential release of radioactivity and for direct radiation at onsite locations. Description of this DBA should include

- form of the critical material (liquid, solid, or a mixture), total number of fissions expected, and an amount of each radionuclide in dispersible form;

- times over which fissioning and radionuclide dispersal occur;

- containment of oispersible radionuclides and shielding of direct radiation; and

- reduction and removal factors applied to dispersed radionuclide amounts.

Table V contains initial burst yields and total yields based on Stratton's (1967) review of criticality accidents. These yields were chosen by Woodcock (1966) as potential magnitudes for emergency planning purposes. Subsequent guidance was issued by NRC (1977B, 1979A, 1979B) defining a "minimum" criticality accident in a solution in which the total fission yield $\left(10^{19}\right.$ fissions) differs slightly from the $3 \times 10^{19}$ fissions derived by wicudcock. The yields in Table $\mathrm{V}$ are considered suitable for use by the analyst when case-specific analysis is not practical. Case-specific analysis may be aided by experimental results and estimation methods provided by Lecorche (1973), Hooper (1974), and Tuck (1974).

Radioactivity can be dispersed during a criticality accident by fission product generation, or by physical action on a solution containing actinides or other solid radionuclides. The radioactivity available for dispersal

\begin{tabular}{ll}
\hline \hline TABLE IV. FIRE ACCIDENT CATEGORIES \\
\hline Fire & Source \\
\hline General & $\begin{array}{l}\text { vehicle fuel, welding, poor housekeeping } \\
\text { fuel reprocessing facility in fuel bundle shearing } \\
\text { Zirconium }\end{array}$ \\
Organic solverat & $\begin{array}{l}\text { solvent recovery tanks, piping leaks } \\
\text { radiolysis of process solution }\end{array}$ \\
Hydrogen & $\begin{array}{l}\text { source of fire spread, loss of services } \\
\text { Electrical }\end{array}$ \\
Sodium & $\begin{array}{l}\text { licuid sodium spills } \\
\text { Pyrophoric metal } \\
\text { mosphere loss }\end{array}$ \\
Cellulose & $\begin{array}{l}\text { spontaneous combustion of celluiose wipes and nitric } \\
\text { acid }\end{array}$ \\
\hline \hline
\end{tabular}




\begin{tabular}{|c|c|c|}
\hline System & $\begin{array}{c}\text { Initial Burst Yield } \\
\text { (fission?) }\end{array}$ & $\begin{array}{c}\text { Total Yield } \\
\text { (fissions) }\end{array}$ \\
\hline $\begin{array}{l}\text { Solutions under } \\
100 \text { gal }\left(0.46 \mathrm{~m}^{3}\right)\end{array}$ & $1 \times 10^{17}$ & $3 \times 10^{18}$ \\
\hline $\begin{array}{l}\text { Solutions over } \\
100 \text { gal }\left(0.46 \mathrm{~m}^{3}\right)\end{array}$ & $1 \times 10^{18}$ & $3 \times 10^{19}$ \\
\hline Liquid/powder & $3 \times 10^{20}$ & $3 \times 10^{20}$ \\
\hline Liquid/metal pieces ${ }^{c}$ & $3 \times 10^{18}$ & $1 \times 10^{19}$ \\
\hline Solid aranium & $3 \times 10^{19}$ & $3 \times 10^{19}$ \\
\hline Solid plutonium & $1 \times 10^{18}$ & $1 \times 10^{18}$ \\
\hline $\begin{array}{l}\text { Large storage arrays }{ }^{d} \\
\text { (below prompt critical) }\end{array}$ & None & $1 \times 10^{19}$ \\
\hline $\begin{array}{l}\text { Large storage arrays } \\
\text { (above prcmpt critical) }\end{array}$ & $3 \times 10^{22}$ & $3 \times 10^{22}$ \\
\hline \multicolumn{3}{|c|}{$\begin{array}{l}\text { "Basad on a similar table by Woodcock (1965). } \\
\text { "A system where agitation of a powder layer could result in } \\
\text { progressively higher reactivity insertion. } \\
\text { "A system of small pieces of fissile metal. } \\
\text { "Large storage arrays in which many pieces of fissile material are } \\
\text { present and could conceivably come together. }\end{array}$} \\
\hline
\end{tabular}

by the criticality accident can be calculated by the ORIGEN2 computer code (Croff 1980) for amounts of fission products and actinides initially present in a dissolved reactor fuel solution or by the RIBD code (Gumprecht 1968) for amounts of fission products produced by the excursion. Actual radionuclide amounts made airborne by physical action (evaporation of solution) or by production during fissioning may be calculated on an individual basis or established by the assumptions made in the applicable NRC regulatory guide cited above. The NRC assumptions are as follows:

- All of the noble gas fission products (except those removed before the excursion), $25 \%$ of the radioiodine, and $0.1 \%$ of the ruthenium resulting from the excursion or initially present in the spent fuel are released directly to the cell (or room) atmosphere.

- An aerosol, generated from evaporation of solution during the excursion, is released directly to the cell atmosphere. The aerosol comprises $0.05 \%$ of salt (solute) content of the solution that is evaporated.
Persons outside the facility may receive significant dose. Calculations by Selby (1975) indicate major dose contributions at distances as far as $100 \mathrm{~m}$ resulting from prompt neutrons and dose to internal organs from inhalation.

Radionuclides released from a criticality accident would normally be discharged to the atmosphere through the facility stack. Choice of puff or plume motel will depend on duration of the event (Hanna 1982, p.42).

Frequency of occurrence of a criticality accident may be estimated from historic data for the types of processes planned. Probability of a criticality accident in a Pu or U fuel fabrication facility was estimated by Selby (1975) to be approximately $9 \times 10^{-3}$ per plant year. Because this estimate was based on criticality accidents in solutions and a nearly equal number occurred in solutions in other facility types, this rate $\left(10^{-2}\right)$ per plant year is considered a suitable frequency for use in risk assessment. The analyst may choose to perform a casespecific analysis if a lower rate is expected. Probability studies based on historical criticality safety violation 
data indicate the frequency could be assumed much lower, depending on how soon a fault in a criticality safety prograin inight be detected (Lloyd 1979). This duration of a fault would be a site-specific or operationspecific determination.

Source terms, release fractions, and evaluation of criticality accident consequences are discussed further in Section V.

4. Leaks to the Atmosphere. A DBA may result fronı a major leak to the atmosphere caused by equipment failure or operator error. Filter failure, by-passing of removal systems, storage tank rupture, dropped casks causing fuel disruption, material spills outside of confinement areas, and short cooling of spent reactor fuel are examples of this accident type. A detailed list of potential accidents based on event histories in fuel reprocessing plants is included in Perkins (1980). Leaks resulting from natural phenomena or other external events are discussed in Sections IV.B. and IV.C., respectively.

The dispersal mechanisms for this potential DBA include meihanical ejection of disrupted material, atomization of radioactive solutions under pressure, aerosolization of powders, surfacc evaporation producing an aerosol, and perhaps others. A summary of parameters affecting release and transport of radioactive material is included in Walker (1978). Selby (1975) also discusses poteitial releases from accirents caused by internal initiators.

Frequency of occurrence of accidents causing leaks to the atmosphere can be estimated from historical occurrence data. Selby (1975) discusses failure-rate data sources as valuable predictors of release probability in cases where applicable data are available.

Source terms, release fractions, and evaluation of such accident consequences are discussed further in Section V.

5. Leaks to the Aquatic Environment. Some nuclear facilities have the combination of a liquid medium contaminated with radionuclides and a nearby lake, river, or stream that might receive an accidental release. Intake by ingestion of drinking water, consumption of fish, immersion in the contaminated water, and consumption of food crops irrigated with contammated water are potential pathways to be considered.

The discussion of accidental releases of liquid effluents in Section 2.4.13 of the Standard Review Plan (NRC 198!A) and its references may be helpful to the analyst in the evaluation of this type of accident. Source terms, release fractions, and evaluation of such accident consequences are discussed further in Section $V$.

\section{B. Natural Phenomena Events}

Natural phenomena, particularly earthquakes and tornadoes, may be capable of acting as initiators of major accidents at nuciear facilities. These events are evaluated both for their capability of disrupting the confinement system (structure and engineered safety features) and triggering otser failures or effects contributing to dispersal of radioactive material beyond the facility. The discussion applies to evaluation of proposed critical facilities or reevaluation of existing facilities being significantly modified for new operations. In some cases, loadings may be higher than original desigri requirements. The facility modifications should be designed to withstand these higher loadings.

This section reviews major considerations in the analysis of postulated accidents initiated by natural phenomena:

- Site selection-proximity to a known active seismic fault, location in a region of high tornado frequency, in a flood-prone region, or in a region vulnerable to hurricanes.

- Structural adequacy-resistance of an existing or design-phase struciure to natural phenomena.

- Component adequacy-resistance of critical components to natural phenomena and adequacy of these components in allowing the facility to be placed at the proposed site.

- Damage estimation and release fraction-amounts of radioactive material which could be released as a result of postulated damage to structures and com" ponents.

DOE Order 6430.1, Chapter IV, provides general requirements for site selection and designing resistance to natural phenomena into all types of DOE facilities, including facilities for handling, processing, or storing radioactive material, or other facilities considered critical by virtue of their vital importance to DOE programs ( $\mathrm{Pu},{ }^{3} \mathrm{H}$, and $\mathrm{HE} / \mathrm{Pu}$ facilities) or high dollar value. Structural design of buildings other than these critical nuclear facilities must comply with the latest edition of ANSI A58.1 (ANSI 1982) for wind loads and the Uniform Building Code (UBC) for earthquake loads (ICBO 1982).

DOE has initiated a program to prepare site-specific tornado and earthquake hazard models. Compilations of earthquake and extreme wind/tornado hazard curves for many sites have been published by Lawrence Livermore National Laboratory (LLNL) (Coats 1984A, 1984B). Relsted reports are becoming available for earthquake hazards (for example, Tera 1984). The 
purposes of these site-specific models are twofold: first, to tie a probability of occurrence to a maximum expected magnitude and, second, to characterize the design basis event more specifically in a locality than permitted by existing methods found in NRC regulatory guides, ANSI standards, or building codes.

Present guidance to be applied to critical items is expressed in DOE Order 6430.1 as recurrence time. This is $10^{6} \mathrm{yr}$ for tornadoes; no direct recommendation is made for earthquakes although $10^{4} \mathrm{yr}$ is implied in Chapter IV, p. IV-8, of Order 6430.1. A conservative interim value for tarthquakes is considered to be $10^{4}$ yr.*

1. Earthquakes. DOE Order 6430.1 specifies that seismic resistance be provided in critical facilities to withstand a design basis earthquake (DBE). The DBE is also defined as a safe shutdown earthquake (SSE). Jointly occurring accidents should be considered if a joint event is likely to be caused by the earthquake, such as a fire or explosion. That is, a fire or explosion should be assumed to occur unless mitigation is present, such as negligible combustible loading or absence of explosive materials. Because the DBE must be assumed to occur at any time, certain loads, such as common wind loading, snow loading, or intermittent maximum loadings (storage tanks, vaults, cooling pools, and the like), should be added to earthquake loading. A detailed DBE analysis may not be needed if a conservative simple analysis shows another accident to clearly be the DBA.

a Site Selection. DOE Order 6430.1 requires, as quantitative design basis for nuclear facilities against earthquakes, procedures similar to 10 CFR 100, Appen$\operatorname{dix} A$, "Seismic and Geologic Siting Criteria for Nuclear Power Plants" (CFR 1962). These siting requirements as related to capable faults are stated as minimum length of fault to be considered versus distance from the site. Site suitability received further elaboration by NRC (NRC 1975A) in Regulatory Guide 4.7, "General Site Suitability for Nuclear Power Stations," as follows:

- Sites that include capable faults are not suitable for a nuclear power station.

- Sites within about 5 miles $(8 \mathrm{~km})$ of a surface capable fault [greater than $1000 \mathrm{ft}(305 \mathrm{~m})$ in length] are generally not suitable for a nuclear power station.

These conclusions are also considered applicable to criticai DOE nuclear facilities based on DOE Order $5480.1 \mathrm{~A}$ specification of comparability with licensed facilities.

This value supplied by David W. Coats, Lawrence Livermore National Laboratnry, November 1983. b. Structural Adequacy. Adequacy of critical and noncritical nuclear facility structures to withstand vibratory ground motion shall be verified, according to DOE Order 6430.1 , using a suitable dynamic analysis tech. nique, except where the static response technique of the Uniform Building Code (ICBO 1982) can be shown to provide a conservative estimation. A common and recommended design approach is sizing of structural members to meet static loading, then applying a dynamic analysis method to check overail adequacy of the structure. The maximum (peak) loads determined by dynamic analysis are then combined with dead loads and other live loads as described in DOE Order 6430.1.

Figure 1 is a representaticn of logical steps required for analysis of critical nuclear facilities.

(l) Descriftion of the DBE. The DBE is described by site-specific spectra and recurrence time versus peak acceleration data, if available (Coats 1984A). If sitespecific data are not available, one of the following may be used:

- The simplest (and acceptable if shown to be adequately conservative), the UBC Seismic Zone 3 (4 in California and Nevada) description for static analysis (ICBO 1982).

- Regional response spectra based on historical listing of all known earthquake activity in the region (200-mile radius) supplemented by yeological evidence beyond the historical record (10 CFR 100, Appendix A, CFR 1962).

- The characteristics of a single historical earthquake, which in the absence of specific historical data for the region, is believed to conservativeiy represent the most serious earthquake expected at the site. The El Centru earthquake of 1940 is an example of earthquake characteristics selected for this purpose (Newmark 1978).

(2) Stetic Response Method. Earthquake resistance of a noncritical facility structure may be determined by static methods described in the Uniform Building Code (ICBO 1982). Eagling* suggests that Zone 3 classification be the minimum selected, regardless of the location of the facility, and that Zone 4 should be selected in regions of California and Nevada. Although this suggestion may lead to apparent ove design at some locations, it acknowledges the uncertainties in predicting the severity of the DBE for a given site. It is also questionable whether major savings in building costs would be realized if a lower zone classification were assumed. An indication of conservatism contained in structures designed to UBC-related codes is discussed in the Seismic Safety Guide, p. 4-1 (Eagling 1983).

*This work provided by D. G. Eagling, Lawrence Berkeley Laboratory, December 1, 1983. 


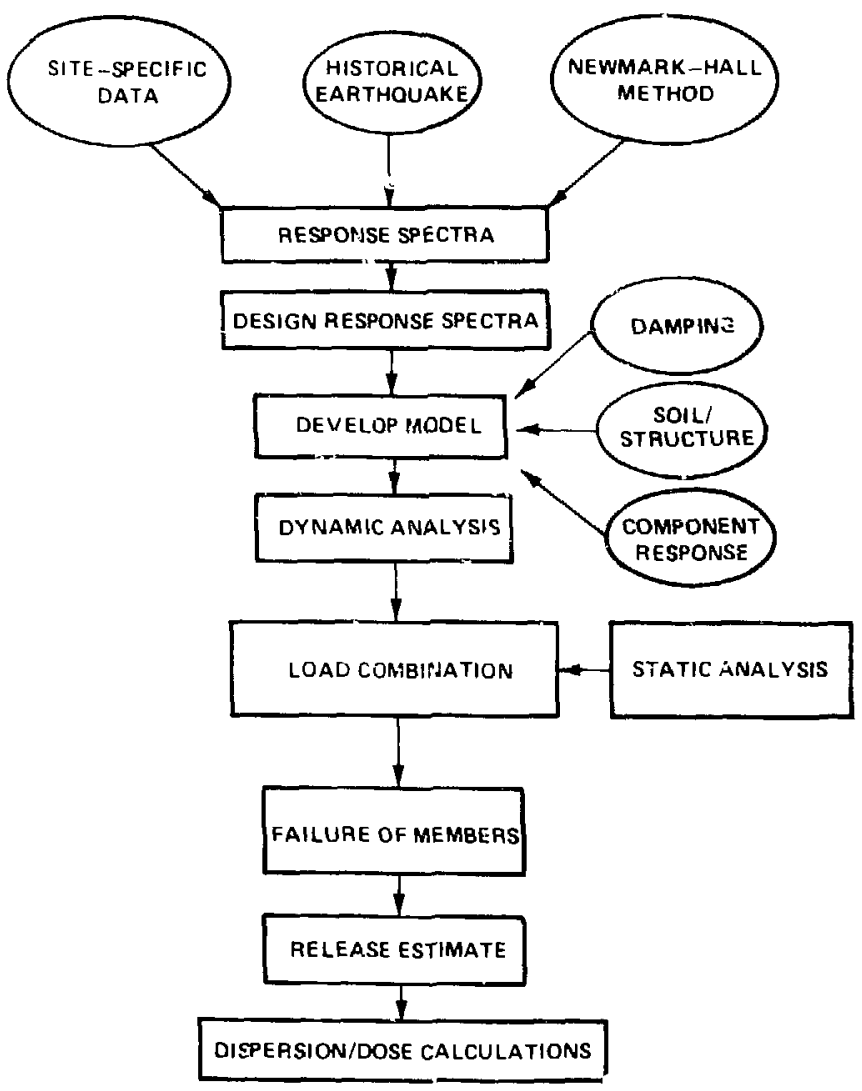

Fig. 1. Earthquake analysis steps.

(3) Dynamic Analysis Method. A variety of dynamic analysis methods are now available. Descriptions of dynamic analysis methods are found elsewhere (Newmark 1973, ASME 1980, and Clough 1975).

(4) Determination of Damping. Calculation of percent of damping in the structure is subject to major uncertainties. Conservative damping values based on experimental data have been determined (Bohm 1973, Hart 1973, Newmark 1978). These values may be used unless higher values can be justified.

(5) Strength Analysis (Combined Response). The combined response from all scurces of loading during the DBE should be accounted for. These responses caused by the earthquake must be combined with the dead load of the structure in the manner described in DOE Order 6430.1. Specific equations are provided for reinforced concrete structures (elastic only) and steel structures (elastic or plastic design method). The adequacy of critical structures and components should be verified for horizontal and vertical motions, with the ratio of vertical to horizontal acceleration set at $2 / 3$ by DOE Order 6430.1 unless a different ratio can be justified. The effects of tipping, tilting, and rotation of the ground during an earthquake have not been studied extensively and usually are not analyzed.

c. Component Adequacy. Dynamic analysis of ESF, safety, and confinement system components in a nuclear facility is performed to assure their continued operation throughout the DBE. Faiiure modes are examined to evaluate integrity of the glove boxes, vaults, pools, tanks, and other confinement components. Possible failure modes include failure of supports or tiedowns, window breakage, filter seal breakage, interruption of ESF operation through loss of power, and the like. 
The floor-design, response-spectra method and the time-history methods similar to those applied to the building structure are used in analysis of component adequacy. A basic approach to these methods is discussed in Regulatory Guide 1.122 (NRC 1978A) and the ASME Boiler and Pressure Vessel Code (ASME 1980). Newmark (1978) has provided useful discussion and references regarding component adequacy.

d. Damage Estimation and Release Fraction. Failure of structural members indicated by one of the analysis methods discussed earliei may or may not affect the confinement system or otherwise cause an accidental release of radioactive :naterial. Assumptions regarding release amounts may L'epend on several conditions:

- proximity of a failed member to the confinement system (that is, does the roof collapse onto a glove box?);

- availability of an energy source that transports the material through a breach in the confinement system; and

- size of the pestulated breach.

Release fractions should contain a suitable level of conservatism in the absence of analytical or experiniental data. Analyses by Selby (1975) and Mishima (1979, 1980,1981 ) may be useful in arriving at suitable release fractions. For example, a fraction (rather than all) of the radioactive material in crushed or perforated glove boxes may be dispersed (Mishima 1981, Mehta 1978). A.s an alternative, a release to the room may be assumed to reach some upper value of airborne concentration in the room, such as $100 \mathrm{mg} / \mathrm{m}^{3} \mathrm{Pu}$ aerosol in the respirable size range (Selby 1975). Removal by the air cleaning system may be assumed according to the reduction and removal fractions listed in Section V.C. only if analysis shows that the air cleaning system remains intact.

2. Tornadoes and Extreme Winds. DOE Order 6430.1 specifies that critical items and systems in a nuclear facility be designed to provide confinement of radioactive material under DBA conditions, one of which is the design basis tornado (DBT). ANSI/ANS 2.2 also discusses guidelines for determining tornado parameters (ANSI 1983). The DBT shall not cause the siting guideline doses to the offsite person to be exceeded. A determination of dose requires knowledge of or assumption of the amiount of radioactive material released and its dispersion under the chaotic meteorological conditions of the tornado. a. Site Selection. Tornadoes and extreme winds have not played a major role in siting of nuclear facilities or nuclear power plants, because safety-related structures and systems can be designed to resist most atmospheric exiremes (Regulatory Guide 4.7, NRC 1975A). However, a site in a region with relatively high frequency of strong tornadoes should not receive equal consideration with a site in a more favorable incation. Strength and effects of tornadoes are not well k lown, and present design methods cannot guarantee a "tornado-proof" nuclear facility. Guidance on what tornado strength is too great to allow design of a facility of reasonable cost is limited. However, this should be considered in the site selection process.

b. Structural Adequacy. Design of a critical nuclear facility is specified by DOE Order 6430.1 to resist a DBT having the characteristics of a tornado with a recurrence time of $10^{6} \mathrm{yr}$. Curves of recurrence time and maximum wind velocity are provided for major DOE sites (Coats 1984A). Other sites without site-specific tornado or high-wind probability data may use characteristics of th: DBT in the appropiiate geographical regions shown in DOE Order 6430.1. Tornado resistance calculations must considur combined loads resulting from rotational plus translational wind speed, rate of pressure drop, and missiles. Combining these loads is accomplished according to the equations shown in DOE Order 6430.1. The components of tornado or wind-load combination $W_{t}$ are discussed by Vellozzi and Healey (Vellozzi 1973). The wind-load forces developed on various walls and roof of a structure hit by a DBT are calculated by the methods described by ANSI A58.1 (1982).

c. Component Adequacy. Adequacy of critical components (ESF and safety systems components required for safe shutdown and confinement of radioactive materials) in resisting the DBT should be assessed unless the building remains intact, missile barriers are provided at ventilation intakes and exhausts, and adequate strength of the components to resist pressure effects is demonstrated. Experimental data from which component strength might be estimated are limited. Simulated tornado effect experiments have been performed on HEPA filter systems that indicate assumptions of filter type and filter loading influence the tornado-induced pressure pulse strong enough to break a HEPA filter (Gregory 1982, Horak 1982). Although these experiments were performed on single filters rather than multiple-stage banks of filters, their results indicate possible breakage of high-capacity HEPA filters if an average maximum differential pressure of approximately $1.6 \mathrm{psi}(11.0 \mathrm{kPa})$ is exceeded; for standard 
HEPA filters, $2.4 \mathrm{psi}(16.5 \mathrm{kPa})$. A reduction of collection efficiency can also be expected if the pressure pulse is survived without structural breakage of the filter. This collection efficiency was measured to be approximately $70 \%$ and represents a reasonable removal fraction (per stage) if other design and damage considerations indicate the DBT will not cause breach of the facility or pressure pulses are not high enough to break the HEPA filters.

d. Damage Estimation and Release Fraction. The quantity of radioactive material relcased from the facility by a DBT wili depend on the source term and what reduction and removal fractions ar: assigned. Extent of damage from tornadoes to structures and glove boxes or similar confinement components is discussed by Mishima $(1979,1980,1981)$. This information suggested various fractions of the contents of the confinement system which might be assumed released to the building air cleaning system. Intact filter stages may be assumed $70 \%$ efficient, as discussed in c. above. Gregory et al. noted partial release of existing filter load from intact filters, which is a release source not yet well defined (Gregory 1982). Tornado-induced flow effects and reentrainment have been studied by Andrae et al. (Andrae 1979) using the TVENT computer code (Andrae 1978).

e. Dispersion Assumptions. Three approaches to meteorological dispersion of released radioactive material have been used in past DBT accident analyses:

- dispersion by straight winds accompanying the tornado;

- uptake of the material by the funnel, followed by return to the ground in heavy precipitation; and

- uptake of the material by the funnel, followed by infinite dispersion (assumed negligible dose).

This third approach is not considered acceptable for the DBT accident analysis. Dispersion by straight winds accompanying the tornado was considered appropriate for an HE/Pu detonation case in the Pantex EIS (Dewart 1982). Uptake by the funnel cloud followed by deposit on the ground by precipitation presents a difficult problem in establishing the location of the exposed offsite person because the $\mathrm{DET}$ T has translational motion and unspecified nonuniform precipitation. A natural phenomena analysis of a plutonium fuel fabrication facility (Pepper 1978) and the Rocky Flats safety analyses and risk assessment (RFP 1982) used this approach.
3. Other Natural Phenomena. The natural phenomena other than earthquake and tornado have not been treated in comparable depth because the hazard of radioactive material released by a related accident is not expected to be comparable. According to DOE Order 6430.1 , "design loads and considerations for other natural phenomena shall provide a conservative margin of safety greater than the maximum historical levels recorded for the site. Protection against flooding shall be based on no less than the probable maximum flood (PMF) for the area as defined by the Corps of Engineers. The possibility of seismically induced damage or failure of upstream dams shall be taken into account in assessing the nature of flood protection required for the facility."

\section{Accidents with External Origins}

Each nuclear facility exists under some probability that an offsite or onsite external hazard may cause a breach of the confinement system resulting in a release of radioactive material. DOE Order 6430.1 specifies that each facility be evaluated for all hazards, such as fire, explosions, gas mains, explosives in large quantities, flammable gases (we would add large onsite vehicles), and potentially hazardous external (offsite) operations such as airports and private industry. Evaluation should include both an estimate of the probability of an external occurrence and the magnitude of a release of radioactive material from damage caused by the occurrence.

1. Pipelines, Tankers, Barges, or Rail Cars Carrying Hazardous Materials. The site should be evaluated for any potential release of radioactive material caused by an explosion, leakage, or fire at any nearby volatile fuel or toxic chemical transportation route. The accidental release could result from missiles, direct blast forces, fire, leakage of volatile fuel near or into the facility, or a leak of toxic chemicals rendering the facility uninhabitable. Determination of structural or component damage and assumptions regarding release amounts can be approached similarly to tornado missile analysis (Section IV.B.2), to fire-related releases (Section IV.A.2), or to blast force damage similar to tornado differential pressure force damage. Uninhabitability issues should be based on inability to perform safe shutdown following exposure to leaking chemicals. Various aspects of external hazards are discussed in the NRC Standard Review Plan, Section 2.2.1 (NRC 1981A), and in several regulatory guides referenced therein. 
2. Aircraft and Airports. The risk of release of radioactive material caused by an aircrait crashing into the facility increases with proximity to an airport. Unless the crash risk can be shown probabilistically to be less than $10^{-6}$ per year, the facility should be analyzed for vulnerability of the confinement system to damage. Assumptions regarding amo' 'nts of radioactive material released to the atmosphere should be consistert with amounts released by other events causing damage to the confinement system, such as natural phenomena (Section IV.B.) and oyerational events (Section IV.A.). In particular, an accompanying fuel fire should be assumed. Various aspects of aircraft and other missile hazards discussed in the NRC Standard Review Plan (Section 3.s.1.6) and its references may be helpful to the analyst in evaluating the hazard of aircraft crash (NRC 1981A).

3. Other Nuclear Facilities or Reactors. The risk of exposure of the facility to radioactive material released accidentally from nearby nuclear facilities or reactors involves possible overexposure of personnel, loss of habitability of the facility, and possible extended loss of important operations. An analysis should demenstrate that an accident at a nearby nuclear facility will not cause an accident at the proposed facility and that it can be safely shut down and evacuated.

4. Large Dams. Presence of a large dam upstream of a facility is cause for an evaluation of risk to the facility in the event of dam failure. Section IV.B.3 contains related requirements stated in DOE Order 6430.1 . Sections 2.4.2 and 2.4.4 of the NRC Standard Review Plan (NRC 1981A) and its izferences may be helpful to the analyst in evaluation of this potential accident.

5. Explosive or Toxic Material Facilities. The possible effect of a major explosion at a nearby explosives facility would be analyzed like the explosion hazard from fuel transportation (Section IV.C.1), that is, for vulnerability of the proposed facility to blast effects, missiles, or fire. Analysis of hazards from a nearby toxic material facility would be approached on the basis of possible release of radioactive material due to uninhabitability of the facility without safe shutdown.

\section{Accidents with Higher Probability}

Doses resulting from an accident witl lower consequences and higher probability of occurrence than the DBA may also be compared, where appropriate, with other dose guidelines lower than the guidelines proposed for DOE Order 6430.1. These accidents with lower consequences may deserve evaluation because of a potential for exposure of the public and workers at nearby facilities. The guideline doses or design goals for these accidents will then depend on their probability of occurrence. Determination of this probability should be based on failure data where possible. A quantitative method currently in use (Durant 1980, 1981) bases accident probabilities on incident frequencies recorded in extensive data bases. Because the relationship between frequency of incidents (component failures, operator errors, etc.) and acciden: probability is not well known, subjective judgment cannot be completely eliminated from the process. Related discussions which may be of use to the analyst are found elsewhere (Swain 1983 , on human reliability analysis; Briscoe 1982, on general topics of risk management).

Several approaches to establish:ng a structure of safety guidelines in terms of probability of occurrence and consequence (dose, in this case) exist within the DOE complex. A qualitative evaluation approach is currently being implemented by several field offices (Lucas 1981, ALO 1982, and ORO 1984) and has been suggested separately by Brynda et al. (Brynda 1981). This method requires subjective judgment in assigning an accident to a probability class (that is, anticipated, unlikely, extremely unlikely, or incredible). These classes are assigned a range of dose guidelines that are fractions of the siting guideline doses. The fraction ultimately selected depends on the analyst's determination of probability; the more probable the accident, the lower the guideline dose selected. Although this method leaves more to the analyst's judgment, it provides a systematic approach to evaluation of lesser accidents than the DBA.

Table VI represents poiential categories of probability and ranges of dose. These values are similar to those referenced above but were adapted to current DOE siting guideline doses. A similar approach in ANSI Standard N287 (ANSI 1976) and in field office orders for implementation of DOE Order 5481.1A (ALO 1982, ORO 1984) may be helpful to the analyst in devising a suitable structure of safety guidelines for these accidents.

\section{EVALUATIONS OF ACCIDENT CONSE- QUENCES}

The analyst should predict with acceptable accuracy the behavior of a DBA under the assumed conditions most appropriate lur the proposed nonreactor nuclear facility. Verification of assumptions, where possible, may be derived from comparisons with exising verifiable experiences/experimental results and, in some cases, with experimental results yet to be gathered. The confidence one can have in predictions of accident behavior is primarily based on these comparisons with 


\begin{tabular}{|c|c|c|c|c|c|c|}
\hline \multirow[b]{2}{*}{$\begin{array}{c}\text { Probability } \\
\text { Category }\end{array}$} & \multirow[b]{2}{*}{$\begin{array}{c}\text { Nominal Range } \\
\text { of Probability } \\
\left(y^{-1}\right)\end{array}$} & \multicolumn{5}{|c|}{ Dose Guideline (rem) } \\
\hline & & $\begin{array}{l}\text { Whal: } \\
\text { Befty }\end{array}$ & Lungs & Thyroid & $\begin{array}{c}\text { Bone } \\
\text { Surface }\end{array}$ & $\begin{array}{c}\text { Other } \\
\text { Organs }^{\mathbf{a}}\end{array}$ \\
\hline Anticiparivd & $>10^{-i}$ & $<0.01$ & $<0.03$ & $<0.12$ & $<.0 .12$ & $<0.06$ \\
\hline Unlikelve & $10^{-4}-10^{-2}$ & $0.01-0.50$ & $0.03-1.5$ & $0.12-6$ & $0.12-6$ & $0.06-3$ \\
\hline $\begin{array}{r}\text { xtremely } \\
\text { unlikelyd }\end{array}$ & $10^{-6}-10^{-4}$ & $0.5 \cdot 25$ & $1.5-75$ & $6-300$ & $6-300$ & $3-150$ \\
\hline Incredible $^{e}$ & $<: 0^{-6}$ & $>25$ & $>75$ & $>300$ & $>300$ & $>150$ \\
\hline \multicolumn{7}{|c|}{$\begin{array}{l}\text { "Based on ICRP recommendation of weighting factors assigned to each of organs receiving highest } \\
\text { dose equivalent (ICRP 1977). } \\
\text { "Incidents that may be expected to occur once or more during the lifetime of the facility. } \\
\text { "Accidents that are not expected but may occur sometime during the life cycle of the facility. } \\
\text { dAccidents that will probably not occur during the life cycle of the facility. This category includes } \\
\text { design basis accidents. } \\
\text { "Accidents for which a reasonable scenario is not conceivable. }\end{array}$} \\
\hline
\end{tabular}

experience and experimental data. Experimental verification, when available, should demonstrate that the individual mechanisms or processes (accidents) affecting a release are adequately described analytically; all significant mechanisms (accidents) are included; and interactions among individual mechanisms (accidents) or processes are properly described.

Evaluation of potential DBAs of the proposed facility or operation involves

- description of the source term,

- calculation of the dispersion factor $(\chi / Q)$ of dispersed material at the point of interest,

- calculation of dose at the point of interest, and

- estimation of other consequences which should be considered.

Figures 2 ind 3 provide a graphical model of the steps involved in each accident analysis. The model may be adjusted appropriately to accommodate variations among DBAs, but these figures contain the major categories of analysis and description. The following sections provide additional detail and discussion of these major categories.

\section{A. Source Terms}

The source term is defined as the amount of radioactive material available for release after the fiaction of release from primary confinement is applied. It may be the total amount of radioactive material in process or storage but is usually a smaller amount following modification by the release fraction. Release fraction is the fraction of the total available radioactive material that is released from primary confinement in a readily dispersible form. It is assumed that readily dispersible radioactive material is capable of causing radiological dose, either by direct radiation or by inhalation of the respirable fraction or by ingestion. The source term description usually includes a list of radionuclides, the quantity $(\mathrm{Kg}$ or $\mathrm{Ci}$ or $\mathrm{Bq})$ of each, particle size characteristics, and chemical form. These latter two features are discussed in Section V.F. in consideration of their role in radiological dose.

1. Radionuclides. Radionuclides of interest may be originally present or are fission products released by disruption of spent fuel or are produced by a criticality accident. They may be in a pure form or mixed with other radionuclides. The list should include all radionuclides contributing more than a few percent of the activity of source term after cooling time or decay time is allowed from the time of the accident to the time the radionuclide is inhaled by the exposed person. Each radionuclide should be screened according to its contribution to the dose. A suitable method can be based on ranking of the ratio of quantity at the time of intake and the annual limit on intake (ALI) of the nuclide from ICRP 30 (ICRP 1979). Another method is the ranking of radionuclides by the product of quantity $(\mathrm{Ci}$ or $\mathrm{Bq})$ at the time of intake and organ dose factor $(\mathrm{rem} / \mathrm{Ci}$ or 


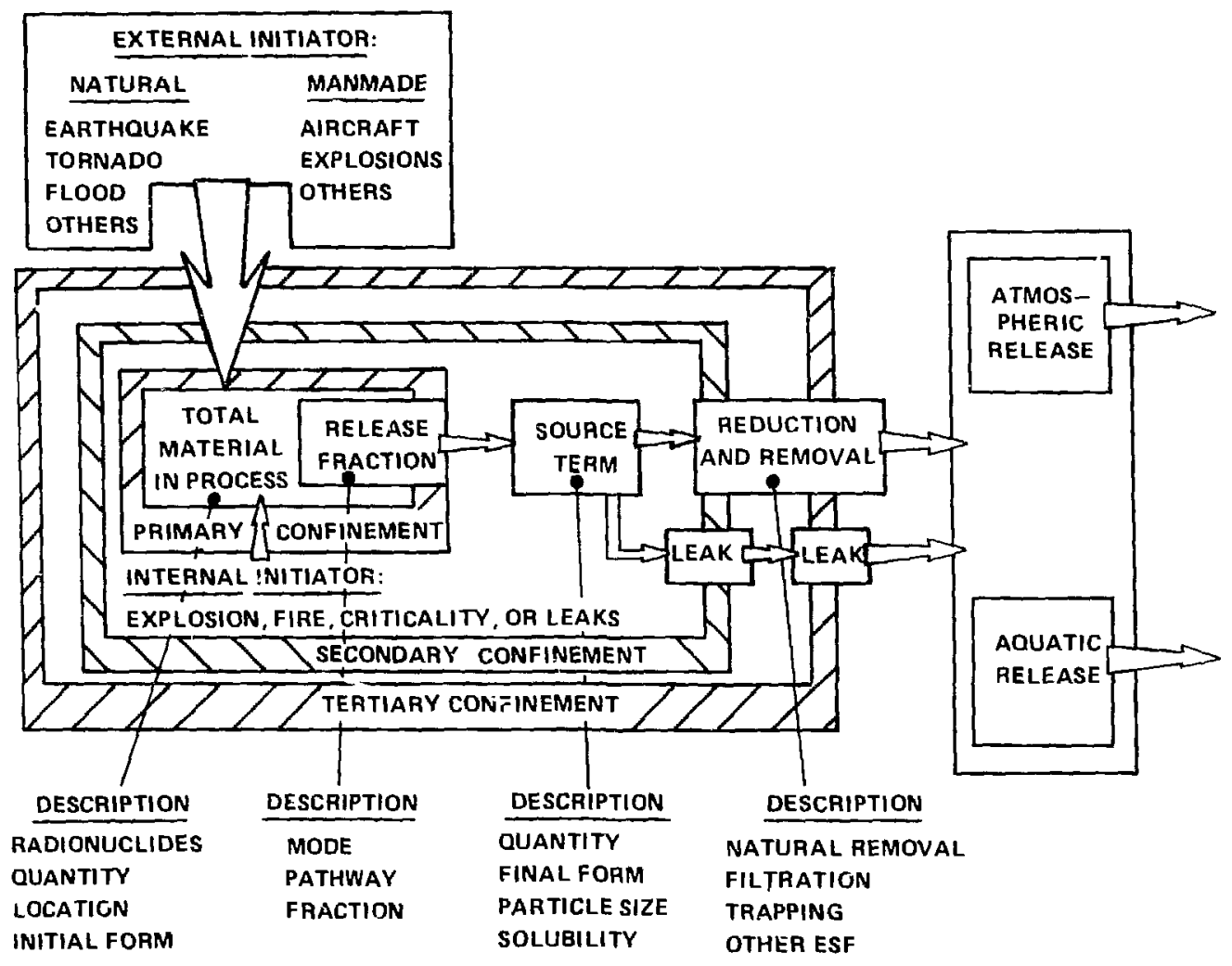

Fig. 2. Accident release steps.

$\mathrm{Sv} / \mathrm{Bq}$ ) appropriate to the intake pathway. The radionuclides to be included in dose calculations could then be all those contributing significantly toward total dose to any orgin (for example, to $99 \%$ or some lower value consistent with the uncertainty of the dose calculation). Nuclide quantities and dose evaluation are discussed further in Sections V.A.2. and V.F., respectively.

Table VII contains a list of radionuclides (fission products, activation products, and actinides) that are likely to figure in accidental dose calculations. The list is taken from analyses involving accidents followed by very little decay time (reactor accident, short-cooled fuel, or criticality accidents) and with longer decay time (reactor fuel reprocessing accidents) (WASH 1400, Appendix VI, pp. 13-21, NRC 1975B). Although this list should not be considered all-inclusive for all combinations of nuclides and potential accidents, these nuclides should be considered in the source term descriptions for major accidents. Sources of information on nuclides with major dose potential are WASH 1400 for spent reactor fuel (NRC 1975B) and ICRP 30 (ICRP 1979, 1980).

Activation products are of limited importance for most accidents in DOE nuclear facilities because of their general lack of mobility. However, special cases may exist that should be investigated.

2. Radionuclide Quantities. The source term for a radionuclide in dispersible form will normally be the total activity present multiplied by a release fraction (discussed later). Quantities of fission products, activation products, or actinides that could be dispersed from spent fuel are determined on the basis of power history (burnup) of the feed material and its cooling time. A suitable source for fission product and actinide inventories is the ORIGEN2 code (Croff 1980). RIBD (Gumprecht 1968) is also used to obtain fission product inventory. These codes require as input the fissile enrichment of the fuel, the average neutron flux (neutrons $/ \mathrm{cm}^{2} \cdot \mathrm{s}$ ), the total uranium or other heavy metal in the core, and the irradiation time. Code output is a tabulation of actinide, activation product (ORIGEN2 only), and fission product activities as a function of cooling time. If ORIGEN2 or a comparable code is not available, a simplified thermination of the fission product and actinide source terms of cooled reactor fuel may be performed by scaing from example equilibrium source terms for a standard set of conditions, if 


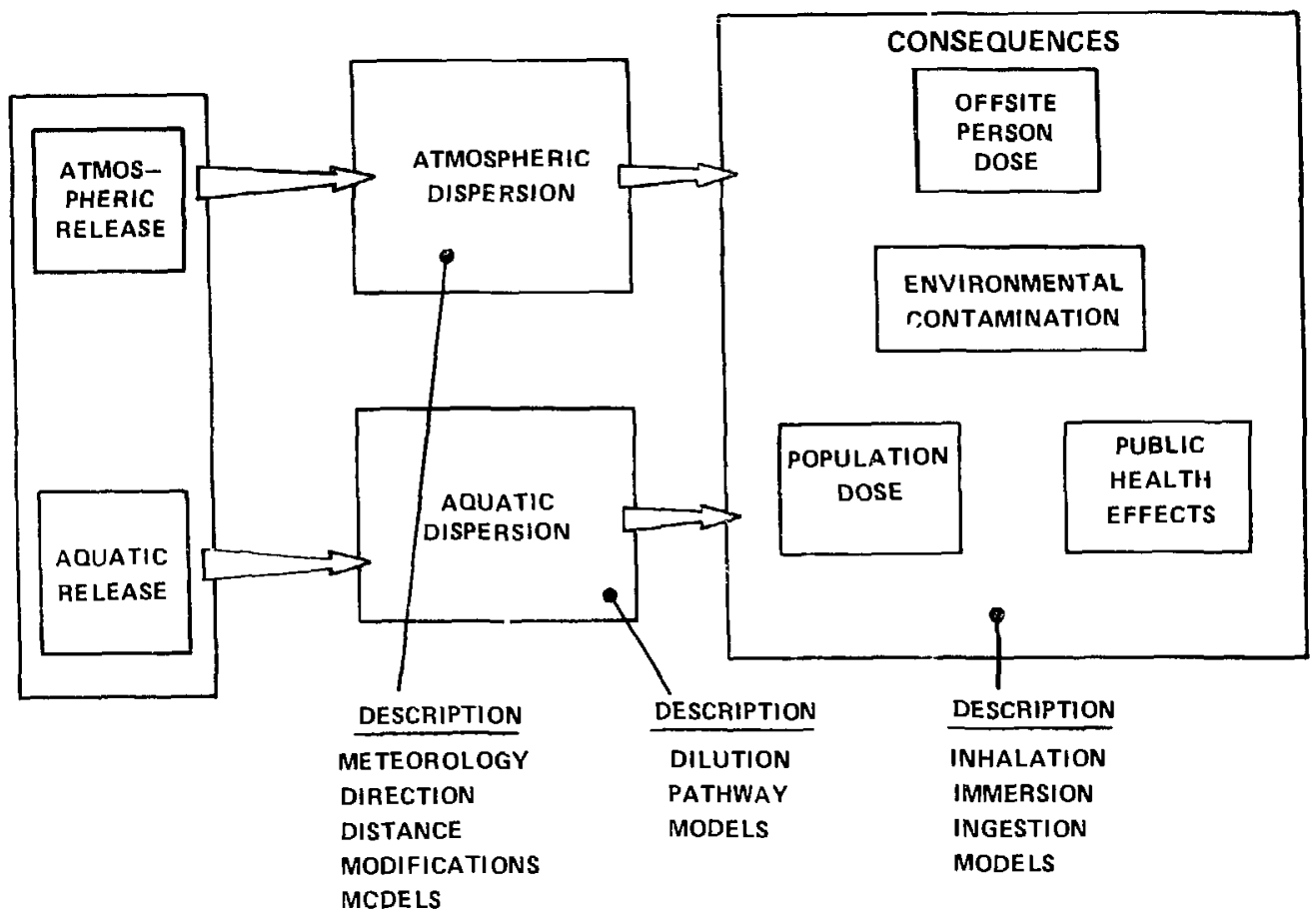

Fig. 3. Accident consequence steps.

similarity between the reactors is observed. Scaling from example values in the ORIGEN2 manual is possible because the inventory of the long-lived radionuclides is proportional to burnup (power density times time) and is not sensitive to power density at any given time.

\section{B. Release Fractions}

The release fraction is that fraction applied to the total radioactive material in process to obtain the source term (that amount released from primary confinement in dispersible form). Release fractions established in TID 14844 (AEC 1962) to allow calculation of doses for comparison with 10 CFR 100 dose criteria are as follows:

noble gases

halogens

solid fission products
$100 \%$, $50 \%$, and

$1 \%$.
The solid fission product category was apparently intended to also include the semivolatile solid fission products $(\mathrm{Ru}, \mathrm{Rb}, \mathrm{Cs}, \mathrm{Te}, \mathrm{Tc}$, and $\mathrm{Se})$. A later addition to this list was a Pu and $\mathrm{U}$ or other particulate actinides category of 1\% (NRC 1977A). These - rlease fractions were nonmechanistically determined for use in site suitability calculations for light-water reactors where the system is quite complex. Their applicability to accidents in nonreactor nuclear facilities is not clear; their use as an upper limit in SARs is common. However, nonreactor nuclear operations in DOE facilities are, for the most part, relatively straightforward. The accident sequence may be readily understandable, compared with the reactor case, and use of other lower values may be justified. In specific accident cases for which applicable experimental data exist, lower values may be considered, if conservative. Table VIII presents an excerpted summary of recommended safety analysis parameters compiled by Walker (1978). These values are based on existing experimental data. Some values are justifiably 


\begin{tabular}{|c|c|c|c|c|c|}
\hline TABLE VII. & $\begin{array}{l}\text { MPORT } \\
\text { OSE CA }\end{array}$ & $\begin{array}{l}\text { NT RAD } \\
\text { LCULATI }\end{array}$ & $\begin{array}{l}\text { ONUCI } \\
\text { ONS }\end{array}$ & IDES FO & OR ORGAN \\
\hline $\begin{array}{l}\text { Release } \\
\text { Radionuclide }\end{array}$ & $\begin{array}{l}\text { Whole } \\
\text { Body }\end{array}$ & $\begin{array}{c}\text { Bone } \\
\text { Marrow }\end{array}$ & Lung & $\begin{array}{c}\text { Bone } \\
\text { Surface }\end{array}$ & Other \\
\hline $\begin{array}{l}\mathrm{He}-3 \\
\mathrm{Co}-58 \\
\mathrm{Co}-60 \\
\mathrm{Kr}-85\end{array}$ & & & & & 1 \\
\hline $\begin{array}{l}r r-85 m \\
K r-87 \\
K r-88\end{array}$ & $\begin{array}{l}1 \\
2\end{array}$ & & & & \\
\hline $\begin{array}{l}\text { Rb-86 } \\
\text { Sr-89 } \\
\text { Sr-90 }\end{array}$ & & $\begin{array}{l}2 \\
1\end{array}$ & 2 & 2 & i \\
\hline $\begin{array}{l}\text { Sr-91 } \\
Y-90 \\
Y-91\end{array}$ & 1 & 1 & 1 & 1 & \\
\hline $\begin{array}{l}\mathrm{Zr}-95 \\
\mathrm{Zr}-97 \\
\mathrm{Nb}-95\end{array}$ & 1 & & 1 & & \\
\hline $\begin{array}{l}\text { Mo-99 } \\
\text { Tc-99m } \\
\text { Ru-103 }\end{array}$ & 1 & 1 & $\begin{array}{l}1 \\
1\end{array}$ & & 1 \\
\hline $\begin{array}{l}\text { Ru-105 } \\
\text { Ru-106 } \\
\text { Rh-105 }\end{array}$ & 1 & & 2 & & 1 \\
\hline $\begin{array}{l}\text { Te-127 } \\
\text { Te-127m } \\
\text { Te-129 }\end{array}$ & & & 1 & & \\
\hline $\begin{array}{l}\text { Te-129m } \\
\text { Te-131m } \\
\text { Te-132 }\end{array}$ & $\begin{array}{l}1 \\
1\end{array}$ & $\begin{array}{l}1 \\
1 \\
2\end{array}$ & $\begin{array}{l}1 \\
1 \\
2\end{array}$ & $\begin{array}{l}1 \\
2\end{array}$ & 2 \\
\hline $\begin{array}{l}\text { Sb-127 } \\
\text { Sb-129 } \\
\mathbf{I - 1 3 1}\end{array}$ & $\begin{array}{l}1 \\
1\end{array}$ & 1 & 1 & 1 & 1 \\
\hline $\begin{array}{l}1-132 \\
I-133 \\
I-134\end{array}$ & $\begin{array}{l}2 \\
2 \\
1\end{array}$ & $\begin{array}{l}1 \\
1\end{array}$ & 1 & & $\begin{array}{l}1 \\
1\end{array}$ \\
\hline $\begin{array}{l}-135 \\
\text { Xe-133 } \\
\text { Xe-135 }\end{array}$ & $\begin{array}{l}2 \\
1 \\
1\end{array}$ & 1 & 1 & & 1 \\
\hline
\end{tabular}




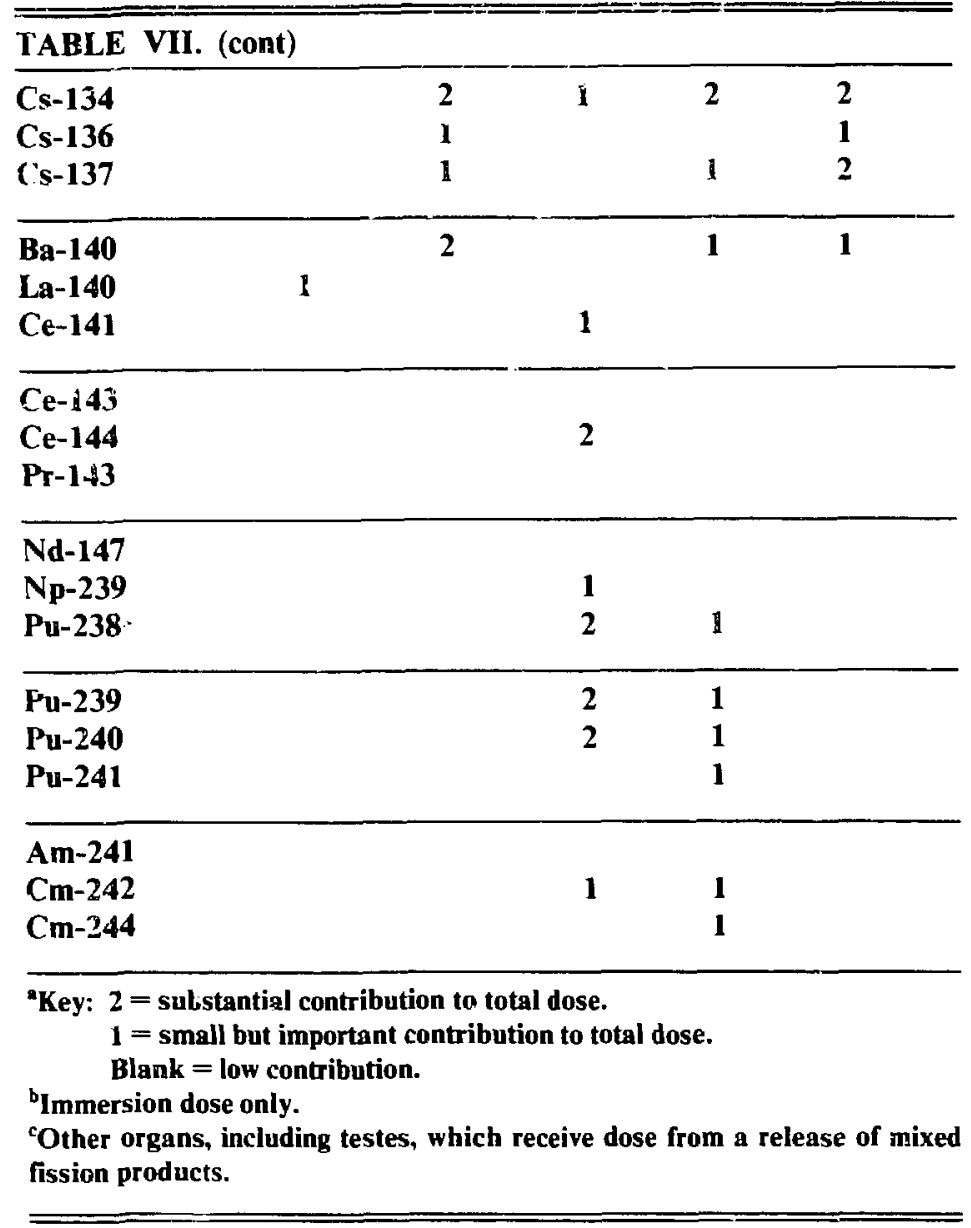

lower than the TID 14844 criteria (AEC 1962) and are considered suitable except as noted below.

- Total fissions from a criticality in a large liquid system might be as high as $3 \times 10^{19}$ fissions; from criticality in a liquid/powder system, $3 \times 10^{20}$ fissions (Section IV.A.3).

- Nonvolatile solids released from solutions spilled within building confinement are expected to be less than $10^{-2} \%$. $^{*}$

The experience at TMI-2 and recent experiments at OP.NL and elsewhere indicate the 50\% halogen release fraction may be too large (NRC 1981B). Smaller releases are expected due to a large amount of elemental iodine $\left(\mathrm{I}_{2}\right)$ reacting with cesium to form CsI, a much less volatile and more water-soluble form than $\mathrm{I}_{2}$. Although it is apparent that a reduction in release fraction is

*This work provided by W. S. Durant, Savannah River Laboratory, August 1983. forthcoming, a consensus on a smaller release iraction is lacking at the present time.

Semivolatile solids (called volatile solids in Table VIII, and iricluding $\mathrm{Ru}, \mathrm{Sb}, \mathrm{Rb}, \mathrm{Cs}, \mathrm{Te}, \mathrm{Tc}$, and $\mathrm{Se}$ ) are released over a broad range of release fractions (up to $80 \%$ ). Because of the radiological importance of this nuclide group, each case should be reviewed.

Release fractions of other materials, such as plutonium or uranium compounds in powder form, have been reviewed and summarized by Walker (1978) and Selby (1975). Their release fraciions depend on many variables, including temperature, air velocity, and particle size. However, a simplifying assumption of 100 $\mathrm{mg} / \mathrm{m}^{3}$ airborne concentration after settling and agglomeration of particles has been used.

\section{Reduction and Removal Factors}

Reduction and removal factors are those factors by which the released radionuclides may be reduced by 


\begin{tabular}{|c|c|c|c|c|}
\hline Release $t_{\text {_. }}$ nanism & Safety Analysis Parameter & Range of Observation & Current Practice & Recommended Value \\
\hline $\begin{array}{l}\text { Failed Fuel-Gap Release } \\
\text { (Fraction released } \\
\text { except as noted) } \\
\qquad\end{array}$ & $\begin{array}{l}\text { (a) Noble Gas } \\
\text { Krypton- } 85 \\
\text { (b) Halogens } \\
\text { lodine-129 } \\
\text { (c) Volatile Solids (Cs, Rb, Ru) } \\
\text { (d) Nonvolatile Solids }\end{array}$ & $\begin{array}{l}0.015-0.34 \\
- \\
0.025-0.49 \\
- \\
<4 \times 10^{-6}-0.80 \\
<2 \times 10^{-6}-8 \times 10^{-4}\end{array}$ & $\begin{array}{l}0.018-0.10 \\
0.30 \\
0.0032-0.10 \\
0.30 \\
- \\
<10^{-} \cdot 0.05\end{array}$ & $\begin{array}{l}0.10 \\
0.30 \\
0.10 \\
0.30 \\
0.01 \\
0.01\end{array}$ \\
\hline $\begin{array}{l}\text { Fire Release } \\
\text { (Fraction released } \\
\text { except as noted) }\end{array}$ & $\begin{array}{l}\text { (a) Noble Gas } \\
\text { (b) Halogen } \\
\text { (c) Yolatile Solids } \\
\text { (d) Nonvolatile Solids } \\
\text { (e) Fly Ash } \\
\text { (f) Airborne Particle Size }(\mu \mathrm{m})\end{array}$ & $\begin{array}{l}- \\
0.65-0.84 \\
3 \times 10^{-6}-0.01 \\
4 \times 10^{-6}-0.38 \\
5 \times 10^{-4}-0.20 \\
<0.1-10\end{array}$ & $\begin{array}{l}0.90-1.00 \\
1.00 \\
0.01-0.90 \\
0.01-0.60 \\
0.01-0.05 \\
<5\end{array}$ & $\begin{array}{l}1.00 \\
1.00 \\
0.01 \\
0.01 \\
0.01 \\
<5\end{array}$ \\
\hline $\begin{array}{l}\text { Explosion } \\
\text { (Fraction released } \\
\text { except as noted) }\end{array}$ & $\begin{array}{l}\text { (a) Noble Gas } \\
\text { (b) Halogens } \\
\text { (c) Volatile Solids } \\
\text { (d) Nonvolatile Solids } \\
\text { (e) Airborne Material } \\
\text { (f) Airborne Particle Size }(\mu \mathrm{m})\end{array}$ & $\begin{array}{l}- \\
- \\
9 \times 10^{-5}-0.14 \\
1.0-71 \mathrm{mg} / \mathrm{m}^{3} \\
-\end{array}$ & $\begin{array}{l}1.00 \\
1.00 \\
0.001 \\
0.01 \\
10-100 \mathrm{mg} / \mathrm{m}^{3} \\
<10-30\end{array}$ & $\begin{array}{l}1.00 \\
1.00 \\
0.01 \\
0.01 \\
100 \mathrm{mg} / \mathrm{m}^{3} \\
<10\end{array}$ \\
\hline Criticality & $\begin{array}{l}\text { (a) Initial Pulse-Fissions } \\
\text { (b) Secondary Pulse-Fissions } \\
\text { Pulse Interval } \\
\text { (c) Total Fissions } \\
\text { Total Tine } \\
\text { (d) Gas Release Fraction } \\
\text { (e) Halogen Release Fraction } \\
\text { (f) S.jlid Release Fraction }\end{array}$ & $\begin{array}{l}1 \times 10^{15}-4.68 \times 10^{18} \\
\text { No Estimate } \\
\text { No Estimate } \\
3 \times 10^{15}-1.2 \times 10^{20} \\
\text { No Estimate } \\
\text { No Estimate } \\
\text { No Estimate } \\
\text { No Estimate }\end{array}$ & $\begin{array}{l}1 \times 10^{18}-3.7 \times 10^{18} \\
0.4 \times 10^{17}-5 \times 10^{17} \\
10 \mathrm{~min} \\
1 \times 10^{18}-1 \times 10^{20} \\
7 \mathrm{~min}-24 \mathrm{~h} \\
1.00 \\
0.25-1.00 \\
0.001-0.20\end{array}$ & $\begin{array}{l}1.0 \times 10^{18} \\
1.9 \times 10^{17} \\
10 \mathrm{~min} \\
b_{1.0} \times 10^{19} \\
8 \mathrm{~h} \\
1.00 \\
0.25 \\
\text { d }\end{array}$ \\
\hline $\begin{array}{l}\text { plicable to particulate } n \\
\text { text for discussion of a } \\
\text { ludes release and plater }\end{array}$ & $\begin{array}{l}\text { I oniy. } \\
\text { te values. }\end{array}$ & & & \\
\hline
\end{tabular}

either natural or engineered means. A natural reduction factor commonly applied to halogen release is $50 \%$ plateout factor allowed by NRC (1977B, 1979A, 1979B). This $50 \%$ of the $50 \%$ inventory release results in $25 \%$ of the halogen inventory reaching the containment barrier or the removal system. Another natural removal process is deposition of particles from a cloud of released material, both inside and outside of the facility. Deposition outside the facility is considered most important and is discussed in Section V.E.

Engineered safety features receive credit for removal if they are designed, installed, tested, and maintained according to prescribed standards (Brynda 1981). Table IX provides a summary of removal factors from the literature (Walker 1978). Although not all these factors were investigated independently during preparation of the Guide, the recommended values in Table IX provide a basis for common usage, with the possible exception of HEPA filter efficiency. Three situations can be en isisioned under which decisions must be made regarding credit for HEPA filter stages. First, should credit be allowed for any stage of HEFA filters which is not protected against heavy smoke loading? In this case, protection is not likely to be realized at any stage because upstream HEPA stages are likely to fail. Second, what credit should be allowed if the postulated accident is unlikely to affect the HEPA filters (no common failure occurs)? In this case, it appears acceptable to allow credit commensurate with in-place test results, that is, approximately $99.95 \%$. Third, an unclear situation may exist in which degraded performance should be assumed. The practice set by DOE-AL (ALO 1971) uses the following efficiencies for HEPA filters under accident conditions, if it may be assumed they are testable as installed and protected by prefilters, sprinklers (or equivalent), and demisters:

$\begin{array}{ll}\text { - Ist stage } & 99.9 \% \\ \text { - 2nd stage } & 99.8 \%, \\ \text { - 3rd stage } & 99.8 \% \text {, and } \\ \text { - } 4 \text { th stage } & 99.8 \% .\end{array}$




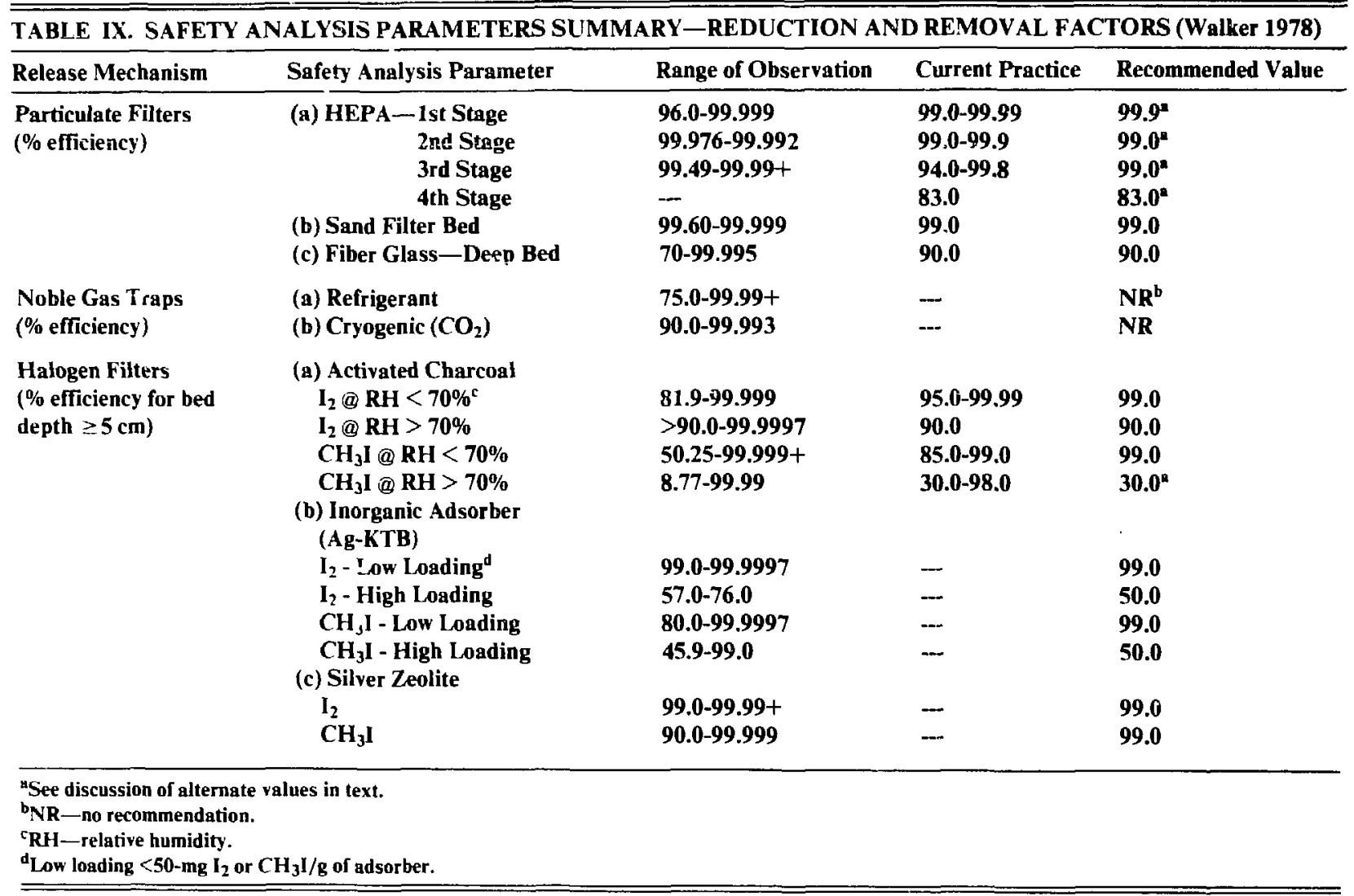

Regulatory Guide 1.52 recommends $99 \%$ in case of an accident (NRC 1978B); this is considered too low. Faust et al. assumed only one stage of operable filtration providing 99.9\% removal (Faust 1977); this is considered too restrictive when other tested stages are present. A general discussion of HEPA filter credit under accident conditions is contained in the Nuclear Air Cleaning Handbook (Burchsted 1976).

Sand filter efficiency is expected to be $99.5 \%$, based on extensive operating experience at the Savannah River Plant (Orth 1980). This value is the 97th percentile efficiency experienced with operating filters; $99.97 \%$ is the median efficiency from the same data. This value (99.5\%) may be used to calculate accidental releases (including fire, if the filter has been suitably sized or protected from plugging by combustion products).

Halogen removal is affected by humidity, loading, and its chemical form. The accident description should include estimation of each effect and choice of efficiencies which lead to conservative estimates of release. Those suggested in Table IX are considered suitable except for $30 \%$ efficiency against $\mathrm{CH}_{3} \mathrm{I}$ at high humidities. Although recommended by NRC in Regulatory Guide 1.52 (NRC 1978B), the 30\% figure is at the low end of experimental data summarized by Walker (1978) and is not considered conservative. An alternative value in the range 50 to $80 \%$ is considered more appropriate.

\section{Release Duration}

Release duration for the accident case in nonreactor facilities will usually be short (less than $8 \mathrm{~h}$ ). In most cases, the total release may be averaged over the total time of release; however, some effort should be made to characterize the timing of the release. If a peak concentration exists during a short period of the release, that period and concentration may be appropriate for use in the dispersion and dose calculations. Evacuation or other mitigation may affect the concentration selected for the exposure. 


\section{E. Meteorological Analysis and Dispersion}

Dispersion of radioactive material in the atmosphere following a major postulated accident requires use of models that account for the major features of the accidental reicase: its relatively short duration, its cloud more often a puff than a plume, and a pote :ially high concentration of radioactive material. The postulated accident case is simplified sonewhat by its brevity; that is, it may be assumed in most cases that no major change in meteorology occurs during the duration of cloud dispersion.

This section deals with a suitable model, its general acceptability, and the approximate range of its applicability. Choice of model and the adjustments to models may have a major impact on the result. It is suggested that ihe analyst consider each adjustment as an important source of additional accuracy, while keeping in mind the general level of uncertainty inherent in each calculation leading to the dose. As in all other steps of dose calculation, conservativism in the selection of dispersion models and parameters is suggested.

1. Gaussian Dispersion Model. The straight-line Gaussian dispersion equation (Slade 1968) is in general use to model dispersion of chronic and accident releases. Its use for estimating the time-integrated air concentration $\chi\left(\mathrm{Ci} \cdot \mathrm{s} / \mathrm{m}^{3}\right.$ or $\left.\mathrm{Bq} \cdot \mathrm{s} / \mathrm{m}^{3}\right)$ at downwind locations is recommended for most accident conditions, unless site-specific models of some other form have been developed and verified. The basic Gaussian dispersion equation has been adjusted by various authors to accommodate release and dispersion effects. These adjustments are discussed briefly in the following sections and in greater detail in Appendix D. The range of distances over which the Gaussian model should be used varies with conditions (see Section C-I in Appendix $D$ ) but the model is considered generally applicable over the range 0.1 to $10-20 \mathrm{~km}$. Beyond $20 \mathrm{~km}$ results should not be considered better than order-of-magnitude estimates.

2. Dispersion Parameters/Stability Classifications. The horizontal and vertical dispersion coefficients, $\sigma_{y}$ and $\sigma_{z}$, required in the Gaussian dispersion equation are obtained either from site-specific meteorological measurements (standard deviations of wind angles) or by estimatirg an atmospheric stability class for which standard coefficients have been established. Methods for using site-specific data are cited in Appendix D. If the necessary meteorological measurements are not available, several methods for determining stability class may be used. Examples are contained in Turner 1970. NRC 1974, and NRC 1983. See Appendix D for others. The vertical temperature gradient method is no longer recommended by the AMS (see Appendix D). Assumption of a conservative stability class (for example, slightly stable or moderately stable) is an acceptable and frequently used method for ground-level releases.

Determination of $\sigma_{y}$ and $\sigma_{z}$ from existing curves is common and acceptable practice For $\sigma_{y}$, the AMS (1978) has suggested that the Pasquill-Gifford (Gifford 1961) curves and the McElroy-Pooler (1968) urban curves are acceptable if adjustments are made for sampling duration and surface roughness. Curves presented by Briggs (1973) have combined data from PasquillGifford and several other sources to describe dispersion of elevated releases.

The differences between puff and plume dispersion by the Gaussian dispersion equation can be (and usually should be) accounted for in the accident case. Methods for calculating puff dispersion coefficients have been addressed by Gifford (1977), Hanna (1982), and Turner (1970).

3. Release Effects. The dispersion equation may require modifications due to release effects, notably plume or puff rise (buoyant or momentum) and building wake effects.

a. Plume Rise. Credit for plume rise has not always been laken in SARs and regulatory guides. However, calculation of an effective release height above stack height is considered reasonable for the accident case. Equations appropriate for the descriptions of buoyant and momentum plume rise have been presented by Briggs (1969, 1975). An expression for cloud rise from high-explosive detonation has been presented by Church (1969).

b. Stack and Building Wake Effects. Stack tip effects will be observed if exit velocity does not exceed 1.5 times the wind velocity. Building wake effects will also be observed if the release height does not exceed 2-1/2 times the height of nearby structures. Adjustments for these effects are discussed in Appendix D.

4. Dispersion Effects. As the cloud of released material moves downwind, several dispersion effects may alter the air concentrations obtained by the Gaussian equation. Of these, radioactive decay, plume trapping by an inversion, dry deposition, and fumigation are considered of possible importance and are discussed here and in Appendix D. Wet deposition, although considered an inappropriate cloud depletion etfect for the accident case, is discussed briefly in Appendix $D$. Chemical change of state by absorption of a gas by atmospheric water or the chemical reaction with vegetation may be identified removal mechanisms for some 
compounds; these are not expected to be important removal mechanisms.

a. Radioactive Decay. Radioactive decay will be important only in depleting short-lived radionuclides released from a criticality accident. Decay effects are accounted foi $n$ the decay and buildup models cited in Section V.A., Source Terms.

b. Inversion Lid. As a general rule, unlimited mixing depth should not be used. Dispersion analysis of some locations with chronic inversions lasting more than a few hours must include some restriction of mixing depth (Turner 1970). Several alternatives for determining mixing layer depth are discussed in Appendix D.

c. Fumigation. Fumigation conditions are capable of causing locally high concentrations. Modifications to the Gaussian equation to account for frequent fumigation conditions are presented in Turner (1970) and Hanna (1982). Further discussion is provided in Appendix D.

d. Terrain. Effective release height should be reduced by the terrain height or the release height divided by 2 , whichever is smaller (Briggs 1973). Combined effects of stability and terrain are discussed in Appendix D.

e. Dry Deposition. Dry deposition of particulate matter or gases may be of interest for ground deposition estimates or for reduction of the source term at a downwind distance. However, depletion of the cloud by deposition of respirable particles $(<10-\mu \mathrm{m}$ aerodynamic equivalent diameter) will not have significant effect on inhalation doses due to the low deposition velocity of respirable particles. Ground deposition is discussed further in Appendix D.

5. Meteorology. Two meteorological categories, median and unfavorable, are used to establish a range of release dispersion from expected to extreme conditions. These categories correspond to $50 \%$ and $0.5 \%$ sector probability distribution of $\chi / Q s$, respectively. Specific definitions of median and unfavorable dispersion factors are provided in Appendix D.

6. Population Dose. If population dose estimates are needed, dispersion factors used to calculate conservative population doses may be assumed in the direction having the largest nearby population. The unfavorable dispersion factor for this sector could be used to calculate the collective dose to the people residing in that sector (out to some minimum dose contour, such as $25 \mathrm{mrem}$ ). If there are population centers in several directions from the release, several sector evaluations may be appropriate.
It is not appropriate to consider the entire population exposed to the concentration at the cloud centerline. Integrated activity concentrations over the area containing people and the actual population density in those areas would be appropriate for population dose calculations.

\section{F. Radiological Dose}

Choice of models and input parameters are important if dose conversion factors are to be obtained and applied in a reasonably consistent manner. Doses to the whole body and to specific organs are calculated for comparison with the dose guidelines proposed for Chapter I of DOE Order 6430.1. This section deals with the models and parameters used to calculate doses from accident-caused exposures that are expected to be the major contributors to accident consequences: inhalation of radioactive material during cloud passage, direct radiation received by immersion in the cloud, and ingestion dose. Dose methods are discussed in greater detail in Appendix E. A comparison of several dispersion and dose codes was made using common input for two postulated release cases. The results of this comparison are presented in Appendix F.

1. Inhalation Dose. The inhalation model described by the ICRP Task Group on Lung Dynamics (TGLD) is incorporated in most major computer codes for calculating inhalation doses (ICRP 1966). Formulation of the TGLD model was based only on the need for protection against harmful effects of radiation and is not necessarily an accurate detailed description of the behavior of inhaled radionuclides. This model is, however, considered suitable for the purpose of analyzing hypothetical accidents, that is, estimating fractional deposition of important radionuclides in the compartments $\mathrm{cf}$ the respiratory system and subsequent transfer to other organs. The TGLD model is intended for use with particle distributions that have an activity median aerodynamic diameter (AMAD) between 0.2 and $10 \mu \mathrm{m}$ with geometric standard deviations of less than 4.5. For the unusual distribution having an AMAD greater than $20 \mu \mathrm{m}$, complete nasopharyngeal deposition can be assumed. The model does not apply to aerosols with AMADs below $0.1 \mu \mathrm{m}$.

The TGLD model is included in the ICRP 30 dose model (ICRP 1979), a major upgrading of the ICRP 2 dose model (ICRP 1959). A transition to the ICRP 30 model, which accounts for dose to an organ from gamma and beta emitters deposited in the organ itself and in nearby organs, is occurring within the DOE complex. This transition is expected to continue as computing facilities acquire the computer codes and as various radiation standards such as $10 \mathrm{CFR} 20$ and 
DOE Order 5480.1A, Chapter XI, are revised using ICRP 30 or similar models. In the interim, the following (elaborated in Appendix E) are provided for 'npropriate use:

- Codes based on ICRP 2 dose models may be modified to use organ masses from ICRP reference man (ICRP 1974) and quality factors from ICRP 26 (ICRP 1977).

- Transfer fractions and biological half-times in ICRP 30 models may be incorporated in models where possible.

- Solubility classes of compounds in ICRP 30 may be used in all calculations.

- Bone doses calculated for comparison with the surface bone guideline dose proposed for DOE Order 6430.1 may be calculated by ICRP 30 model or by the ICRP 2 model of volume bone dose times a distribution factor of $n=5$.

- The exposed person may be considered ICRP reference man (ICRP 1974) (see definitions in Sections III.B.2. and III.B.3.).

- The AMAD chosen as input to the TGLD model represents the respirable fraction of the particle cloud rather than the total particle mass.

- A 50-yr dose accumulation time may be used to take advantage of occupational dose conversion tabulations (differences between $50-\mathrm{yr}$ and $70-\mathrm{yr}$ conversion factors are minor).

- Doses to more than one organ from a single inhalation exposure may be combined into an effective dose equivalent by a method similar to the ICRP 26 method (ICRP 1977).

2. Direct Irradiation from Cloud Immersion. Two models are commonly used to calculate direct gamma or beta dose from cloud immersion: the finite plume model or the semi-infinite plume model. The finite plume model is preferred for most accident analysis cases where a puff release occurs and the lateral dimension of the cloud is limited by unfavorable meteorology. If a semi-infinite model is used, a "finite plume" correction factor should be applied to calculation of close-in doses $(<10 \mathrm{~km})$ (Strenge 1980). NRC recommendations contained in Regulatory Guide 3.33 (NRC 1977B) state that immersion dose to the whole body should be assumed at the $5-\mathrm{cm}$ tissue depth (Strenge 1980). ICRP 30 also uses an acceptable mcthod of calculating immersion dose by the method of Poston and Snyder (Poston 1974). Calculation of dose to skin is rarely necessary because its biological significance is usually low compared with that of other organs receiving dose.

3. Ingestion Dose. Ingestion dose as a controlling consequence of in: accidental release is considered a lower likelihood than either inhalation or immersion dose. However, a major leak to nearby waterways should be considered in some instances. Although unlikely to approach the radiation dose limits proposed for Chapter I of DOE. Order 6430.1, ingestion dose might fall in the category of "other consequences to be considered" discussed in Section V.G. of the Guide.

Dispersion of radionuclides into the aquatic environment can be estimated by the method of Regulatory Guide 1.113 NRC (1977C). Doses from ingestion of contaminated water have been calculated by several models; Regulatory Guide 1.109 (NRC 1977D), Strenge (1980), Huang (1983), and ICRP 30 (ICRP 1979) are examples.

\section{G. Other Consequences to be Considered}

Potential consequences of radiological accidents other than dose to individuals may influence decisions on site selection and major design features. The consequences of environmental contamination, population dose, and public health effects may be significant considerations when a comparison must be made among several alternative sites. In the absence of numerical guidance, the conditions under which each of the consequences could be evaluated are discussed, leaving assessment of the result to an authority other than the analyst. Usefulness of each result will depend on individual circumstances.

1. Environmental Contamination. Contamination by radionuclides from the postulated accident could cause an economic impact or production loss in excess of that deemed acceptable. Although numerical guidance has not been provided in DOE orders or in NRC regulatory guides, the cost of zanup or the impact of lost production at nearby facilities may be significant considerations in the site evaluation and faclity design.

The public health consequences of long-term exposure to residual accident debris, after decontamination and return to original use, are small compared with direct inhalation exposure doses and may usually be neglected (see Appendix G). A possible exception might arise if radioiodine were the major radionuclide released into the environment by the accident. The cow-milkinfant pathway for radioiodine may cause more restricting doses than the dose from direct inhalation from the passing cloud.

At present, consensus has not been reached among government agencies on appropriate decontamination limits for soil and property. Three approaches are commonly made toward limits: those based on health effects, food chains, and pathway analysis; those on detection levels and ALARA concepts; and those which 
are expedieist in terms of cost and political considerations. Preferred limits should be based on levels that would give little additional health risk to the public once the land and property are decontaminated and returned to normal use. It is assumed that confiscation and condemnation of private property in lieu of decontamination and renovation to original use are not acceptable approaches to this problem.

Current soil remedial action guidelines (DOE 1984) for actinides and common fission products have been derived for the DOE FUSRAP and SFMP programs based on earlier work by Healy and the EPA (Healy 1971, 1977, 1979A, 1979B; Naper 1982; ORO 1983; Gilbert 1983; EPA 1977; and EPA 1983). The EPA has recently published the final remedial-action guidelines for the natural uranium decay series in 40 CFR 192 (EPA 1983). The soil remedial-action derivation methods (pathway analyses) given in ORO 831 and 832 (ORO 1983, Gilbert 1983) have been used by the DOE to be the basis for developing action guidelines for other radionuclides when they are needed.

Several proposed cleanup levels currently exist for actinides. The EPA has suggested a soil screening level for plutonium (EPA 1977). This screening level was calculated by EPA to meet the EPA proposed dose guidance ( $1 \mathrm{mrad} / \mathrm{yr}$ to lung and $3 \mathrm{mrad} / \mathrm{yr}$ to bone) with no remedial action necessary. Another suggested level is a limit also based on a maximum dose to any organ (Healy 1977, 1979A, and 1979B). These proposed criteria are based upon limiting the amount of plutonium that could be inhaled or ingested by the general public living or working in areas contaminated with plutonium.

Decontamination cost estimates may be based on the approach used in WASH 1400 (NRC 1975B) and in the Pantex EIS (Wenzel 1982). This approach includes three land use categories (farm, suburban, and commercial), but does not refine the analysis to the extent of including site specification features beyond these three categories. Other potential costs, such as decontamination of onsite buildings and loss of operating time at contaminated onsite buildings, could be considered separately.

Decontamination methods, decontamination guidelines, and cost estimates are discussed in greater detail in Appendix G.

2. Population Dose. Population dose and population center distance were defined earlier in Section III.B. Calculation of radiological doses to individual members of a population is also discussed elsewhere (Section V.F. and Appendix E). Population dose can be valuable as an additional index of the suitability of a site and as an intermediate result needed in the estimation of potential health effects of a postulated accident.

The population which is subject to exposure is commonly considered the total population within an $80-\mathrm{km}$ radius of the proposed site. However, the accident case usually involves only that part of the population containing individuals directly contacted by the accident cloud. That is, a limited number of people could be exposed to potentially high concentrations of airborne radioactive material. In this limited population, a higher incremental health risli or a higher risk to the individual receiving the average dose would be expected to occur than in the total population. Therefore, dilution of the population dose over a larger population should be avoided when using the population dose in an estimation of incremental health effects due to a major accident.

Population dose may be calculated using integrated concentration values and population densities. Cloud centerline doses times the total population is considered overly conservative for this estimate.

Assumptions regarding makeup of the exposed population may require variation to suit the actual population and the radionuclides released. If population dose is the desired endpoint, say for comparison among several alternative sites, a homogeneous population made up of adults is an asceptable assumpition. Errors resulting from assuming a homogeneous population are considered relatively minor in comparison with possible errors in other areas of dose calculation (Etnier 1979). However, basing a siting or major design feature decision on a homogeneous population dose does not account for differences in health risk factors as influenced by age at the time of exposure and sex distribution of the population. More study is needed to assess the егror magnitudes when homogeneous population doses are used to estimate health effects. In the meantime, care should be taken to use conservative age- and sex-averaged health risk factors with homogensous population doses.

Credii for a fraction of the population being indoors during cloud passage may be justified if a suitable model has been devised. The protection factor afforded by being indoors is discussed by Cohen (1979). Credit for emergency planning and evacuation should not be taken unless the release is delayed beyond the time in which effective action could be taken.

3. Public Health Effects. Public health effects may result from a postulated radiological accident at a DUE nuclear facility. These health effects might include acute effects but would usually involve only delayed effects such as cancer mortality and perhaps serious hereditary effects. Estimates should be based on health risk factors which have been recommended by recognized advisory groups. As discussed in Section V.G.2, health effects estimates should be based on conservative age- and sexaveraged risk factors when using a homogeneous (alladult) population dose. Two methods of estimating health risks resulting from exposure to low levels of 
ionizing radiation have been prepared for use in DOE NEPA documents (Buhl 1984). The first method is used when demographic data are not available for the exposed population; in this case, age- and sex-averaged lifetime cancer (or serious hereditary defect) risk factors are provided, based on the makeup of the US population. The second method provides for a more detailed risk calculation when the exposed population is significantly different from the US population. Use of risk factors averaged by age and sex over the US population would lead to differences of a factor of 2 to 3 from the exposed populations with more extreme age and sex distributions (Buhl 1984). Health risk factors which are considered appropriate for the purpose are discussed in greater detail in Appendix B.

Advice on terminology to be used when reporting estimated health effects in safety analysis documents has varied among peer ieviewers of the Guide. Better public understanding or reduced chance of misinterpretation of the data by the reporting media or by members of the public is the objective when reporting potential health effects. It is difficult to put any nonvoluntary health risk into a more positive or favorable light. The negative as well as the positive aspects of DOE activities should be reported objectively without shading meaning or loss of accuracy.

A number of semitechnical terms have been used in the past to describe health risk. Tile following are examples of terms that can be used under appropriate circumstances: delayed cancer mortality, incremental risk of eventual cancer death, expected cancer deaths, projected cancer deaths, potentia! health effects, and perhaps others. The term used should acknowledge the fact that radiation can cause cancer (or potentially serious hereditary defects) but at low doses to individuals, this likelihood is quite low. Increased chance of eventual cancer death and incremental risk of eventual cancer death are similar terms which accurately describe the situation of an individual who receives a dose as a result of a postulated accident. This dose represents a risk of cancer, not a certainty. It is also considered helpful to the understanding of this increased risk to include increased risks from common activities of the public for purposes of comparison.

Points to be made in providing hea'th effect information are (1) a finite but small probability exists that an accident might occur which could have offsite consequences; (2) should the accident occur, the analysis shows some members of the public could receive radiation doses; (3) it is not clear whether any of these doses would be large enough to cause observable health effects-it is known that these effects would probably not be observable for many years; (4) these health effects are purposely overestimated in the analysis to assure that any error in the estimate is accounted for; and (5) these estimates are made to promote more informed deci- sions regarding the location of the nuclear facility and the major design features included to minimize the effects of any potential accident.

\section{ACKNOWLEDGMENTS}

Thi: has been a project of many participants. The authors are indebted to the 14 peer reviewers and approximately 30 other interested people who spent time and effort reviewing and contributing to the Guide. We also wish to thank Raymond Cooperstein of the DOE Office of Nuclear Safety for his contributions as project monitor.

In particular, we acknowledge the extra effort of James Denovan of Battelle Pacific Northwest I aboratories, William Durant of Savannah River Laboratory, and Douglas Wenzel of Westinghouse Idaho Nuclear, who met with the authors and Raymond Cooperstein to aid in reconciling comments of the reviewers. The authors also appreciate special assistance provided by Jack Healy and Joel Bennett of Los Alamos, Milton Bullock of EG\&G Idaho, and David Coats and William King of Lawrence Livermore National Laboratory.

Finally, our appreciation goes to our faithful word processors: Cheryl Lemons, Vickie Martinez, and Rosemary Guenther, without whose diligence the many verions of the guide would have been unmanageable. Thanks also to technical editor Virginia Reichelt for her timely and thorough effort.

\section{REFERENCES}

AEC 1962: J. J. DiNunno, F. D. Anderson, R. E. Baker, and R. L. Waterfield, "Calculation of Distance Factors for Power and Test Reactor Sites," US Atomic Energy Commission report TID-14844 (March 1962).

ALO 1971: "HEPA Filtration Guidelines," US Atomic Energy Commission Operational Safety Division/Engineering and Construction unnumbered report (December 9, 1971).

ALO 1982: "Safety Analysis and Review System for AL Operations," DOE Albuquerque Operations Office Order AL 5481.1A (September 15, 1982).

AMS 1978: American Meteorological Society, "Accuracy of Dispersion Models-A Position Paper of the AMS 1977 Committee on Atmospheric Turbulence and Diffusion,"Bulletin of the American Meteorological Society 59 (8) (August 1978).

Andrae 1978: R. W. Andrae, K. H. Duerre, and W. S. Gregory, "TVENT-A Computer Program for Analysis 
of Tornado-Induced Transients in Ventilation Systems," Los Alamos Scientific Laboratory report LA-7397-MS (July 1978).

Andrae 1979: R. W. Andrae, R. A. Martin, and W. S. Gregory, "Analysis of Nuclear Facilities for TornadoInduced Flow and Reentrainment," Los Alamos Scientific Laboratory report LA-7571-MS (NUREG/CR-0521) (January 1979).

ANSI 1976: "Criteria for the Design of Plants for the Manufacture of Mixed Oxide (U-Pu) Fuels," ANSI N287-1976 (American National Standards Institute, Inc., New York, 1976).

ANSI 1980: "Guidance for Defining Safety-Related Features of Nuclear Fuel Cycle Facilities," ANSI N46.1 (American National Standards Institute, Inc., New York, 1980).

ANSI 1982: "Minimum Design Loads for Buildings and Other Structures," ANSI A58.1 (American National Standards Institute, Inc., New York, 1982).

ANSI 1983: "Standard for Estimating Tomado and Extreme Wind Characteristics at Nuclear Power Sites," ANSI/ANS-2.3-1983 (American Nuclear Society, La Grange Park, Illinois, 1983).

ASME 1980: "Dynamic Analysis Methods," in $A S M E$ Boiler and Pressure Vessel Code (American Society of Mechanical Engineers, New York, 1980), App. N, Sec. III, pp. 595-627.

Bohm 1973: G. J. Bohm, "Damping for Dynamic Analysis of Reactor Coolant Loop Systems," ANS National Topic Meeting, CONF-730304 (US Atomic Energy Commission, Salt Lake City, Utah, March 1973).

Briggs 1969: G. A. Briggs, Plume Rise, AEC (ritical Review Series TID-25075 (Clearing House for Federal Scientific and Technical Information, Springfield, Virginia, 1969).

Briggs 1973: G. A. Briggs, "Diffusion Estimation for Small Emissions," ATDL Contribution File No. 79 (Atmospheric Turbulence and Diffusion Laboratory, Oak Ridge, Tennessee, 1973).

Briggs 1975: G. A. Briggs, "Plume Rise Predictions," in "Lectures on Air Pollution and Environmental Impact Analyses, Workshop Proceedings, Boston, MA, Sept. 2-Oct. 3, 1975" (American Meteorological Society, Boston, Massachusetts, 1975).
Briscoe 1982: G. J. Briscoe, “Risk Management Guide," EG\&G Idaho report SSDC-11 (September 1982).

Brynda 1981: W. J. Brynda, L. Junker, R. C. Karol, P. R. Lobner, and L. A. Goldman, "Nonreactor Nuclear Facilities: Standards and Criteria Guide," US Department of Energy report DOE/TIC-11603, BNL 51444 (September 1981).

Buhl 1984: T. E. Buhl and W. R. Hansen, "Estimating the Risks of Cancer Mortality and Genetic Defects Resulting from Exposures to Low Levels of Ionizing Radiation," Los Alamos National Laboratory report LA-9893-MS (May 1984).

Burchsted 1976: C. A. Burchsted, J. E. Kahn, and A. B. Fuller, "Nuclear Air Cleaning Handbook," Energy Research and Development Administration report ERDA 76-21 (1976).

Castleman 1969: A. W. Castleman, F. L. Horn, and G. C. Lindauer, "On the Behavior of Aerosols Under Fast Reactor Accident Conditions," Brookhaven National Laboratory report BNL-14070 (September 1969).

CFR 1962: "Reactor Site Criteria," Code of Federal Regulations, Title 10, Part 100 (1962) (revised 1984).

Church 1969: H. W. Church, "Cloud Rise from High Explosive Detonations," Sandia National Laboratories report SC-RR-68-903 (May 1969).

Clemens 1982: P. L. Clemens, "A Method of Combinatorial Failure Probability Analysis Using MILSTD-882A," Sverdrup Technology, Inc., report (April 1982).

Clough 1975: R. W. Clough and J. Penzien, Dynamics of Structures (McGraw-Hill, New York, 1975), pp. 521-609.

Coats 1984A: D. W. Coats, "Natural Phenomena Hazards Modeling Project: Seismic Hazards Models for Department of Energy Sites," Lawrence Livermore National Laboratory report UCRL 53582 (September 1984).

Coats 1984B: D. W. Coats, "Natural Phenomena Hazards Modeling Project: Extreme Wind/Tornado Hazard Models for Department of Energy Sites," Lawrence Livermore National Laboratory report UCRL 53526 (February 1984). 
Cohen 1979: A. F. Cohen and B. L. Cohen, "Infiltration of Particulate Matter Into Buildings," US Nuclear Regulatory Commission report NUREG/CR-1151 (November 1979).

Croff 1980: A. G. Croff, "A User's Manual for the ORIGEN2 Computer Code," Oak Ridge National Laboratory report ORNL/TM-7175 (July 1980).

Dewart 1982: J. M. Dewart, B. M. Bowen, and J. C. Elder, "Supplementary Documentation for an Environmental Impact Statement Regarding the Pantex Plant: Dispersion Analysis for Postulated Accidents," Los Alamos National Laburatory report LA-9445-PNTX-D (December 1982).

DOE 1981A: "Environmental Protection, Safety, and Health Protection Program for DOE Operations," US Department of Energy Order 5480.1A (1981), Chap. I.

DOE 1981B: "Environmental Protection, Safety, and Health Protection Standards," US Department of Energy Order 5480.1A (1981), Chap. V.

DOE 1981C: "Safety Analysis and Review System," US Department of Energy Order 5481.1A (1981).

DOE 1983A: "General Design Criteria Manuâl," US Department of Energy Order 6430.1 (December 12, 1983), proposed Chap. I revision (June 25, 1984).

DOE 1983B: "Final Envirc rmental Impact Statement, Pantex Plant Site," US Department of Energy report DOE/EIS-0098 (October 1983).

DOE 1984: "Interim Residual Contamination and Waste Control Guidelines for Formerly Utilized Sites Remedial Action Program (FUSRAP) and Remote Surplus Facilities Management Program (SFMP) Sites," DOE internal review (in preparation, Wayne $R$. Hansen, HSE-8, Los Alamos National Laboratory) (March 1984).

Durant 1980: W. S. Durant, "The Application of Probabilistic Risk Assessment to Nuclear Fuel Reprocessing Facilities at Savannah River Plant," Savannah River Laboratory report DP-MS-80-59 (November 1980).

Durant 1981: W. S. Durant, "Data Banks for Risk Assessment of Fuel Reprocessing Plants," Savannah River Laboratory report DP-MS-81-90 (October 1981).

Eagling 1983: D. G. Eagling, "Seismic Safety Guide," Lawrence Berkeley Laboratory report LBL-9143 (September 1983).
EPA. 1977: "Summary Report Proposed Gividance on Dose Limits for Persons Exposed to Transuranic Elements in the General Environment," US Environmental Protection Agency, Office of Radiation Programs, Criteria and Standards Division report EPA 540/4-77-106 (September 1977).

EPA 1983: "Standards for Remedial Action at Inactive Uranium Processing Sites. Final Rule," Title 40, Code of Federal Regulations, Part 192, Federal Register 48 (3), 590 (January 5, 1983), Chap. I, Subchap. F.

Etnier 1979: E. L. Etnier and I. E. Till, "Significance of Incorporating Age-Dependent Data into Population Dose Estimates," Health Physics 37, 774-775 (December 1979).

Faust 1977: L. G. Faust, L. W. Brackenbush, L. A. Carter. et al., "A Guide to Good Practices at Plutonium Facilities," Battelle Pacific Northwest I aboratories report BNWL-2086 (September 1977).

Gifford 1961: F. A. Gifford, "Uses of Routine Meteorological Observations for Estimating Atmospheric Dispersion," Nuclear Safety 2 (4), 47-51 (1961).

Gifford 1977: F. A. Gifford, "Tropospheric Relative Diffusion Observations," Journal of Applied Meteorology 16, 311-313 (1977).

Gilbert 1983: T. L. Gilbert, P. C. Chee, M. J. Knight, et al, "Pathways Analysis and Radiation Dose Estimates fo" Radioactive Residues at Formerly Utilized MLD/AEC Sites," Oak Ridge Operations report ORO-832 (March 1983).

Gregory 1982: W. S. Gregory and P. R. Smith, "Response of Standard and High-Capacity HEPA Filters to Simulated Tornado and Expiosive Transients," Los Alamos National Laboratory report LA-9210-MS (March 1982).

Gumprecht 1968: R. O. Gumprecht, "Mathematical Basis of Computer Code RIBD," Douglas United Nuclear, Inc., report DUN-4136 (June 1968).

Hanna 1982: S. R. Hanna, G. A. Briggs, and R. P. Hosker, "Handbook on Atmospheric Diffusion," US Department of Energy report DOE/TIC-1 1223 (1982).

Hart 1973: G. C. Hart and P. Ibanez, "Experimental Determination of Damping in Nuclear Power Plant Structures and Equipment," Nuclear Engineering and Design 25 112-125 (1973). 
Healy 1971: J. W. Healy, "Surface Contamination: Decision Levels," Los Alamos Scientific Laboratory report LA-4558-MS (September 1971).

Healy 1977: J. W. Healy, "An Examination of the Pathways from Soil to Man for Plutonium," Los Alamos Scientific Laboratory report LA-6741-MS (April 1977).

Healy 1979A: J. W. Healy and J. C. Rodgers, "Limits for the Burial of the Department of Energy Transuranic Wastes," Los Alamos Scientific Laboratory document LA-UR-79-100 (1979) (revision in preparation, HSEDO).

Healy 1979B: J. W. Healy, J. C. Rodgers, and C. L. Wienke, "Interim Soil Limits for Decontamination and Decommissioning Projects," Los Alamos Scientific Laboratory document LA-UR-79-1865-Rev. (1979).

Hooper 1974: R. L. Hooper, T. Olsen, V. O. Uotinen, and C. L. Brown, "Empirical Method for Estimating the Total Number of Fissions from Accidental Criticality in Uranium or Plutonium Systems," Battelle Northwest Laboratories report BNWL-1840 (July 1974).

Horak 1982: H. L. Horak, W. S. Gregory, C. I. Ricketts, and P. R. Smith, "Structural Performance of HEPA Filters Under Simulated Tornado Conditions," Los Alamos National Laboratory report LA-9197-MS (February 1982).

Huang 1983: J. C. Huang, "Analysis Aids for Consequence Calculations of Postulated SRP Surface Water Releases," E.I. DuPont de Nemours memorandum DPST-83-870 (1983).

ICBO 1982: "Uniform Building Code" (International Conference of Building Officials, Pasadena, California, 1982).

ICRP 1959: "Report of Committee II on Permissible Dose for Internal Radiation," International Commission on Radiological Protection, Publication 2 (1959).

ICRP 1966: "Deposition and Retention Models for Internal Dosimetry of the Human Respiratory Tract," International Commission on Radiological Protection report in Health Physics 12 (2), 173-207 (1966).

ICRP 1974: "Report of the Task Group on Reference Man," international Commission on Radiological Protection, Publication 23 (October 1974).
ICRP 1977: "Recommendations of the ICRP," International Commission on Radiological Protertion Publication 26 (1977).

ICRP 1979: "Limits for Intake of Radionuclides by Workers," International Commission on Radiological Protection, Publication 30, Part 1 (July 1979).

ICRP 1980: "Limits on Intakes by Workers," International Commission on Radiological Protection, Publication 30, Part 2 (1980).

Lecorche 1973: P. Lecorche and R. L. Seals, "A Review of the Experiments Performed to Determine the Radiological Consequences of a Criticality Accident," Union Carbide Corporation report Y-CDC-12 (November 1973).

Lloyd 1979: R. C. Lloyd, S. W. Heaberlin, E. D. Clayton, and R. D. Carter, "Assessment of Criticality Safety," Nuclear Technology 42, 13 -21 (January 1979).

Lucas 1981: D. E. Lucas, "Safety Analysis Guide for Nonreactor Nuclear Facilities," Hanford Engineering Development Laboratory report HEDL MG-153 (1981).

McElroy 1968: J. L. McElroy and F. Pooler, "St. Louis Dispersion Study," US Department of Health, Education, and Weifare, Analysis Report AP-53 (1968), Vol. 2.

Mehta 1978: K. C. Mehta, D. A. Smith, and J. R. McDonald, "Response of Structures to Extreme Wind Hazard at the Westinghouse Plutonium Fuel Development Laboratory, Cheswick, Pennsylvania" (Institute for Disaster Research, Texas Tech University, Lubbock, Texas, 1978), Vol. I.

Mishima 1966: J. Mishima, "Plutonium Release Studies," Battelle Northwest Laboratories report BNWL-357 (November 1966).

Mishima 1970: J. Mishima and L. C. Schwendiman, "The Amount and Characteristics of Plutonium Made Airborne Under Thermal Stress," Pacific Northwest Laboratories report BNWL-SA 3379 (October 1970).

Mishima 1979: J. Mishima, L. C. Schwendiman, and J. E. Ayer, "Estimated Airborne Release of Plutonium from Westinghouse Cheswick Site as a Result of Postulated Damage from Severe Wind and Seismic Hazard," Battelle Pacific Northwest Laboratory report PNL-2965 (May 1979). 
Mishima 1980: J. Mishima, L. C. Schwendiman, and J. E. Ayer, "Estimated Airborne Release of Plutonium from the Exxon Nuclear Mixed Oxide Fuel Plant at Richland, Washington, as a Result of Postulated Damage from Severe Wind and Earthquake Hazard," Battelle Pacific Northwest Laboratory report PNL-3340 (February 1980).

Mishima 1981: J. Mishima and J. E. Ayer, "Estimated Airborne Release of Plutonium from Atomics International Nuclear Material Development Facility in the Santa Susana Site, California, as a Result of Postulated Damage from Severe Wind and Earthquake Hazard," Battelle Pacific Northwest Laboratory report PNL-3935 (August 1981).

Napier 1982: B. A. Napier, "A Method for Determining Allowable Residual Contamination Levels of Radionuclide Mixtures in Soil," Pacific Northwest Laboratories report PNL-3852 (May 1982).

Newmark 1973: N. M. Newmark and W. J. Hall, "Procedures and Criteria for Earthquake Resistant Design," in Building Practices for Disaster Mitigations, National Bureau of Standards Building Science Series 46 (1973), p. 209.

Newmark 1978: N. M. Newmark and W. J. Hall, "Development of Criteria for Seismic Review of Selected Nuclear Power Plants," US Nuclear Regulatory Commission report NUREG/CR-0098 (May 1978).

NRC 1974: "On-site Meteorological Programs," US Nuclear Regulatory Commission Regulatory Guide 1.23 (1974), p. 6.

NRC 1975A: "General Site Suitability Criteria for $\mathrm{Nu}$ clear Power Stations," US Nuclear Regulatory Commission Regulatory Guide 4.7 (November 1975).

NRC 1975B: "Calculation of Reactor Accident Consequences," Reactor Safety Study, US Nuclear Regulatory Commission report WASH-1400 (NUREG 75/014) (Uuiober 1975), App. VI.

NRC 1977A: "Site Suitability Report in the Matter of Clinch River Breeder Reactor Plant," US Nuclear Regulatory Commission report NUREG-0786 (March 1977).

NRC 1977B: "Assumptions Used for Evaluating the Potential Radiological Consequences of Accidental Nuclear Criticality in a Fuel Reprocessing Plant," US Nuclear Regulatory Commission Regulatory Guide 3.33 (April 1977).
NRC 1977C: "Estimating Aquatic Dispersion of Effluents from Accidental and Routine Reactor Releases for the Purpose of Implementing Appendix I," US Nuclear Regulatory Commission Regulatory Guide 1.113 (April 1977).

NRC 1977D: "Calculation of Annual Doses to Man from Routine Releases of Reactor Effluents for the Purpose of Evaluating Compliance with 10. CFR, Part 50, Appendix I," US Nuclear Regulatory Commission Regulatory Guide 1.109 (October 1977).

NRC 1978A: "Development of Floor Design Response Spectra for Seismic Design of Floor-Supported Equipment or Components," US Nuclear Regulatory Commission Regulatory Guide 1.122 (February 1978).

NRC 1978B: "Design, Testing, and Maintenance Criteria for Post Accident Engineered-Safety-Feature Atmosphere Cleanup System Air Filtration and Absorption Units of Light-Water-Cooled Nuclear Power Plants," US Nuclear Regulatory Commission Regulatory Guide 1.52 (March 1978).

NRC 1979A: "Assumptions Used for Evaluating the Potential Radiological Consequences of Accidental Nuclear Criticality in a Uranium Fuel Fabrication Plant," US Nuclear Regulatory Commission Regulatory Guide 3.34 (July 1979).

NRC 1979B: "Assumptions Used for Evaluating the Potential Radiological Consequences of Accidental Nuclear Criticality in a Plutonium Processing and Fuel Fabrication Plant," US Nuclear Regulatory Commission Regulatory Guide 3.35 (July 1979).

NRC 1981A: "Standard Review Plan for the Review of Safety Analysis Reports for Nuclear Power Plants," US Nuclear Regulatory Commission report NUREG-0800 (July 1981).

NRC 1981B: "Technical Bases for Estimating Fission Product Behavior During LWR Accidents," US Nuclear Regulatory Commission report NUREG-0772 (June 1981).

NRC 1983: "A Guide to the Performanre of Probabilistic Risk Assessments for Nuclear Power Plants," US Nuclear Regulatory Commission report NUREG/CR-2300 (1983).

ORNL 1970: "Siting of Fuel Reprocessing Plants and Waste Management Facilities," Oak Ridge National Laboratory report ORNL-445I (July 1970). 
ORO 1983: "Radiological Guidelines for Application to DOE's Formerly Utilized Sites Remedial Action Program," Oak Ridge Operations Office report ORO-831 (March 1983).

ORO 1984: "Safety Analysis and Review System," Oak Ridge Operations Office Order OR-5481.1B (May 23, 1984).

Orth 1980: D. A. Orth, G. H. Sykes, and J. M. McKibben, "Performance of Sand Filters for the Separation Areas at Savannah River Plant," in "Proceedings of the 16th ERDA Nuclear Air Cleaning Conference," CONF 801038 (1980), p. 745.

Pepper 1978: D. W. Pepper, "Calculation of Particulate Dispersion in a Design Basis Tornadic Storm from the Babcock and Wilcox Plant, Leechburg, Pennsylvania," US Department of Energy report DP-1487 (E. I. du Pont de Nemours and Co., Aiken, South Carolina, March 1978).

Perkins 1980: W. C. Perkins, W. S. Durant, and A. H. Dexter, "Potential Safety-Related Incidents with Possible Applicability to a Nuclear Fuel Reprocessing Plant," US Department of Energy report DP-1558 (E. I. du Pont de Nenours and Co., Aiken, South Carolina, December 1980).

Perkins 1981: W. C. Perkins and A. H. Dexter, "A Preliminary Hazards Analysis of a Breeder Fuel Reprocessing Facility," US Department of Energy report DP-1584, (E. I. du Pont de Nemours and Co., Aiken, South Carolina, October 1981).

Poston 1974: J. W. Poston and W. S. Snyder, "A Model for Exposure to a Semi-Infinite Cloud of a Photon Emitter," Health Physics 26, 287-293 (April 1974).

RFP 1982: "Safety Analyses and Risk Assessment in Support of the Long Range Rocky Flats Utilization Study," Rockwell International report SAR-279 (232)-3 (November 1982).

Selby 1975: J. M. Selby, E. C. Watson, J. P. Corley, et al., "Considerations in the Assessment of the Consequences of Effluents from Mixed Oxide Fuel Fabrication Plants," Battelle Pacific Northwest Laboratories report BNWL-1697 (June 1975).

Slade 1968: D. H. Slade, Ed., "Meteorology and Atomic Energy," US Ator,ic Energy Commission report TID-24190 (July 1968).
Stratton 1967: W. R. Stratton, "Review of Criticality Accidents," Los Alamos Scientific Laboratory report LA-3611 (January 1967).

Strenge 1980: D. L. Strenge, "Models Selected for Calculation of Doses, Health Effects and Economic Costs due to Accidental Radionuclide Releases from Nuclear Power Plants," US Nuclear Regulatory Commission report NUREG/CR-1021 (PNL-3108) (May 1980).

Swain 1983: A. D. Swain and H. E. Guttman, "Handbook of Human Reliability Analysis with Emphasis on Nuclear Power Plant Applications," IIS Nuclear Regulatory Commission report NUREG/CR-1278 (June 1983).

Tera 1984: "Final Report: Seismic Hazard Analysis for the Bendix, Los Alamos, Mound, Pantex, Rocky Flats, Sandia-Albuquerque, Sandia-Livermore, and Pinellas Sites," Tera Corporation report B-82-261 (March 1984).

Tuck 1974: G. Tuck, "Simplified Methods of Estimating the Results of Accidental Solution Excursions," Nuclear Technology 23 (August 1974).

Turner 1970: D. B. Turner, "Workbook of Atmospheric Dispersion Estimates," US Department of Health, Education, and Welfare report PB 191482 (1970).

Vellozzi 1973: J. W. Vellozzi and J. J. Healey, "Procedures and Criteria for Wind Resistant Design," in Building Practices for Disaster Mitigation, National Bureau of Standards Building Science Series 46 (1973), p. 237.

Walker 1978: E. Walker, "A Summary of Parameters Affecting the Release and Transport of Radioactive Material from an Unplanned Incident," Bechtel National report BNFO-81-2 (September 1978).

Wenzel 1982: W. J. Wenzel and A. F. Gallegos, "Supplementary Documentation for an Environmental Impact Statement Regarding the Pantex Plant: Decontamination Methods and Cost Estimates for Postulated Accidents," Los Alamos National Laboratory report LA-9445-PNTX-N (1982).

Woodcock i966: E. R. Woodcock, "Potential Magnitude of Criticality Accidents," United Kingdom Atomic Energy Authority report AHSB (RP)R-14 (1966). 


\section{APPENDIX A}

\section{GLOSSARY*}

Absolute risk. Expression of excess risk due to a radiation exposure as the arithmetic difference between tise risk among those exposed and risk in the absence of exposure.

Absorbed dose. The energy imparted to matter by ionizing radiation per unit mass of irradiated material at the place of interest. Its unit is the rad or gray (Gy) (see Metric units).

Accumulated dose. A dose term coined for use in the Guide to fit the postulated case of dose equivalent accumulated over a time interval after a single accidental intake of long-lived radionuclides. No new source of dose is added during the interval. The accumulation interval should be specified; $50 \mathrm{yr}$ is recommended, for the reasons described in Appendix E, Section I.

Activity median aerodynamic diameter $(A M A D)$. The aerodynamic equivalent diameter below or above which half of the activity of an aerosol with lognormallv distributed particle diameters is associated.

Aerodynamic equivalent diameter $\left(\mathrm{D}_{\mathrm{ac}}\right)$. The diameter of a unit-density sphere that would have the same terminal velocity due to gravity in air as the particie under consideration.

Annual Limit on Intake (ALI). An ICRP secondary limit on occupational exposure, as intake in 1 yr of radionuclides resulting in stochastic effects in all organs equivalent to $0.05 \mathrm{~Sv}(5 \mathrm{rem})$ or nonstochastic effects in a single organ equivalent to $0.5 \mathrm{~Sv}$ ( 50 iem).

ANSI. American National Standards Institute.

As low as reasonably achievable (ALARA). The criterion stated in $10 \mathrm{CFR} 20$ that exposures of personnel to radiation during routine operation (of $L W R s$ ) will be "as low as reasonably achievable."

BEIR. Biological Effects of Ionizing Radiation (National Academy of Sciences Committee on ...).

Breathing rate. The volumetric rate of air exchange by the respiratory system; the product of tidal volume and respiration rate. The ICRP has established the following standard breathing rates for reference man:
Resting
Light activity
Heavy work
Heavy exercise

Committed dose or dose commitment. The radiation dose calculated for radiation protection purposes to evaluate the dose received during some period of exposure plus the dose accumulated over a period of years, say 50 yr of occupational exposure, resulting from radionuclides deposited within the body during the exposure period.

Confinement. Usually refers to a system of cladding, containers, piping, glove boxes, other barriers, and air cleaning equipment, which prevent release of radioactive material into occupied spaces. Primary confinement refers to the first barrier provided for this purpose.

Coniainment. Usually refers to a structure capable of containing (with some nominal leakage) an cyerpressure caused by explosion or release of pressurized contents of vessels.

Credible eveni. An event whose probability of occurrence is above a specified threshold (recommended in the Guide to be greater than $10^{-6}$ per year).

Critical facility. A nuclear facility for radioactive material handling, processing, or storage, and other facilities having vital importance to DOE programs or high dollar value, such as plutonium processing, tritium processing, weapon assembly $(\mathrm{Pu} / \mathrm{HE})$, and certain storage facilities.

Critical system. A system whose continued integrity and operation are essential to assure confinement or measure the release of radioactive materials in the event of a DBA. Usually the ventilation, fire detection and suppression, electrical, and utility systems.

Criticulity accident. The accidental assembly of sufficient fissionable material to initiate a self-sustaining neutron chain reaction. The resulting neutron burst, if unshielded, is a major hazard to nearby workers. The energy produced disperses fission products which can cause potential health effects onsite and offsite.

"Terms in italics are defined elsewhere in this glossary. 
Damping. Dissipation of energy by motion within a structure or in underlying, geologic formations. Usually an index of the ability of a structure to withstand vibratory damage.

Decontamination factor. The quantity of radionuclide per unit area before decontamination divided by the quantity remaining after decontamination. Also the ratio of upstream lo downstrea rin concentration applied to removal capability of fluid cleaning systems.

Design basis accident (DBA). See definition and discussion in Section III.B. 1.

Dilution factor. The ratio of concentration of radio nuclides $\left(\mathrm{Ci} / \mathrm{cm}^{3}\right)$ in samples of standard volume taken before and after dilution of contaminated material by a iarger volume of a medium.

Dispersible form. The form of radioactive material which makes it subjeci to airborne or waterborne dispersion by the dispersive energy at hand; at least a fraction of the dispersed material will be directly respirable (see respirable fraction) or subject to conversion to a respirable or ingestible form by exposure in the environment.

Dispersion. The process of natural mixing of a material released to the atinosphere with cir, causing a reduction in concentration with distance from the source. See median dispersion factor and unfavorable dispersion factor.

Dispersion factor $\left.\chi / Q ! s / \mathrm{m}^{3}\right)$. Ratio of the ir concentration $\left(\mathrm{g} / \mathrm{m}^{3}\right.$ or $\left.\mathrm{Ci} / \mathrm{m}^{3}\right)$ and the release rate $(\mathrm{g} / \mathrm{i}$ or $\mathrm{Ci} / \mathrm{s})$ or the ratio of the time-integrated concentration $\left(\mathrm{g} \cdot \mathrm{s} / \mathrm{m}^{3}\right.$ or $\mathrm{Ci} \cdot \mathrm{s} / \mathrm{m}^{3}$ ) and the toial quantity released ( $\mathrm{g}$ or $\mathrm{Ci}$ ). Dispersion factor yields dose when multiplied by an amount released, a breathing rate, and a dose conversion factor.

Dose accumulation time. A time period over which expected dose from a long-lived radionuclide retained in the body after a single accidental intake is estimated (see accumulated dose).

Dose conversion /.ctor. A factor with units of dose equivalent per uni. activity inhaled or ingested which is multiplied by other factors to obtain the dose equivalent received by a specific organ (see Appendix E, Section II).
Dose equivalent. A quantity that expresses all kinds of radiation on a common scale for calculating the effective absorbed dose; defined as the product of absorbed dose in rad (or Gy) and modifying factors such as quality factor or an organ distribution factor. The unit of dose equivalent is rem (or Sv).

Effective dose equivalent. See definition and discussion in Section III.B.

Effective release height. Height above ground at which a .elease of airborne radionuclides is assumed to occur. Usually stack height plus adjustments for buoyant or momentuint plume rise and any terrain effect (see Appendix D, Section III).

Elevated release. A point source release occurring above ground level $>0-3 \mathrm{~m}$ ' Usually refers to a release at the effective releuse height.

Engineered safety feature (ESF). Any feature of a nuciear facility, including structures, systems, and components, provided to prevent or mitigate the accidental release of radioactive materials from the facility. Typical ESFs are containment structures, confinement barriers, air cleaning systems (filters, absorbers, traps, scrubbers), devoted emergency cleanup systems, fire protection systems, and safety systems.

\section{EIS. Environmental Impact Statement.}

EPA. Eivironmental Protection Agency.

Event tree analysis. An inductive analysis which portrays the various paths or scenarios that may result in a major consequence when some initiating event drives a system out of its standard operating mode.

Facility boundary. The boundary, usually a fence or other physical barrier, provided for the security of the facility. Some facility boundaries provide a radiological accident exclusion area.

Fault tree analysis. A deductive failure analysis which focuses on one undesired event and provides a systematic method for determining causes of this event. The undesired event constitutes the top event in a fault tree diagram and may be a catastrophic failure. 
Fumigation. An atmospheric inversion condition prevalent just after dawn in which newly developed convective eddies mix the effluent plume within the shallow unstable layer next to the ground. This condition can cause the greatest ground-level concentrations observed in the neighborhood of a stack over periods of about $30 \mathrm{~min}$ to $1 \mathrm{~h}$.

Genetic effect. Serious health effects in future generations resulting from a radiation dose to either parent, usually autosomal dominant and $x$-linked, irregular inherited, recessive, and chromosomal aberrations.

HEPA filter. A high-efficiency particulate air filter, usually capable of $99.97 \%$ efficiency as measured by a standard photometric test using $0.3-\mu \mathrm{m}$ droplets (aerodynamic equivalent diameter) of dioctylphthalate (DOP).

ICRP. International Commission on Radiological Protection.

Incremental risk. A risk added to existing or accepted risk by a proposed new activity.

\section{INEL. Idaho National Engineering Laboratory.}

Inversion. A meteorological condition which exists when remperature increases with altitude in the atmosphere. Characteristically, a layer is formed which blocks normal plume rise.
Life table. A statistical determination of age-specific probabilities of death from all causes among various population groups. Associated survival and longevity data are included. Life tables nıay be used to estimate the number of radiation-induced cancer deaths that would result from accidental exposure of a population.

Low population zone. The area (immediately surrounding an exclusion area) which contains members of the public, the total number and density of which are such that there is reasonable probability that appropriate protective measures could be taken in their behalf in the event of a serious accident.

$L W R$. Light-wâter reactor, either pressurized-water reactor or boiling-water reactor.

Median dispersion factor. The dispersion factor $((\chi / \mathrm{Q}))$ which is exceeded by $50 \%$ of the hourly $\chi / Q$ s observed in the sector and at the distance to the person whose dose is to be calculated.

Metric ton. One thousand kilograms or $2205 \mathrm{lb}$.

Metric units. The metric system or System International (SI) units are recommended for voluntary adoption in DOE Order 6430.1. The radiological units and conversion factors are as stated below.

Mitigation. Minimizing the effect of a postulated accident by means of facility siting or its major design features.

\begin{tabular}{|c|c|c|c|c|}
\hline Quantity & $\begin{array}{l}\text { New SI } \\
\text { Unit, Symbol }\end{array}$ & $\begin{array}{l}\text { Basic SI } \\
\text { Dimensions } \\
\text { Symbol } \\
\end{array}$ & $\begin{array}{l}\text { Old Unit } \\
\text { Symbol }\end{array}$ & Conversion \\
\hline Exposure & & $\begin{array}{c}\text { coulomb per } \\
\text { kilogram }\end{array}$ & roentgen, $R$ & $\begin{array}{l}1 \mathrm{Ckg}^{-1}= \\
3.9 \times 10^{3} \mathrm{R}\end{array}$ \\
\hline Absorbed Dose & grgy, Gy & $\begin{array}{l}\text { joules per } \\
\text { kilogram }\end{array}$ & rad, rad & $1 \mathrm{~Gy}=100 \mathrm{rads}$ \\
\hline Dose Equivalent & sievert, $\mathbf{S v}$ & $\begin{array}{l}\text { joules per } \\
\text { kilogram }\end{array}$ & rem, rem & $1 \mathrm{~Sv}=100 \mathrm{rems}$ \\
\hline Activity & becquerel, $\mathbf{B q}$ & $\begin{array}{l}\text { ner second, } \\
\mathrm{s}^{-1}\end{array}$ & curie, $\mathbf{C i}$ & $\begin{array}{l}1 \mathrm{~Bq}= \\
\quad 2.7 \times 10^{-11} \mathrm{Ci}\end{array}$ \\
\hline
\end{tabular}


Nonnuclear detonation or single-point detonation. A chemical reaction within the high-explosive components of a nuclear weapon, which results in an explosion that can disperse radioactive materials in the weapon component but with less nuclear yield than the equivalent of $4 \mathrm{lb}$ of TNT (approximately $2.5 \times 10^{17}$ fission in plutonium).

Nonstochastic effects. A radiation effect whose severity in an individual is a function of dose.

NRC. Nuclear Regulatory Commission.

Nuclear detonation. An energy release through a nuclear process that is equivalent to the detonation of more than the equivalent of $4 \mathrm{lb}$ of TNT within a few microseconds (approximately $2.5 \times 10^{17}$ fissions in plutonium).

Nuclear facility. See definition in Section I.C.

Offsite. Any location beyond the site boundary where a member of the public can be legally situated beyond the control of the owner and operator of the nuclear facility. Related details are discussed in Section III.B.2.

Offsite person. See definition and discussion in Section III.B.2.

Onsite. Any location inside the site boundary but not within the facility under evaluation.

Population center distance. Distance from the nuclear faci ${ }^{*}$, structure to the nearest population center of greater than 25000 inhabitants (see Section III.B.5).

Populal' $n$ dose. See definition and discussion in Section III.B.4.

$P R A$. Probabilistic risk assessment.

Protective response recommendation ( $P R R$ ). A projected numerical radiation dose to individuals in the population that may trigger a protective response by emergency response agencies.

Recurrence time or return period. A statistically determined time period after which natural phenomena or other events of a particular severity would be expected to be repeated. based on historical records supplemented in some vases by expert opinion.

Reduction factors. A factor by which the released radionuclides are reduced by natural means (plateout, gravitational deposition, absorption, etc.). See Section V.C.
Relative risk. Expression of risk due to an exposure to radiation as the ratio of the risk among those exposed to the risk in the absence of exposure. Relative risk projection method assumes the rate of future cancer mortalities due to radiation dose is proportional to the rate of natural cancer mortalities that would occur if no radiation dose had occurred.

Release fraction. That fraction of total radioactive material in process or in storage which is assumed released from primary confinement in dispersible form by a postulated accident. See Section V.B.

Removal factor. A factor by which the released radionuclides are removed by engineered means (absorption beds, filters, sprays, etc.). See Section V.C.

Respirable fraction. The mass associated with airborne particles whose aerodynamic equivalent diameter is less than $10 \mu \mathrm{m}$.

Respiration rate. The rate at which a full respiratory cycle takes place (inhalation and exhalation).

Risk, risk assessment. See definition and discussion in Section III.B.

Safet! system. Active systems such as detection systems, isolation valves and dampers, annunciators, and other automatic systems required to achieve + high level of safety in normal operations or safe shutdown in the event of an accident.

Site boundary. Usually the boundary of the property over which the owner or operator can exercise strict control without the aid of outside authorities. The site boundary does not nave to be a fence or other physical barrier. See discussion in Sections III.B.2 and III.B.5.

Solubility class. One of three classes of biological halftimes $\left(t_{B}\right)$ established by the ICRP to indicate rate of clearance of radionuclides from the pulmonary region of the lungs: Class D, 1 to 10 days; Class W, 10 to 100 days; and Class $Y$, more than 100 days.

Somatic effects. Harmful effects of an agent (such as a radioactive material) within the body of the person or animal receiving dose, rather than in offspring of the receptor.

Source term. The amount of radioactive material available for release after the release fraction from primary confinement is applied; it is therefore the amount of radioactive material released from primary confinement in dispersible form. 
SRP. Savannah River Plant.

Stochastic effects. A radiation effect where the probability of occurrence, rather than severity, is a direct function of dose; a radiation effect occurring without threshold, such as hereditary effects and carcinogenesis.
Tidal Volume. Volume of air inspired or expired during each respiratory cycle.

UBC. Uniform Building Code.

Unfavorable dispersion factor. The dispersion factor $(\chi / \mathrm{Q})$ which is exceeded by $0.5 \%$ of the hourly $\chi / \mathrm{Qs}$ observed in the sector and at the distance to the person whose dose is to be calculated. 


\section{APPENDIX B}

\section{RADIATION DOSE AND HEALTH EFFECTS}

\section{INTRODUCTION}

Radiation health effects data were reviewed with these objectives: to provide recommended health risk factors for consideration of public health effects, and to review the method for calculating effective dose equivalent where more than one organ receives significant dose from a single intake of radioactive material.

Appropriate health risk factors are in debate within the radiation health and epidemiological communities and major uncertainties exist. However, public health effects from routine operation and potential accidents in nuclear facilities have come under scrutiny and deserve consideration.

Whether health risk estimates need to be reported will probably depend on the magnitude of the dose. If the estimated dose is lower than annual background radiation, it would cause little additional health risk. Reporting trivial risks would be of little value. However, doses to individuals in the range between background and the 25-rem siting guideline dose could cause health effects which may warrant consideration.

Portions of this discussion can be found in greater detail in a Los Alamos report (Buhl 1984). This report provides methods of estimating radiation health risk for use in National Environmental Policy Act (NEPA) documents prepared by DOE.

\section{ESTIMATES OF RADIATION-INDUCED HEALTH RISK}

Estimates of the increased risk of cancer mortality resulting from exposure to ionizing radiation have been published by

- the Committee on the Biological Effects of Ionizing Radiations (BEIR Committee) of the US National Academy of Sciences in 1972 (the BEIR I report, BEIR 1972) and in 1980 (the BEIR III report, BEIR 1980);

- the United National Scientific Committee on the Effects of Atomic Radiation (the UNSCEAR Committee, UNSCEAR 1977, 1982); and

- the International Commission on Radiological Protection (ICRP 1977).
Different approaches were taken by these organizations in presenting their risk estimates. Both UNSCEAR and the ICRP published age-averaged and sex-averaged risk coefficients, giving the incremental lifetime risk of an individual dying of a radiation-induced cancer either per unit absorbed dose (UNSCEAR) or per unit dose equivalent (ICRP). The BEIR Committees on the other hand, tended to publish age- and sex-specific risk rates, giving the annual risk of dying of cancer in terms of age at exposure and elapsed time since the exposure.

The first approach has the advantage of simplicity. If the cumulative organ dose to a population in an assessment area is given, the number of health effects resulting from that dose is easily estimated by multiplying the cumulative organ dose by the risk factor for that organ. However, if the population at risk were significantly different from the population over which the risk factors had been averaged (for example, if the population consisted of male radiation workers between ages 20-25), the estimate of health effects using an age- and sexaveraged risk factor may not be representative.

This difficulty is remedied by using the second approach, which employs risk-rate coefficients for each sex and age group. The enhanced flexibility in this approach, however, is offset by an increased complexity. Input data required to perform this health effects calculation include the population distribution by age and sex, life table for each sex, and if a relative risk projection model is used, cancer mortality rates by age and sex.

The risk estimates from BEIR III age- and sexaveraged lifetime risk factors were calculated from the BEIR III risk-rate factors (when lifetime risk factors were not given). These estimates are listed in Table B-I for the most important organs of concern. In obtaining the BEIR III lifetime risk factors, we used a life-table calculation with the 1980 US population distribution by age and sex (US Bureau of the Census 1982) and the US decennial life tables (US National Center for Health Statistics, 1975).

The BEIR III lifetime risk estimates were calculated using the linear (L) dose response curve, which assumes that the cancer risk increases linearly with dose (for both low-LET and high-LET radiation); the quadratic (Q), which assumes a quadratic model to provide a lower bound (low-LET radiation only); and the linear-quadratic (LQ) (low-LET radiation only), which is an intermediate estimate. The BEIR III Committee recommended that a linear-quadratic model be used for lowLET radiation. However, the linear function may be 
preferable in view of the recent reassessment of the doses at Hiroshima-Nagasaki, which has resulted in a reduction of the estimated neutron flux, especially at Hiroshima. The linear dose response function is less affected by changes in the neutron relative biological effectiveness and neutron flux and at this time would appear to conservatively estimate the risk of cancer induction by radiation (Buhl 1984).

For completeness, the risk of serious genetic disorder in all subsequent generations that may result from exposure to ionizing radiation has also been included in Table B-I. This risk was taken as the equilibrium risk from the UNSCEAR and BEIR III repcrts, since as pointed out in BEIR III, "the total of all serious" genetic effects that will be expressed over all future generations as a consequence of exposure limited to a single generation, is numerically equal to the total for each generation in the equilibrium situation" (BEIR 1980). The genetic risk estimator recommended by the ICRP was adopted (ICRP 1977), in which the risk of serious hereditary ill health in the first two generations was estimated to be $100 \times 10^{-6} / \mathrm{rem}$ and of the same magnitude in later generations. The total risk was taken by the ICRP to be $200 \times 10^{-6} / \mathrm{rem}$.

Risk estimates applied to postulated accident cases should be derived from similar exposure modes where possible. Similariiy in radiation type, exposure pathway, dose rate, population makeup, and clearance time wouid be ideal but is seldom available. What choices should be made when similarity is lacking, or whether differences can be tolerated, is a major question.

The major points to be made (each considered applicable to health effects considerations in accident ana!yses) are as follows:

- Primary reference. The BEIR III report can be relied upon heavily in arriving at recommended risk factors, primarily because the BEIR III report is the most recent, thereby benefiting from input from the earlier reports and from experimental data reported in the meantime. Extensions of the BEIR III report results were made to broaden its areas of applicability.

- Population comparability. Use of age- and sexaveraged cancer risk factors is recommended for estimating health risk in a population similar to the 1980 US population (or a population of unknown makeup, but probably similar to the 1980 US population). These factors are basically the same as those listed in Table B-I. A a more detailed calcula- tion might be preferred for estimating health risk from an exposure of a population much different than the US population (that is, a nearby work force composed primarily of men aged 25 to $30 \mathrm{yr}$ ). A computer code is available for this purpose (Buhl 1984). Use of risk factors averaged by age and sex over the US population may lead to differences of up to a factor of 2 or 3 from a similar treatment of exposed population with more extreme age and sex distributions. The analyst would evaluate the significance of this uncertainty and decide whether a more detailed calculation is appropriate.

- Reporting health risk. When results of health risk calculations are expressed, many options are available. As shown in Table B-I, the BEIR III report expressed organ caucer risks from low-LET radiation in terms of linear, linear-quadratic, and quadratic dose response equations, each modified by an absolute or relative risk projection model. Other than an indication of the lower limit of uncertainty in risk estimation, the quadratic calculation is not considered to acceptably fit dose response data. The linear-quadratic form, although recommended by the BEIR III Committee as a preferred central value, has recently come into question following review of Hiroshima-Nagasaki gamma and neutron doses. Until the ensuing recalculation is completed and accepted by radiation protection bodies, use of a model which conservatively estimates risk is advisable. The linear model is unanimously considcred by UNSCEAR, BEIR III, and ICRP to overestimate low-LET radiation risk. For most cases, risk results calculated by the linear model are considered also suitable for use as an upper limit of uncertainty. The range bounded by the absolute risk projection and the relative risk projection of the linear estimate are considered appropriate for expressing risk results of accident analyses (Buhl 1984).

- Dose rate and level considerations. The NCRP recommends a reduction of linearly extrapolated total cancer risk from whole-body low-LET radiation, if the exposure is at low doses and low dose rate. This allowance compensates for the effect of biological repair mechanisms. Reducing the risk factor in the all-cancer category for whole-body radiation (in Table B-I) by a factor of two would be appropriate if the dose rate were less than $5 \mathrm{rad} /$ year and the dose level were less than 20 rad.

*Autosomal dominant and x-linked; irregular inherited, recessive, and chromosomal aberrations (BEIR 1980). 


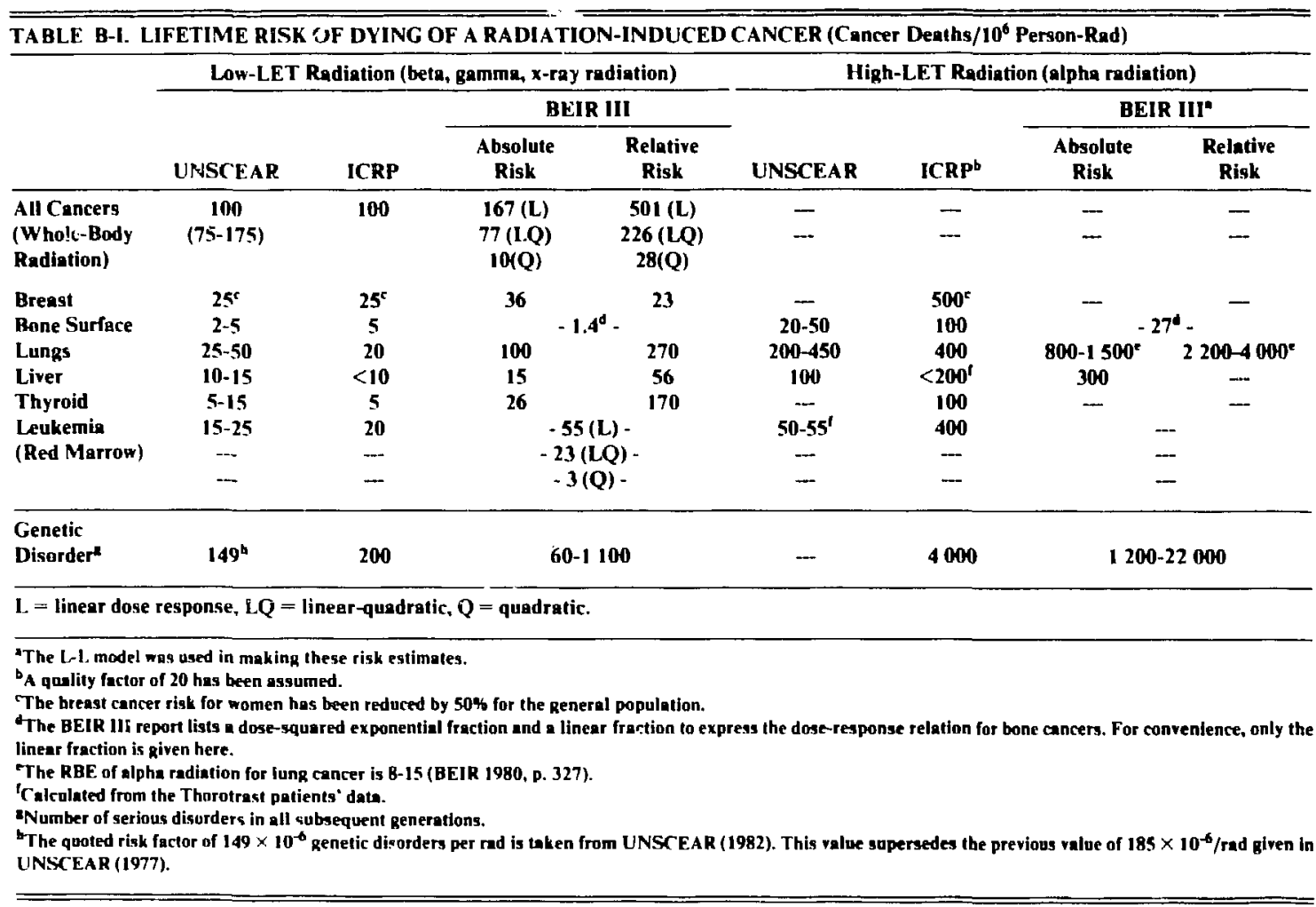

\section{EFFECTIVE DOSE EQUIVALENT}

Doses calculated fer potential accidents can be compared with guideline doses existing for individual organs in a straightforward manner, unless significant dose is calculated for more than one organ. In this case, a method is needed to consider the contribution of each organ dose to possible delayed health effects. The purpose of this appendix is to review existing health effect data (Table B-I) and suggest a method which could be used to evaluate a quantity equivalent to a single-organ dose. For the purposes of the Guide, the desired quantity is called effective dose equivalent and is related to the whole-body dose. The effective dose equivalent may be compared with the 25 -rem wholebody dose limit proposed for DOE Order 6430.1, Chapter I. The effective dose equivalent may be derived by establishing a risk equivalence between multipleorgan doses and a single whole-body dose. Establishing this risk equivalence was suggested earlier by Strom and Watson (Strom 1975) and by the ICRP (ICRP 1977). The ICRP states in ICRP 26 that the risk of delayed mortality should be treated the same whether the whole body is irradiated uniformly or whether several organs receive the dose. Derivation of organ weighting factors from health effects data available in 1976-1977 allowed ICRP to calculate an effective dose equivalent. A similar method for calculating weighting factors is recommended, although not necessarily using the ICRP 26 organ risk factors. The finalized risk factors calculated from BEIR III (Table B-I) after review by epidemiologists and health scientists will probably be adopted. In the meantime use of weighting factors in ICRP 26 (ICRP 1977) may be appropriate.

\section{REFERENCES}

BEIR 1972: National Academy of Sciences, National Research Council, Advisory Committee on the Biological Effects of Ionizing Radiations, "The Effects on Populations of Exposure to Low Levels of Ionizing Radiation" (National Academy of Sciences, Washington, DC, 1972).

BEIR 1980: National Academy of Sciences, National Research Council, Committee on the Biulogical Effects of Ionizing Radiations, "The Effects on Populations of Exposure to Low Levels of Ionizing Radiation" (National Academy Press, Washington, DC, 1980). 
BUHL 1984. T. E. Buhl and W. R. Hansen, "Estimating the Risks of Cancer Mortality and Genetic Defects Resulting from Exposures to Low Levels of Ionizing Radiation," Los Alamos National Laboratory report LA-9893-MS (May 1984).

ICRP 1977: "Recommendations of the ICRP," International Commission on Radiological Protection Publication 26 (1977).

STROM 1975: P. O. Strom and E. C. Watson, "Calculated Doses from Inhaled Transuranium Radionuclides and Potential Risk Equivalence to Whole Body Radiation," International Atomic Energy Agency report IAEA-SM-199/114(1975).

UNSCEAR 1977: United Nations Scientific Committee on the Effects of Atomic Radiation, "Sources and Effects of Ionizing Radiation" (United Nations, New York, 1977).
UNSCEAR 1982: United Nations Scientific Committee on the Effects of Atomic Radiation, "Ionizing Radiation: Sources and Biological Effects" (United Nations, New York, 1982).

US Bureau of the Census 1982: "Preliminary Estimates of the Population of the United States by Age, Sex, and Race: 1970 to 1981," US Bureau of the Census, Current Population Reports, Series P-25, No. 917 (US Government Printing Office, Washington, DC, 1982).

US National Center for Health Statistics 1975: "United States Life Tables: 1969-71," US Department of Health, Education, and Welfare Publication (HRA) 75-1150 (US Government Printing Office, Washington, DC, 1975). 


\section{APPENDIX C}

\section{RISK ASSESSMENT METHODS}

\section{INTRODUCTION}

Risk is the combination of probability of the occurrence of a serious event and the possibie consequences of the event, either to persons, facilities, or the environment. Various procedures have been employed for the determination of estimated risks, including deterministic, probabilistic, judgmental, and cost benefit (Rhyne 1983).

In deterministic assessment, specific releases are postulated without an identified mechanism causing the release and without any known probability of occurrence. The primary example of this is the large "loss of coolant accident" assumed for LWRs. A calculated consequence such as a radiological dose is compared with some upper limit, with the facility site considered acceptable if no consequence exceeds this limit. No inference of the safety of the reactor is made in this assessment, only of the legal acceptability of the site.

Probabilistic criteria provide an upper limit on the probability that a consequence will exceed a given value and thus require that all events which could contribute significantly to performance criteria be considered. Although inherently more complex and requiring more data, this method provides greater insight into potential system failures.

Judgmental procedures are useful when acceptability criteria are not explicitly defined and are left to the judgment of the analyst or the regulator. This procedure is not considered a viable basis for many safety review criteria.

The cost-benefit criteria are attempts to compare the expected costs with the expected benefits using a common value system; however, there is a difficulty in placing a common value on human life and injury. While used in some NRC regulatory processes, decisions based upon this method are usually of a relatively narrow scope rather than the basis for the entire process.

Current regulatory processes consist largely of overall safety criteria developed over several decades. The analyst reviews the design to assure that the criteria have been met. Current DOE and NRC criteria are largely deterministic and are based on scenarios and values that have been used in the past. For a number of reasons, probabilistic methods are presently used more to supplement deterministic methods than to replace them.
Of the three approaches considered acceptable for use, the deterministic approach has the advantages of greater familiarity and wider acceptance by reviewers including the lay public, less complexity, and generally taking less time to perform the analysis. Its major disadvantage is the lack of formal structure which allows greater variety of results, depending on the judgment of the analysts. NRC is encouraging greater use of probabilistic methods (NRC 1983). Although they result in a more comprehensive analysis, the probabilistic methods require extensive training of the analyst and extensive supporting data.

In performing a deterministic risk analysis, the analyst starts with a known or conservatively assumed sequence of events leading to a major release. Consequences of the release are calculated and then cumpared with a given upper limit. If the postulated consequences do not exceed this upper limit, the facility site and major design features are acceptable under this event. The calculations are repeated for each event and can be repeated for the contributions between interrelated or possible contributing events which might mitigate or enhance a given accident.

The analyst starts a probabilistic analysis with the consideration of all events which can contribute to the performance (failure) of all of the given systems, assigning a probability value to each component of the system. Usually this probability is the possibility of a failure per unit of time, obtained from historical data and failure records and also best estimations. One then considers the magnitude of both the probability and the potential consequences to arrive at an assessment of the risk presented by the particular failure. An estimate is made of the consequences possible through a stated chain of events. While more complex and requiring a greater amount of time and data, this method provides greater insight in to potential system failures and potential interactions of the set of systems. For example, failure of a second system may produce amplification of the consequences postulated from a prior failure.

One approach is to use a combination of the deterministic and the probabilistic methods, starting with the deterministic method and following with probabilistic risk analysis as a confirmatory process. Useful tools for these techniques are available, including fault tree analysis (NRC 1981) and the Management Oversight Risk Tree (MORT) diagrams (MORT 1975, Briscoe 1979). These must be coupled with adequate data bases. The safety analyst uses these to 
- identify sources of energy within a system which are large enough to cause a major release of radioactive or otherwise hazardous material,

- identify the conditions under which this material could be released as well as the factors which could amplify or mitigate the release, and

- estimate the probability and magnitude of the postulated release and estimate the consequences of the postulated release.

This same procedure is followed for each step from the initiating event, through the entire system, to the estimation of the consequences to the facility, the people exposed, and the environment. For whatever method and tools are used by the safety analyst in the assessment of risks, it is extremely important that the methods, estimations, and calculations be adequately supported by documentation and examples, to allow reviewers to approximate the steps in the analysis and validate the conclusions of the analyst.

\section{QUALITATIVE RISK METHODS}

A qualitative or relative risk evaluation approach currently in use (Lucas 1981, ANSI 1976, Brynda 1981, DOD 1977, ORO 1984) requires subjective judgment in assigning an accident to a probability class, for example, anticipated, unlikely, extremely unlikely, or incredible. These classes may be assigned ranges of numerical probabilities. A dose guideline may be selected depending on the analyst's determination of probability class; the more probable the accident, the lower the dose guideline selected. This method leaves more to the analyst's judgment but provides a systematic approach to risk assessment.

\section{QUANTITATIVE RISK METHODS}

Quantitative methods are currently in use at DOE nuclear facilities (Durant 1980, 1981; Lucas 1981). Accident probabilities are based on incident frequencies recorded in extensive data bases. Because the relationship between frequency of incidents (component failures, operator errors, etc.) and accident probability is not well known, subjective judgment cannot be completely eliminated from the process. However, formalized risk assessment methods such as PRA (probabilistic risk assessment) (NRC 1983) and fault tree analysis (NRC 1981), coupled with an adequate incident data base, can be valuable tools in evaluating the risks associated with a facility. A conservative risk limit may also be applied in conjunction with this risk evaluation method.
For many DOE facilities, an adequate incident data base may not exist, preventing an estimate of the probability of occurrence of a certain event. Because broadly accepted risk guidelines do not presently exist and present experience is not adequate to allow calculation of the probabilities of most accidents, adoption by DOE of a risk assessment method is not recommended. The probabilistic methods certainly provide a useful supplement to the deterministic method currently in use and should be continued by local option.

\section{REFERENCES}

ANSI 1976: "Criteria for the Design of Plants for the Manufacture of Mixed Oxide (U-Pu) Fuels," ANSI N287-1976 (American National Standards Institute, Inc., New York, December 30, 1976).

Briscoe 1979: G. J. Briscoe, "Application of Management Oversight Risk Tree (MORT) to Review of Safety Analysis," EG\&G Idaho report SSDC-17 (1979).

Brynda 1981: W. J. Brynda, L. Junker, R. C. Karol, P. R. Lobner, and L. A. Goldman, "Nonreactor Nuclear Facilities: Standards and Criteria Guide," US Department of Energy report DOE/TIC-1 1603 (BNL 51444) (September 1981).

DOD 1977: "Military Standard System Safety Program Requirements," US Department of Defense document MIL-STD-882A (June 1977).

Durant 1980: W. S. Durant, "The Application of Probabilistic Risk Assessment to Nuclear Fuel Reprocessing at the Savannah River Plant," E. I. du Pont de Nemours and Co., Savannah River Laboratory, US Department of Energy report DP-MS-80-59 (November 1980).

Durant 1981: W. S. Durant, "Savannah River Laboratory Data Banks for Risk Assessment of Fuel Reprocessing Plants," US Department of Energy report DPMS-81-90 (E. I. du Pont de Nemours and Co., Aiken, South Carolina, October 1981).

Lucas 1981: D. E. Lucas, "Safety Analysis Guide for Nonreactor Nuclear Facilities," Hanford Engineering Development Laboratory report HEDL-MG-153 (1981).

MORT 1975: "Management Oversight and Risk Tree" (System Safety Development Center, Aerojet reneral, Idaho Falls, Idaho, June 16, 1975). 
NRC 1981: "Fault Tree Handbook," US Nuclear Regulatory Commission report NUREG-04'2 (January 1981).

NRC 1983: "PRA Procedures Guide. A Guide to the Performance of Probabilistic Risk Assessments for Nuclear Power Plants," Vols. I and II, US Nuclear Regulatory Commission report NUREG/CR-2300 (January 1983).
ORO 1984: "Safety Analysis and Review System," DOE Oak Ridge Operations Office Order OR-5481. I B (May 23, 1984).

Rhyne 1983: W. R. Rhyne, "A Proposed Approach for the Safety Review of the New Production Reactor Project" (H \& R Technical Associates, Inc., Oak Ridge, Tennessee, January 1983). 


\section{APPENDIX D}

\section{DISPERSION CALCULATION METHODS}

\section{BASIC DISPERSION EQUATION}

To calculate downwind doses from an accidental release of radioactive material, air concentrations of the gas or airborne particulate material must be determined. The straight-line Gaussian dispersion equation is typically used. The Gaussian formula for the air concentration, $\chi$, at a downwind location $(x, y, z)$ may be found in Slade (1968).

Air concentratious should be calculated for $16 \mathrm{com}-$ pass directions $\left(22.5^{\circ}\right.$ sectors centered on north-north northeast, etc.).

The Gaussian dispersion model is estimated to be accurate to within a factor of 2 for distances of 0.1 to $10-20 \mathrm{~km}$ when onsite meteorological tower data are available and conditions are reasonably steady and horizontally homogeneous (AMS 1978). Beyond $20 \mathrm{~km}$, Gaussian dispersion calculations can only be considered to be order-of-magnitude estimates. Conditions which will reduce the accuracy of the Gaussian dispersion calculations include aerodynamic wake flows, rough or urban terrain, very buoyant or dense gases, or dispersion under very stable or unstable conditions.

The use of the Gaussian model may not be appropriate for reactive gases and particulate matter. Alternative methods accounting for possible transformations should be investigated. The dispersion of dense gases is discussed by Britter (1979, 1980, 1983).

\section{DISPERSION PARAMETERS/STABILITY CLASSIFICATIONS}

The horizontal and vertical dispersion coefficients, $\sigma_{\mathrm{y}}$ and $\sigma_{\mathrm{z}}$, required for the Gaussian dispersion equation can be estimated from measurements of the standard deviation of the wind angles or by estimating the atmospheric stability and using a set of curves which are a function of downwind distance and stability. If measurements of $\sigma_{\theta}$, the standard deviation of the horizontal crosswind component of the wind, are available, $\sigma_{\theta}$ is estimated from the formula $\sigma_{y}=\sigma_{\theta} \mathrm{xf}(\mathrm{x})$, where $\mathrm{x}$ is the downwind distance from the source. Several sets of functions have been presented for $f(x)$ (Cramer 1976, Draxler 1976, Horst 1979, Irwin 1979A, Pasquill 1976); some of these functions have been reviewed by Irwin (1983).

If measurements of $v_{\theta}$ are not available, the stability class must be determined. Several metheds for estimating stability class are currently in use (Turner 1970,
NRC 1974, NRC 1983). The NRC has also issued regulatory guides which apply to specifir facilities; Regulatory Guides 1.4 (NRC 1974A) and 3.33 (1977A) are typical. One of the more widely used methods, the vertical temperature gradient $(\Delta T)$ method (Hanna 1977, NRC 1983), has the disad vantage of not assessing the mechanical component of turbulence, that is, wind shear and surface roughness. Thus, one of the other methods, including both the effects of buoyancy and mechanical mixing, may be a better selection. The Richardson number, bulk Richardson number, and MoninObukhov length (Golder 1972) can also be used to determine the stability class.

Functions relating measurements of $\sigma_{\mathfrak{c}}$, the standard deviation of the vertical wind angle, to $\sigma_{\mathrm{z}}$ have been presented (Draxler 1976, Cramer 1976, Pasquill 1976, Irwin 1979A). However, determining $\sigma_{z}$ directly from $\sigma_{e}$ has not been recommended by the American Meteorological Society (Hanna 1977) as the standard method for determining $\sigma_{z}$ because of the difficulty in making accurate measurements of $\sigma_{e}$. Thus the atmospheric stability class can be determined in a manner similar to that described for $\sigma_{z}$, and $\sigma_{z}$ is then determined from a set of curves. Many sets of curves are available for determining $\sigma_{y}$ and $\sigma_{z}$, depending on the source height, averaging time, etc. For $\sigma_{y}$, the AMS (Hanna 1977) has suggested that Pasquill-Gifford (Gifford 1961) curves and the McElroy-Pooler (1968) urban curves are acceptable if adjustments are made for sampling duration and surface roughness. Curves presented by Briggs (1973) for $\sigma_{\mathrm{y}}$ and $\sigma_{z}$ have combined data from the Pasquill-Gifford, Brookhaven, and TVA curves for dispersion from elevated sources. Lamb (1979) has presented equations for $\sigma_{z}$ (and the effective release height $h$ ) for nonbuoyant releases into an unstable atmosphere. Some site-specific dispersion curves have also been developed (Yanskey 1966, Fuquay 1964) which are the most appropriate choices for those sites.

Curves describing plume dispersion are often used to describe the dispersion of a puff release. However, puff releases initially have a faster rate of growth than plumes (Hanna 1982). Gifford (1977) has summarized 22 experiments of relative (puff) diffusion showing cloud width proportional to (time) (1) $^{3 / 2}$ for travel times between 1000 and $3000 \mathrm{~s}$. Beyond $10000 \mathrm{~s}(2.78 \mathrm{~h})$, the puff growth rate slows to approximately a linear dependence on time. A method for calculating puff dispersion coefficients is presented by Hanna (1982). To account for the size of the puff at the release point, the dispersion coefficients should be initially set equal to (puff radius)/2.15 (Turner 1970). 


\section{RELEASE EFFECTS}

The dispersion equations may require modifications due to plume rise or building wake effects. The specific nodifications are presented in the sections dealing with those topics.

\section{A. Plume Rise}

Equations appropriate for the description of buoyant and momentum plume rise have been presented by Briggs $(1969,1975)$. The reader is referred to these sources for a complete presentation of these plume rise equations. An expression for the cloud rise from a highexplosive detonation has been presented by Church (1969). The vertical dispersion coefficient, $\sigma_{7}$, may also require modification due to plume rise. Pasquill (1976) has suggested that $\sigma_{t}$ be enhanced for a buoyant plume.

\section{B. Stack and Building Wake Effects}

If the exit velocity of a stack release is less than 1.5 times the wind speed at stack height, stack tip downwash is considered. Briggs (1973) presents a method for calculation.

If the release height is less than two and one-half times the height of the building or adjacent solid structure, building wake effects are considered. Hosker (1981) and NRC (1982) present guidance for the selection of appropriate equations to assess building wake effects.

\section{DISPERSION EFFECTS}

As the cloud of released material moves downwind, a number of processes may affect the air concentrations. These include radioactive decay, plume trapping by an inversion, dry deposition, etc. The necessary modifications to the dispersion equation are presented in the following sections.

\section{A. Radioactive Decay}

The amount of radioactive material will be affected by radioactive decay and daughter product buildup as the release travels downwind. These effects are accounted for in the decay and buildup models cited in Section V.A., Source Terms.

\section{B. Inversion Lid}

As the release travels downwind, its vertical spread can be limited by the presence of an inversion or by the mixing height. The Gaussian dispersion equation is modified to consider reflection from this elevated stable layer. The Gaussian equation is adjusted to include reflection from a stable layer by adding terms according to Turner (1970). Climatological estimates of mixing heights can be obtained from Holzworth (Holzworth 1972). Hourly estimates of mixing heights can be made using radiosonde data, acoustic sounder measurements, or a parametric relationship which specifies mixing height as a function of other boundary-layer parameters (Arya 1981, Venkatram 1980, Benkley 1979). The value of the vertical dispersion coefficient, $\sigma_{z}$, should be limited to the depth of the mixing layer or the inversion heignt. Alternatively, the Gaussian dispersion equation can be used without modification if $\sigma_{z}$ is limited to $0.8 R$, where $l$ is the depth of the mixing layer. Beyond the distance where $\sigma_{z}=\ell$, the material is spread uniformly between the ground and the lid. The air concentration can then be expressed in a simpler form of the Gaussian equation (Turner 1970).

\section{Fumigation}

High ground-level concentrations can be produced during fumigation conditions (Hanna 1982). These conditions can occur in the proximity of large bodies of water (NRC 1982) or for a short period following sunrise when a surface-based inversion is present. Modifications to the Gaussian equation to account for fumigation are presented by Turner (1970) and Hanna (1982). Guidance on the length of time fumigation conditions may be observed is provided by NRC (1982). Idaho National Engineering Laboratory uses !-h duration if release height exceeds $75 \mathrm{~m}$ and $15-30 \mathrm{~min}$ for lower release heights.

\section{Terra in}

Under unstable or neutral atmospheric conditions, an airborne release will tend to rise over downwind terrain obstacles. However, the original effective release height above the terrain will not be maintained. The effective release height should be reduced by the terrain height or the release height divided by 2 , whichever is smaller (Briggs 1973). Under stable atmospheric conditions, the release will not rise with the terrain and so may impinge on the ground if the obstacle is sufficiently tall.

If a release impacts elevated terrain, an arificial jump in the concentration at the terrain feature can occur due to the reflection term in the Gaussian equation (Egan 
1979). This effect can be corrected by the requirement that along the axis of maximum concentration. the concentration cannot increase with distance.

Under stable conditions, diffusion in a valley is limited by the valley walls. When the width of the valley, $w$, is equal to $2 \sigma_{y}$, the highest concentrations occur along the valley wall. These may be calculated as shown by Hanna (1982).

Another approach to estimating concentrations in complex terrain under neutral and stable conditions is to define an amplification factor, the ratio of the maximum concentration occurring in the presence of terrain to the maximum concentration from the same source located in level terrain. Snyder (1983) has summarized several wind-tunnel and towing-tank studies which have been performed to define amplification factors for sources located in various positions with respect to terrain features.

Complex terrain can also increase the horizontal and vertical dispersion of a plume or puff as it travels downwind. If the Pasquill-Gifford stability typing scheme is used for a location in complex terrain, it has been suggested (Strimaitis 1981) that during nighttime stable conditions, the Pasquill-Gifford stability should be changed by one class toward unstable to reflect the increased dispersion. Where possible, onsite data should be evaluated to determine appropriate modifications of dispersion parameters in complex terrain.

\section{E. Dry Deposition}

Ground deposition can be estimated by multiplying the radionuclide concentration in air at ground level by a deposition velocity representative of the particles in the cloud. Deposition velocities for unit-density spherical particles, 0.1 - to $100-\mu \mathrm{m} \mathrm{D}_{\mathrm{ae}}$, range from $10^{-4}$ io $25 \mathrm{~cm} / \mathrm{s}$. A common assumption is that deposition velocity varies from 0.1 to $10 \mathrm{~cm} / \mathrm{s}$ with an average of 1 $\mathrm{cm} / \mathrm{s}$ (Sehmel 1980).

Dry deposition for gases is treated in the same manner as particulate material. Deposition velocities for gases range from $10^{-4}$ to $10 \mathrm{~cm} / \mathrm{s} ; 1 \mathrm{~cm} / \mathrm{s}$ is often assumed for deposition calculations (Sehmel 1980). Noble gases should be treated as having a zero deposition velocity.

If ground deposition is calculated, downwind air concentrations are modified to reflect the effective decrease in the source term. This is done by replacirg the total emission, $\mathrm{Q}$, in the dispersion equation with $\mathrm{Q}(\mathrm{x})$, the source remaining at a downwind distance, $x$ (NRC 1983) Overcamp (1976) has presented a modified Gaussian plume model for calculating dry deposition of fine and heavy particles and gases. It combines a downward sloping plume to account for settling and a constant deposition velocity.

\section{F. Wet Deposition}

Plume depletion from wet deposition may be considered for determining the total amount of material deposited on the ground following the release. In general, wet deposition should not be included in the calculation of air concentrations unless it can be shown that the release has a strong probability of occurrence during a rainstorm or snowstorm.

The amount of material deposited on the ground can be calculated as a function of the air concentration (NRC 1983). The air concentration may be reduced by washout as it traveis downwind (Hanna 1982). A scavenging coefficient can be determined as a function of rainfall rate and a stability-dependent coefficient arcording to Ritchie (1978).

\section{METEOROLOGY}

The meteorological variables required for evaluating downwind air concentrations are typically devcloped from 2-3 yr of data collected at a location representative of the site of the release (Strimaitis 1981) or are conservatively speciried as Pasquill Type $F$ and wind speed of $1 \mathrm{~m} / \mathrm{s}$. Guidance for onsite meteorolcgical measurement programs, including instrument location and measurement techniques, is presented by Strimaitis (1981). The estimation of wind speed at release height is discussed by Irwin (1979B) and Hanna (1982). The treatment of calm winds is discussed in NRC (1977B) and Hanna (1982). Two meteorological categories, median and unfavorable, are suggested for accident-release dispersion calculations. Because accident releases are of short duration, the median and unfavorable dispersion factors are assumed to be constant during the duration of the release. Descriptions of unfavorable and median categories are provided below.

\section{A. Unfavorable Dispersien}

To calcilate the concentration to which the exposed person is exposed under unfavorable conditions, hourly dispersion factors $(\chi / Q)$ should be calculated at the distance of the offsite person. For each of 16 sectors, a cumulative probability distribution of $\chi / Q$ s should be constructed. The $\chi / Q$ value that is exceeded by $0.5 \%$ of the total number of hourly $\chi / Q$ s in the data set is the "unfavorable" dispersion factor for that sector. For example, if the data set comprises 8760 observations, the $0.5 \% \chi / Q$ for the sector is the $\chi / Q$ exceeded by 0.005 $x 8760$ or 44 observations. The sector having the highest unfa vorable dispersion factor defines the wind direction assumed to occur during the release, and the un- 
favorable dispersion factor in this sector is used to calculate the desired dose.

The $0.5 \% \chi / \mathrm{Q}$ was selected for consistency with NRC Regulatory Guide 1.145 (NRC 1982). The $0.5 \%$ sector $\chi / Q$ was chosen by the NRC as being consistent with the $5 \%$ direction-independent $\chi / Q$ (NRC 1981), while allowing the consideration of the directional dependence of atmospheric diffision conditions. The NRC retained a requirement in Regulatory Guide 1.145 for comparing the highest $0.5 \%$ sector $\chi / Q$ with the $5 \%$ directionindependent $\chi / Q$ and selecting the highest for dose calculations. Howiver, from a parametric study (NRC 1981 ), it was judged that for most sites the $0.5 \% \chi / Q$ will be the most conse! vative $\chi / Q$ and the comparison with the $5 \%$ direction iro:pendent $\chi / Q$ need not be included.

\section{B. Median Dispersion}

To calculate the concentration to which the maximally exposed person is exposed under median conditions, a similar procedure is followed. For each sector in which the person is lccated, hourly dispersion factors are calculated for the distance to the person from the point of release. A cumulative probability distribution of $\chi / \mathrm{Q}$ is developed, and the $\chi / \mathrm{Q}$ which is exceeded by $50 \%$ of the hourly dispersion factors in that one sector is defined as the "median" dispersion factor. The sector having the highest median dispersion factor defines the wind direction assumed to occur during the release, and the dispersion factor in this sector is used to calculate the desired dose.

\section{Population Dose}

To calculate the population dose, the release is assumed to travel in the direction having the largest ntarby population. The meteorological conditions producing the unfavorable dispersion factor for this sector are used to calculate the dose to the people in that sector. If there are pcpulation centers in several directions from the release, several sectors may require evaluation to determine the largest population dose.

It is not considered necessary to expose the entire population to the concentration at the cloud centerline. Integrated activity concentrations over the area containing people and the actual population density in those areas would be used to calculate population dose.

\section{REFERENCES}

AMS 1978: American Meteorological Society, "Accuracy of Dispersion Modeis-A Position Paper of the AMS 1977 Committee on Atmosnheric Turbulence and Diffusion," Bulletin of the American Meteorological Society 9 (8) (August 1978).

Arya 1981: S.P.S. Arya, "Parameterizing the Height of the Stable Atmospheric Boundary Layer," Journal cf Applied Meteorology 20, 11 92-1202 (1981).

Benkley 1979: C. W. Benkley and L. L. Shulman, "Estimating Hourly Mixing Depths from Historical Meteorological Data," Journal of Applied Meteorologv 18. 772-780 (1979).

Briggs 1969: G. A. Briggs, Plume Rise, AEC Critical Review Series TID-25075 (Clearing House for Federal Scientific and Technical Information, Springfield, Virginia, 1969).

Briggs 1973: G. A. Briggs, "Diffusion Estimation for Small Emissions," ATDL Contribution File No. 79 (Atmospheric Turbulence and Diffusion Laboratory, Oak Ridge, Tennessee, 1973).

Briggs 1975: G. A. Briggs, "Plume Rise Predictions," in Lectures on Air Pollution and Environmental Impact Analyses, Workshop Proceedings, Boston, Massachusetts, September 2-October 3, 1975 (American Meteorological Socıety, Boston, Massachusetts, 1975).

Britter 1979: R. E. Britter, "The Spread of a Negatively Buoyant Plume in a Calm Environment," Atmospheric Environment 13, 1241-1247 (1979).

Britter 1980: R. E. Britter, "The Ground Extent of a Negatively Buoyant Plume in a Turbulent Boundary Layer," Atmospheric Environment 14, 779-785 (1980).

Britter 1983: R. E. Britter and R. F. Gritfiths, Eds., Dense Gas Dispersion (Elsevier Scientific, 152 Vanderbilt Ave., New York, 1983).

Church 1969: H. W. Church, "Cloud Rise from High Explosive Detonations," Sandia National Laboratories report SC-RR-68-903 (May 1969).

Cramer 1976: H. E. Cramer, "Improved Techniques for Modelling the Dispersion of Tall Stack Plumes," in "Proceedings of the 7th Int. Technical Meeting on Air Pollution Modelling and its Application," National Technical Information Service report PB 270799 (1976), pp. 731-780. 
Draxler 1976: R. R. Draxler, "Determination of Atmospheric Diffusion Parameters," Atmospheric Environment 10, 99-105 (1976).

Egan 1979: B. A. Egan, R. D'Errico, and C. Vaudo, "Estimating Air Quality Levels in Regions of High Terrain Under Stable Atmospheric Conditions," in Fourth Symposium on Turbulence, Diffusion, and Air Pollution (American Meteorological Society, Boston, Massachusetts, January 1979).

Fuquay 1964: J. J. Fuquay, C. L. Simpson, and W. T. Hinds, "Prediction of Environmental Exposures from Sources Near the Ground Based on Hanford Experimental Data." Journa! of Applied Meteorology 3, 761-770 (1964).

Gifford 1961: F. A. Gifford, "Uses of Routine Meteorological Observations for Estimating Atmospheric Dispersion," Nuclear Safety 2 (4), 47-5I (1961).

Gifford 1977: F. A. Gifford, "Tropospheric Relative Diffusion Observations," Journal of Applied Meteorclogy 16, 311-313 (1977).

Golder 1972: D. F. Golder, "Relations Among Stability Parameters in the Surface Layer," Boundary Layer Meteorology 3, 47-58 (1972).

Hanna 1977: S. R. Hanna, G. A. Briggs, J. Deardorff, B. A. Egan, F. A. Giffurd, and F. Pasquill, "AMS Workshop on Stability Classification Schemes and Sigma Curves-Summary of Recommendations," Bulletin of the American Meteorological Society 58, 1305-1309 (1977).

Hanna 1982: S. R. Hanna, G. A. Briggs, and R. P. Hosker, "Handbook on Atmospheric Diffusion," US Department of Energy report DOE/TIC-1 1223 (1982).

Holzworth 1972: G. C. Holzworth, "Mixing Heights, Wind Speeds, and Potential for Urban Air Pollution Throughout the Contiguous United States," US Environmental Protection Agency report AP-101 (1972).

Horst 1979: T. W. Horst. J. C. Doran, and P. W. Nickola, "Evaluation of Empirical Atmospheric Diffusion Data," US Nuclear Regulatory Commission report NUREG/CR-0798, PNL-2599 (1979).

Hosker 1981: R. P. Hosker, "Methods for Estimating Wake Flow and Effluent Dispersion Near Simple BlockLike Buildings," NDAA Tech Memorandum ERL ARL-108 (Atmospheric Turbulence and Diffusion Laboratory, Oak Ridge, Tennessee, 1981).
Irwin 1979A: J. S. Irwin, "Estimating Plume Dispersion-A Recommended Generalized Scheme," Proceedings of 4th Symposium on Turbulence, Diffusion, and Air Pollution (American Meteorological Society, Boston, Massachusetts, 1979), pp. 62-69.

Irwin 1979B: J. S. Irwin, "A Theoretical Variation of the Wind Profise Power Law Exponent as a Function of Surface Roughness and Stability," Atmospheric Environment 13, 191-194 (1979).

Irwin 1983: J. S. Irwin, "Estimating Plume Dispersion-A Comparison of Several Sigma Schemes," Journal of Climate and Applied Meteorology 22, 92-114 (1983).

Lamb 1979: R. G. Lamb, "The Effects of Release Height on Material Dispersion in the Convective Planetary Boundary Layer," Fourth Symposium on Turbulence, Diffusion, and Air Pollution (American Meteorological Society, Boston, Massachusetts, January 1979).

MzElroy 1968: J. L. McElroy and F. Pooler, "St. Louis Dispersion Study," US Department of Health, Education, and Welfare report AP-53 (1968), Vol. 2.

NRC 1974:: “Onsite Meteorological Programs," US Nuclear Regulatory Commission Regulatory Guide 1.23 (1974).

NRC 1974A: “Assumptions Used for Evaluating the Potential Radiological Consequences of a Loss of Coolant Accident for Pressurized Water Reactors," US Nuclear Regulatory Conmmission Regulatory Guide 1.4 (June 1974).

NRC 1977A: "Assumptions Used for Evaluating the Potential Radiological Consequences of Accidental Nuclear Criticality in a Fuel Reprocessing Plant," US Nuclear Regulatory Commission Regulatory Guide 3.33 (April 1977).

NRC 1977B: "Methods for Estimating Atmospheric Transport and Dispersion of Gaseous Effluents in Routine Releases from Light-Water-Cooled Reactors," Nuclear Regulatory Commission Regulatory Guide 1.111 (July 1977).

NRC 1981: “Technical Basis for Regulatory Guide 1.145: Atmospheric Dispersion Models for Potential Accident Consequence Assessments at Nuclear Power Plants," US Nuclear Regulatory Commission report NUREG,'CR-2260 (1981). 
NRC 1982: "Atmospheric Dispersion Models for Potential Accident Consequence Assessments at Nuclear Power Plants," US Nuclear Regulatory Commission Regulatory Guide 1.145 (1982), p. 14.

NRC 1983: "A Guide to the Performance of Probabilistic Risk Assessments for Nuclear Power Plants," US Nuclear Regulatory Commission report NUREG/CR-2300 (1983).

Overcamp 1976: T. J. Overcamp, "A General Gaussian Diffusion-Deposition Model for Elevated Point Sources," Journal of Applied Meteorology 15, 1167-1171 (1976).

Pasquill 1976: F. Pasquill, "Atmospheric Dispersion Parameters in Gaussian Plume Modeling: Part 2, Possible Requirements for Change in the Turner Workbook Values," US Environmental Protection Agency report EPA-600/4-76-0306 (1976).

Ritchie 1978: L. T. Ritchie, W. D. Brown, and J. R. Wayland, "Effects of Rainstorms and Runoff on Consequences of Atmospheric Releases from Nuclear Reactor Accidents," Nuclear Safety 19, 220-238 (1978).

Sehmel 1980: G. A. Sehmel, "Particle and Dry Gas Deposition: A Review," Atriaspheric Environment 14, 983-1011 (1980).
Slade 1968: D. H. Slade, Ed., "Meteorology and Atomic Energy," US Atomic Energy Commission report TID-24190 (July 1968).

Snyder 1983: W. H. Snyder, "Fluid Modeling of Terrain Aerodynamics and Plume Dispersion-A Perspective View," Sixth Symposium on Turbulence and Diffusion (American Meteorological Society, Boston, Massachusetts, March 1983).

Strimaitis 1981: D. Strimaitis, G. Hoffnagle, and A. Bass, "Onsite Meteorological Instrumentation Requirements to Characterize Diffusion from Point Sources, Workshop Report," US Environmental Protection Agency report EPA-600/9-81-020 (April 1981).

Turner 1970: D. B. Turner, "Workbook of Atmospheric Dispersion Estimates," US Department of Health, Education, and Welfare report PB 191482 (1970).

Venkatram 1980: A. Venkatram, "Estimating the Monin-Obukhov Length in the Stable Boundary Layer for Dispersion Calculations," Boundary Layer Meteorology 19, 48i -485 (1980).

Yanskey 1966: G. R. Yanskey, E. H. Markee, and A. P. Richter, "Climatography of the National Reactor Testing Station," US Environmental Science Service Administration report IDO-12048 (1966). 


\section{APPENDIX E}

\section{DOSE METHODS}

\section{INTRODUCTION}

Doses to whole body and to specific organs from a postulated accident are calculated for comparison with the site criteria doses proposed for Chapter I of DOE Order 6430.1. Contributions to dose from the accident case come primarily from radioactive material inhaled during cloud passage and direct radiation to the whole body received while immersed in the cloud. Other possible sources of dose (ingestion by the cow-milkhuman or crop-food-human pathways, direct radiation from the facility, or delayed exposures from contaminated water or land) are secondary contributors which may require evaluation under special conditions.

\section{INHALATION DOSE MODELING}

Inhalation dose depends on the time-integrated radionuclide activity concentration $\left(\mathrm{Ci} \cdot \mathrm{s} / \mathrm{m}^{3}\right.$ or $\left.\mathrm{Bq} \cdot \mathrm{s} / \mathrm{m}^{3}\right)$, the breathing rate of the subject $\left(\mathrm{m}^{3} / \mathrm{s}\right)$, the fraction of the inhaled radionuclide reaching the organ of interest, and the organ dose conversion factor ( $\mathrm{rem} / \mathrm{Ci}$ or $\mathrm{Sv} / \mathrm{Bq}$ ). Recommendations are made in the choice of parameters to calculate these major doserelated frctors.

\section{A. Organ Dose Conversion Factors}

Dose to an organ depends on how soon the radionuclide clears the lungs, how niuch of it is transferred to the organ through the bloodstream, and how much and how long it is retained by the organ tissue. Several models are available which also account for dose received by an organ from nearby organs containing radioactive material.

The primary methods used to calculate dose or dose conversion factors have been published by the International Commission on Radiological Protection (ICRP), an authoritative radiation protection organization. The various contractors and offices in the DOE are in varying stages of transition from the ICRP Publication 2 models for lung, bone, and other organs (ICRP 1959) to the recent models in ICRP Publication 30 (ICRP 1979, 1980). More complex than ICRP 2, the ICRP 30 models account for dose to (target) organs from beta- or gammaemitting nuclides deposited in neighboring (source) organs. This added complexity accounts for no change in dose if the nuclide is an alpha emitter but may be quite large for some organs if the nuclide is a gamma emitter. For example, lung dose directly from deposited ${ }^{137} \mathrm{Cs}-{ }^{137} \mathrm{Ba}$ (Class $\left.\mathrm{D}\right)$ would be only $0.0025 \mathrm{rem} / \mathrm{Ci}(6.8 \mathrm{x}$. $10^{-10} \mathrm{~Sv} / \mathrm{Bq}$ ), while dose from neighboring organs would contribute an additional $0.014 \mathrm{rem} / \mathrm{Ci}\left(3.8 \times 10^{-9}\right.$ $\mathrm{Sv} / \mathrm{Bq}$ ). Dosi calculations for mixed fission products generally yield higher results with the ICRP 30 models than with earlier models. The major differences in the ICRP 2 and ICRP 30 models have been discussed in several publications (Bair 1979, Runkle 1981).

The apparent movement toward adoption of ICRP 30 models is considered favorable based on the following observations:

- The methods are recommended by a recognized international commission whose earlier recommendations have been broadly accepted.

- The methods are believed to be made more accurate by the source-target dose refinement described above and by updated transfer fractions incorporated in it.

- Progress is being made toward adoption of ICRP 30 models or variations of them by NRC, EPA, and other US agencies, such as the current revision of 10 CFR 20 occupational dose standards by NRC.

- DOE is currently revising Chapter XI of DOE Order 5480.1A to provide ICRP 30-based exposure limits.

Computer codes based on models other than ICRP 30 generally yield comparable results for alpha emitters if common input parameters are used. The major sources of variation come from choice of quality factor, organ mass, transfer fraction, compound solubility (clearance rate), and dose model for some organs. The organ dose models and major parameters used in the major dose codes are described in later sections.

Since ICRP has converted to the International System of Units (SI), using sievert (Sv) for dose equivalent and becquerel $(\mathrm{Bq})$ for activity, similar usage within the DOE adds convenience for those offices using the ICRP 30 models. According to DOE Order 6430.1, increased use of SI units is encouraged on a voluntary basis. In this transition period, it is suggested that quantities in other units be accompanied by converted quantities in SI units. 


\section{B. Lung Clearance Model}

The ICRP Task Group on Lung Dynamics (TGLD) model (ICRP 1966) has been incorporated into most of the computer codes presently in use within DOE. The 1966 model has been modified slightly in ICRP 19 and ICRP 30 (ICRP 1979). The form recommended for use is found in ICRP 30. Regional deposition fractions are provided in ICRP 30 and its supplements for only one particle size $(1.0-\mu \mathrm{m}$ activity median aerodynamic diameter), although a formula for calculating deposition fractions of particles of other sizes is provided.

The ICRP lung model is based on these assumptions and considerations (Bair 1979):

- Irradiation of the lung is more limiting than irradiation of lymphatic tissues, although for some radionuclide compounds, the average doses to lymph nodes may be many times greater than the average lung dose.

- The risk of radionuclides as particles in the lungs is likely to be less than if the same amount of material is distributed more uniformly.

- Dose equivalents to specific regions of the respiratory tract can be estimated; however, because of the many uncertainties regarding cells at risk, localization of deposited radionuclides, etc., it was concluded that such estimates are unwarranted.

- In adults, the tracheobronchial region, pulmonary region, and the pulmonary lymph nodes are considered as one organ of $1000 \mathrm{~g}$.

- The dose to the nasopharyngeal region was neglected since it is usually smai! compared witn other regions.

- Radioactive daughters remain with and behave like the parent radionuclide.

\section{GI Tract Model}

The gastrointestinal tract has been partitioned into four sections (stomach, small intestine, upper large intestine, and lower large intestine) according to the biological model developed by Eve (Eve 1966). The Eve model has been at least temporarily adopted by ICRP (ICRP 1977, 1979). The Eve mociel calculates the dose at the surface of the bolus (contents), not through the mucous layer or at the site of the most sensitive cells; however, application of a $1 / 100$ factor corrects this defect for alpha emitters (Bair 1979).

The transfer of radioactive materials to body fluids is estimated from the fraction of a stable element absorbed into the blood following ingestion ( $f_{1}$ values). Values of $f_{1}$ for a number of classes of compounds are included for each element (ICRP 1979). For radioactive decay daughters formed in the GI tract, the value of $f_{1}$ used is that appropriate for the parent nuclide. Also, the metabolic behavior of the daughter is assumed to be the same as that $c$, he parent.

\section{Bone Dose Model}

ICRP 30 departs from the ICRP 2 practice, which has been to adjust volume bone dose for distribution of surface seekers ( $\mathrm{Pu}$ and $\mathrm{Sr}$ ) relative to radium by applying a distribution factor $\mathrm{n}$ of 5 . Doses are estimated by the ICRP 30 model for two regions of bone, both of which are considered to be at risk for cancer induction by radiation (Bair 1979):

- Marrow-Since hematopoietic stem cells are assumed to be randomly distributed in the marrow within trabecular bone of adults, the dose equivalent to the hematopoietic cells is calculated as the average over the marrow filling the cavities. The mass of active red marrow in the trabecular bone is taken to be $1500 \mathrm{~g}$.

- Bone Surfaces-For the osteogenic cells on endosteal surfaces and epithelium on bone surfaces, the dose equivalent is calculated as the average over tissue up to a distance of $10 \mu \mathrm{m}$ from the relevant bone surfaces. The total endosteal area is taken to be $12 \mathrm{~m}^{2}$. The mass of the $10-\mu \mathrm{m}$-thick layer is taken to be $120 \mathrm{~g}$.

Several assumptions are made in the absence of data on the distribution of radionuclides in bone:

- Radionuclides of the alkaline earths ( $\mathrm{Mg}, \mathrm{Ca}, \mathrm{Sr}$, $\mathrm{Ba}, \mathrm{Ra}$ ) with radioactive half-lives of greater than 15 days are considered to be uniformly distributed throughout the bone volume.

- Radionuclides with half-lives of less than 15 days are considered to be distributed on bone surfaces.

Bone dose from actinides can be affected by burial of deposited material $t_{y}$ new bone mineral, which is variable with age of the person and rate of exposure; however, this effect was considered too complex to be accounted for in the ICRP 30 model.

\section{E. Particle Size Distribution}

As noted earlier, the particle size distribution in a newly formed cloud changes with time as small particles agglomerate into larger particles and the larger particles settle out of the cloud. An estimate should be made of the particle size characteristic described by activity median aerodynamic diameter (AMAD) that exists where 
the exposed person receives the exposure. This AMAD becomes input to the TGLD model, from which comes regional deposition in the respiratory system. The AMAD of the respirable fraction [mass associated with particles whose aerodynamic equivalent diameter $\left(D_{u c}\right)$ is less than $10 \mu \mathrm{m}$ ] is the desired input to the TGLD model, rather than AMAD of all particles remaining in the cloud. One-micron AMAD has been used widely to provide a conservative estimate of inhalation dose for plutonium and uranium aerosols; however, the actual AMAD may lead to larger doses from accidents involving particle sizes smaller than $1 \mu \mathrm{m}$.

Particle size information for plutonium undergoing simulated accident conditions is extensive, particularly the plutonium release studies performed by Mishima and his colleagues (1965, 1966, 1968, 1973, and others). Selby (1975) has summarized particle size and concentration data for accident cases involving plutonium. Kirchner (1966) and Elder (1974) characterized plutonium aerosols in glove boxes and ducts under nonaccident conditions. More recent plutonium aerosol characterizations have been reported by Raabe (1978). Information on size and amounts of particles potentially released by accidents in fuel reprocessing or processes involving materiais other than plutonium has not been located during preparation of the Guide.

\section{F. Compound Solubility}

Selection of compound solubility can cause broad variability in results of dose calculations, as can be observed in the ICRP lung model (ICRP 1966). Clearance of inhaled materials in the ICRP lung model is described by $D, W$, or $Y$ classification: $D$ for those with a pulmonary clearance half-time of less than 10 days, $W$ for 10 to 100 days, and $Y$ for greater than 100 days. Radionuclide compounds have been assigned to one of these classifications by ICRP (ICRP 1980). The ICRP assignments to solubility classifications may be appropriate for use in dose calculations unless experimental data to the contrary can be provided.

\section{G. Exposed Person}

Existing DOE orders or NRC regulatory guides do not specify that the exposed person be anyone other than an adult receiving the highest dose as a result of an accident. Past practice has been to assume ICRP reference man as the receptor of accident-induced dose (ICRP 1974). A change in this practice is not considered necessary, although each case should be reviewed on individual merits. Exposure to radioiodine causes higher dose in thyroids of infants and children than in adults and may be a special case which deserves description and evaluation.

Breathing rate of the exposed person may be based on the standard rates established by ICRP for reference man (ICRP 1974). The standard rate of $3.5 \times 10^{-4} \mathrm{~m}^{3} / \mathrm{s}$ corresponding to light activity is recommended for doses received as a result of an accident under 8-h duration.

\section{H. Quality Factor of Radiation}

A single quality factor $(\mathrm{QF})$ for alpha radiation is not consistently used throughout the DOE, allowing a factor of 2 difference in dose. The following list from ICRP 26 (ICRP 1977) contains the recommended quality factors for all radiation types. The quality factor for neutrons may be varied if the average energy or energy spectrum is known.

$\begin{array}{lc}\text { Type of Radiation } & \text { Quality Factor (QF) } \\ \text { Alpha } & 20 \\ \text { Alpha-recoil } & 20 \\ \text { Beta or electron } & 1 \\ \text { Gamma } & 1 \\ \text { Fission fragment } & 20 \\ \text { Fission neutron } & 10\end{array}$

\section{Decay Scheme Data}

Decay scheme data presently in use with ICRP 30 model dose calculations are contained in ICRP Publication ?․ (ICRP 1983) as calculated by an ORNL computer code (Dillman 1980). Other sources of updated data to consider are the ENDF/B fission product data (Rose 1976) and the ORNL radioactive decay handbook (Kocher 1981). The importance of this updated data in improving accuracy of dose calculations is unknown.

\section{J. Uptake Time and Dose Accumulation Time}

Calculation of an accident dose conversion factor is usually based on a short-te- $\boldsymbol{\eta}$ intake of the nuclide (less than $8 \mathrm{~h}$ ). ICRP 30 dose cow v ersion factors are based on 50-yr dose received after intake of a unit amount of the radionuclide and are therefore compatible with acute inhalation exposure.

Dose accumulation times should be selected to be long enough to account for most of the dose. For the purposes of this Guide, the 50-yr period commonly used as a dose accumulation time, roughly equivalent to average occupational lifetime, is used. Fifty years may also be assumed to equal or exceed the remaining life- 
time of the individual of average age in an exposed offsite population. Intermediate times may be useful for illustrative purposes, but for dose calculated to compare with proposed DOE Order 6430.1A dose criteria, $50 \mathrm{yr}$ has been used.

\section{K. Effective Dose Equivalent}

Effective dose equivalent is used when dose to multiple organs from a single exposure is postulated. The methodology for calculating this dose for comparison with whole-body dose limits is simple:

$D_{e}=\check{Y}$ (individual organ dose, $D_{i}$ ) $X$ (individual organ weighting factor, $\mathrm{W}_{\mathrm{i}}$ )

Individual organ weighting factors may be the ICRP weighting factors (ICRP 1977).

\section{DIRECT IRRADIATION FROM CLOUD IM- MERSION}

Two models are commonly used for calculating direct dose from cloud immersion: the finite plume and the semi-infinite plume models (Slade 1968). Although the finite plume model is more complex and requires more computer time to run, it has the advantage of greater accuracy at distances nearer to the accident site (Wenzel 1982). The results of both models converge when the plume is relatively large (compared with the mean free path of gamma photons) and has diffused to the ground. At relatively short downwind distances, the semi-infinite model overestimates the dose for ground-level releases during stable meteorological conditions and underestimates the dose from eltvated releases. It is suggested that use of the semi-infinite cloud model be limited to calculations of dose beyond $10 \mathrm{~km}$ if the release is elevated (Wenzel 1982) or that a "finite" plume correction factor be applied to calculations of close-in doses (Strenge 1980). The finite plume model is preferred under most conditions and is available in several computer codes (RSAC-3, Wenzel 1982; SUBDOSA, Strenge 1975). Codes using the semi-infinite model are also available (EXREM III, Trubev 1973; RSAC-3, Wenzel 1982).

Immersion dose models usually provide a dese rate at the body surface. For the purpose of calculating an immersion dose additive to whole-body dose from other sources, a dose at $5-\mathrm{cm}$ tissue depth has been recommended (NBS 1954, NRC 1977). Total tody dose at 5$\mathrm{cm}$ tissue depth may be calculated from the surface dose as described by Strenge (1980). ICRP 30 calculates whole-body dose from immersion by a different method (Poston 1974), which is also appropriate. Gamma doses to other organs from cloud immersion do not vary greatly from the whole-body $(5-\mathrm{cm})$ dose, as observed by Strenge (1980). If skin dose is the major contributor to dose (airborne beta or weak gamma emitters), the skin dose should be the sum of surface gamma dose and the beta dose at a depth of $7 \mathrm{mg} / \mathrm{cm}^{2}$ (NRC 1977).

\section{INGESTION DOSE MODELIFG}

Ingestion of water contaminated by accidental release of radioactive material to nearby lakes and streams is a possible source of dose. However, neither ingestion by the drinking water pathway or by the cow-milk-human or crop-food-human pathways have been confirmed to be major contributors to dose from a credible DBA. Although it appears unlikely that ingestion dose would approach the limits on radiation dose proposed for Chapter I of DOE Order 6430.1, guidance on ingestion dose is discussed in this appendix on the assumption that ingestion dose may fall in the category of "other consequences to be considered" (Section V.G. of the Guide).

The accident leading to ingestion dose is assumed to be a gross leak of a liquid contaminated with radioactive material, such as tritium, into nearby lakes or streams. An internal dosimetry model such as the GI tract model of the ICRP (1979) is suitable for calculating dose from direct radiation of the GI tract and metabolic transfer from the small intestine to other organs. INREM II (Killough 1978) is a suitable computer code for calculating ingestion dose conversion factors. Dispersion of the radionuclides can be estimated according to Regulatory Guide 1.113 (NRC 1977A); doses from ingestion of contaminated water can be estimated according to Regulatory Guide 1.109 (NRC 1977B). An acute liquid release model for tritium and other radionuclides has been prepared for the Savannah River Plant by Huang (1983).

\section{REFERENCES}

Bair 1979: W. J. Bair, "Review of Report of the International Commission on Radiological Protection Committee 2: Limits for Intakes of Radionuclides by Workers," Battelle Pacific Northwest Laboratories (1979).

Dillman 1980: L. T. Dillman, "EDISTR-A Computer Program to Obtain a Nuclear Decay Data Base for Radiation Dosimetry," Oak Ridge National Laboratory report ORNL/TM-6689 (1980). 
Elder 1974: J. C. Elder, M. Gonzales, and H. J. Ettinger, "Plutonium Aerosol Size Characteristics," Health Physics 27, 45-53 (July 1974).

Eve 1966: I. S. Eve, "A Review of the Physiology of the Gastrointestinal Tract in Relation to Radiation Doses from Radiozctive Materials," Health Physics 12, 131 (1966).

Huang 1983: J. C. Huang, "Analysis Aids for Consequence Calculations of Postulated SRP Surface Water Releases," E. I. DuPont de Nemours memorandum DPST-83-870 (1983).

ICRP 1959: "Report of Committee 2 on Permissible Dose ior Internal Radiation," International Commission on Radiological Protection, Publication 2 (1959).

ICRP 1966: "Deposition and Retention Models for Internal Dosimetry of the Human Kespiratory Tract," International Commission on Radiological Protection report in Health Physics 12 (2), 173-207 (1966).

ICRP 1974: "Report of the Task Group on Reference Man," International Commission on Radiological Protection, Publication 23 (October 1974).

ICRP 1977: "Recommendations of the ICRP," International Commission on Radiological Protection, Publication 26 (1977).

ICRP 1979: "Limits for Intake of Radionuclides by Workers," International Commission on Radiological Protection, Publication 30, Part I (July 1979).

ICRP 1980: "Limits on Intake of Radionuclides by Workers," International Commission on Radiological Protection, Publication 30, Part 2 (1980).

ICRP 1983: "Radionuclide Transformations-Energy and Intensity of Emissions," International Commission on Radiological Protection, Publication 38 (1983).

Killough 1978: G. G. Killough, D. E. Dunning, Jr., and J. C. Pleasant, "INREM II: A Computer Implementation of Recent Models for Estimating the Dose Equivalent to Organs of Man from an Inhaled or Ingested Radionuclide," US Nuclear Regulatory Commission report NUREG/CR-0114, ORNL/NUREG/TM-84 (1978).
Kirchner 1966: R. A. Kirchner, "A Plutonium Particle Size Study in Production Areas at Rocky Flats," American Industrial Hygiene Association Journal (JulyAugust 1966).

Kocher 1981: D. C. Kocher, "Radioactive Data Decay Tables," Oak Ridge National Laboratory report DOE/TIC-11026 (1981).

Mishima 1965: J. Mishima, "Plutonium Release Studies. I. Release from Ignited Metal," Battelle Pacific Northwest Laboratories report BNWL-205 (December 1965).

Mishima 1966: J. Mishima, "Plutonium Release Studies. II. Release from Ignited Bulk Metallic Pieces," Battelle Pacific Northwest Laboratories report BNWL-357 (November 1966).

Mishima 1968: J. Mishima, L. C. Schwendiman, and C. W. Radasch, "Plutonium Release Studies. III. Release from Heated Plutonium Bearing Powders," Battelle Pacific Northwest Laboratories report BNWL-786 (July 1968).

Mishima 1973: J. Mishima, "The Fractional Airborne Release of Dissolved Radioactive Materials During the Combustion of 30 Percent Tri-N-Butyl Phosphate in a Kerosene-Type Diluent," Battelle Pacific Northwest Laboratories report BNWL-B-274 (June 1973).

NBS 1954: "Permissible Dose from External Sources of Ionizing Radiation," National Bureau of Standards Handbook 59 (September 1954).

NRC 1977: "Assumptions Used for Evaluating the Potential Radiological Consequence of Accidental Nuclear Criticality in a Fuel Reprocessing Plant," US Nuclear Regulatory Commission Regulatory Guide 3.33 (April 1977).

NRC 1977A: "Estimating Aquatic Dispersion of Effluents from Accidental and Routine Reactor Releases for the Purpose of Implementing Apoendix I," US Nuclear Regulatory Commission Regulatory Guide 1.113 (April 1977).

NRC 1977B: "Calculation of Annual Doses to Man from Routine Releases of Reactor Effluents for the Purpose of Evaluating Compliance with 10 CFR 50," US Nuclear Kegulatory Commission Regulatory Guide I.109 (October 1977), App. I. 
Poston 1974: J. W. Poston and W. S. Snyder, "A Model for Exposure to a Semi-Infinite Cloud of a Photon Emitter," Health Physics 26. 287-293 (April 1974).

Raabe 1978: O. G. Raabe, S. V. Teague, N. L. Richardson, and L. S. Nelson, "Aerodynamic and Dissolution Behavior of Fume Aerosols Produced During the Combustion of Laser-Ignited Plutonium Droplets in Air," Health Physics 35, 663-674 (November 1978).

Rose 1976: P. F. Rose and T. W. Burrows, "ENDF/B Fission Product Decay Data," Brookhaven National Laboratory report BNL-NCS-50545 (August 1976).

Runkle 1981: G. E. Runkle and J. K. Soldat, "Comparison of ICRP 2 and ICRP 30 for Estimating the Dose and Adverse Health Effects from Potential Radionuclide Releases from a Geologic Waste Repository," Sandia National Laboratories report SAND 81-2163C (1981).

Selby 1975: J. M. Selby, E. C. Watson, J. P. Corley, et al., "Considerations in the Assessment of the Consequences of Effluents from Mixed Oxide Fuel Fabrication Plants," Battelle Pacific Northwest Laboratories report BNWL-1697 (June 1975).
Slade 1968: D. H. Slade, Ed., "Meteorology and Atomic Energy," US Atomic Energy Commission report TID-24190 (July 1968).

Strenge 1975: D. L. Strenge, E. C. Watson, and J. R. Houston, "SUBDOSA-A Computer Program for Calculating External Doses from Accidental Atmospheric Releases of Radionuclides," Battelle Pacific Northwest Laboratories report BNWL-B-35I (June 1975).

Strenge 1580: D. L. Strenge, "Models Selected for Calculation of Doses, Health Effects and Economic Costs due to Accidental Radionuclide Releases from Nuclear Power Plants," US Nuclear Regulatory Commission report NUREG/CR-1021 (PNL-3108) (May 1980).

Trubey 1973: D. K. Trubey and S. V. Kaye, "The EXREM III Computer Code for Estimating External Radiation Doses to Population from Environmental Releases," Oak Ridge National Laboratory report ORNL/TM-4322 (December 1973).

Wenzel 1982: D. R. Wenzel, "RSAC-3-Radiological Safety Analysis Computer Program," Exxon Nuclear Idaho Company report ENICO-1002 (April 1982). 


\section{APPENDIX F \\ DOSE CODE COMPARISON}

\section{INTRODUCTION}

Several computer codes containing the primary inhalation dose morels have been used to calculate inhalation dose from radiological accidents. These codes and their major features are summarized in Table F-l. The objectives of this effort were to

- gain experience with the major codes now in use elsewhere;

- calculate doses with codes of similar capabilities using a sernistandard set of input representative of major postulated accidents;

- intercompare results from these codes to detect major differences which might lead to inconsistencies in the siting and major design feature process;

- identify codes considered most useful for accident analysis; and

- identify the codes written for chronic dose assessment which are adaptable to the accident case.

Results of this effort are preliminary and are summarized in the following sections.

\section{RESULTS AND DISCUSSION}

Standard input for the codes listed in Table F-I was compiled for two postulated releases: an instantaneous elevated (puff) release of ${ }^{239} \mathrm{PuO}_{2}$ and an 8-h groundlevel release of mixed fission products. Those codes capable of dispersion calculation were provided common meteorological data and depletion data. Other data such as particle size, uptake time, and dose accumulation time were also common.
Results from dispersion and dose calculations are presented in Table F-II. Those codes only capable of dose calculation were supplied with a common $\chi / Q$ (at $10000 \mathrm{~m}$ ) from which to calculate organ doses. These results can be summarized as follows:

- The cause of a problem with the elevated dispersion calculation by the HADOC code was not readily located; RSAC-3 and DACRIN $\chi / Q$ values were in good agreement; and CRAC-2 $\chi / Q$ values were low by a factor of 4 for the ground-level release because an expansion factor proportional to the time of release was included in CRAr-2 but not in the other codes.

- Lung doses were in good agreement among HADOC, RSAC-3, DACRIN, and ICRP after quality factor differences were accounted for; CRAC-2 and INREM II were unaccountably lower in $\mathrm{PuO}_{2}$ dose.

- Bone doses were calculated within factors of 2-4 by all codes except CRAC-2, which was unaccountably lower.

- Liver doses were in good agreement (a factor of 2) among HADOC, DACRIN, ICRP, and INREM II.

- Thyroid doses were not valid in this comparison because of poor choice of radioiodine amounts.

Experience with these codes (HADOC, DACRIN, ICRP, and CRAC-2 at Los Alamos and RSAC-3 by D. Wenzel at INEL) showed all were adaptable to input for this simple accident case with the exception of CRAC-2. CRAC-2 was written for analysis of health and environmental consequences and mitigation effects related to a nuclear reactor accident and is too large and complex to allow the dose discrepancies noted above to be readily reconciled, nor is the code amenable to running a simplified problem. 


\begin{tabular}{|c|c|c|c|c|c|c|c|c|c|c|c|}
\hline & \multicolumn{3}{|c|}{ Environmental Transport } & \multirow[b]{2}{*}{$\begin{array}{l}\text { Cloud } \\
\text { lrrad. }\end{array}$} & \multicolumn{3}{|c|}{ Internal Dosimetry } & \multicolumn{2}{|c|}{ Computerization } & \multirow[b]{2}{*}{ Reference } & \multirow[b]{2}{*}{ Remarks" } \\
\hline & Atmospheric & $\begin{array}{l}\text { Wet } \\
\text { Depos. }\end{array}$ & $\begin{array}{l}\text { Dry } \\
\text { Depos. }\end{array}$ & & Inhalation & Ingestion & $\begin{array}{l}\text { Pop. } \\
\text { Dose }\end{array}$ & Language & Computer & & \\
\hline CRAC-2 & $\begin{array}{l}\mathbf{A} \\
\mathbf{R}\end{array}$ & $\begin{array}{l}\mathbf{A} \\
\mathbf{R}\end{array}$ & $\mathbf{A}$ & $\begin{array}{l}\mathbf{A} \\
\mathbf{R}\end{array}$ & $\begin{array}{l}\mathbf{A} \\
\mathbf{R}\end{array}$ & & $\begin{array}{l}\text { A } \\
\mathbf{R}\end{array}$ & FIV & c & Ritchie 1982 & $\begin{array}{l}\text { At SNLA, WASH } 1400 \\
\text { (NRC 1975); TGLD model }^{d}\end{array}$ \\
\hline HADOC & $\mathbf{A}$ & & & $\mathbf{A}$ & $\mathbf{A}$ & & $\mathbf{A}$ & FIV & 7600 & Strenge 1981 & $\begin{array}{l}\text { At PNL, DACRHN, } \\
\text { TGLD model }\end{array}$ \\
\hline DACRIN & $\mathbf{A}$ & & & & $\begin{array}{l}\mathbf{A} \\
\mathbf{R}\end{array}$ & & & FIV & 6600 & Houston 1974 & $\begin{array}{l}\text { At PNL, TGLD model, } \\
\text { ICRP } 2 \text { dose model }\end{array}$ \\
\hline INREM II & & & & & $\begin{array}{l}\mathbf{A} \\
\mathbf{R}\end{array}$ & $\begin{array}{l}\mathbf{A} \\
\mathbf{R}\end{array}$ & & FIV & 7600 & Killough 1978A,B & $\begin{array}{l}\text { At ORNL, similiar } \\
\text { to ICRP 30, TGLD model }\end{array}$ \\
\hline $\begin{array}{l}\text { ICRP } \\
\text { (ORNL) }\end{array}$ & & & & & $\mathbf{A}$ & & & FIV & & Watson 1980 & $\begin{array}{l}\text { At ORNL, ICRP 30, } \\
\text { TGLD model }\end{array}$ \\
\hline ASAC-3 & $\begin{array}{l}\mathbf{A} \\
\mathbf{R}\end{array}$ & $\begin{array}{l}\mathbf{A} \\
\mathbf{R}\end{array}$ & $\begin{array}{l}\mathbf{A} \\
\mathbf{R}\end{array}$ & $\begin{array}{l}\mathbf{A} \\
\mathbf{R}\end{array}$ & $\begin{array}{l}\mathbf{A} \\
\mathbf{R}\end{array}$ & $\begin{array}{l}\mathbf{A} \\
\mathbf{R}\end{array}$ & $\begin{array}{l}\mathbf{A} \\
\mathbf{R}\end{array}$ & FIV & 7600 & Wenzel I982 & At INEL, TGLD model/ICKP2 \\
\hline \multicolumn{12}{|c|}{$A=$ accidental release, $\mathbf{R}=$ routine release } \\
\hline
\end{tabular}


TABLE F-II. SUMMARY OF RESULTS

\begin{tabular}{|c|c|c|c|c|c|c|}
\hline \multirow[b]{2}{*}{ Code } & \multirow[b]{2}{*}{$\chi / Q\left(\mathbf{s} / \mathbf{m}^{3}\right)$} & \multicolumn{5}{|c|}{ Inhalation Dose (rem) } \\
\hline & & Whole Body & Lungs & Bone & Liver & Thyroid \\
\hline \multicolumn{7}{|c|}{ Elevated Release of ${ }^{239} \mathrm{PuO}_{2}$} \\
\hline HADOC & $\begin{array}{l}1.2 \times 10^{-10} \\
\left(2.7 \times 10^{-7}\right)^{b}\end{array}$ & $\begin{array}{c}4.0 \times 10^{-17} \\
\left(9.0 \times 10^{-14}\right)\end{array}$ & $\begin{array}{c}1.9 \times 10^{-8} \\
\left(4.2 \times 10^{-5}\right)\end{array}$ & $\begin{array}{c}6.5 \times 10^{-8} \\
\left(1.5 \times 10^{-4}\right)\end{array}$ & $\begin{array}{c}3.9 \times 10^{-8} \\
\left(8.8 \times 10^{-5}\right)\end{array}$ & -- \\
\hline RSAC-3" & $2.8 \times 10^{-7}$ & $3.1 \times 10^{-6}$ & $4.4 \times 10^{-5}$ & $1.3 \times 10^{-4}$ & $1.7 \times 10^{-5}$ & --- \\
\hline DACRIN" & $2.7 \times 10^{-7}$ & $2.6 \times 10^{-6}$ & $4.6 \times 10^{-5}$ & $7.9 \times 10^{-5}$ & $3.7 \times 10^{-5}$ & -- \\
\hline \multirow[t]{2}{*}{ CRAC-2" } & $1.9 \times 10^{-7}$ & $\cdots$ & $1.4 \times 10^{-5}$ & -- & $\cdots$ & -- \\
\hline & $\left(2.7 \times 10^{-7}\right)^{b}$ & -- & $\left(2.0 \times 10^{-5}\right)$ & -- & -- & -- \\
\hline ICRP & $\left(2.7 \times 10^{-7}\right)^{b}$ & --- & $\left(1.0 \times 10^{-4}\right)$ & $\left(3.1 \times 10^{-4}\right)$ & $\left(6.9 \times 10^{-5}\right)$ & - \\
\hline INREM II ${ }^{a, c}$ & $\left(2.7 \times 10^{-7}\right)^{b}$ & -- & $\left(2.8 \times 10^{-5}\right)$ & $\left(8.7 \times 10^{-5}\right)$ & $\left(3.8 \times 10^{-5}\right)$ & -- \\
\hline \multicolumn{7}{|c|}{ Ground-level Release of Mixed Fission Products } \\
\hline HADOC & $4.8 \times 10^{-6}$ & 0.32 & 6.3 & 4.3 & $-\cdots$ & $7.3 \times 10^{-5}$ \\
\hline RSAC-3 & $4.5 \times 10^{-6}$ & 0.19 & 4.5 & 3.1 & -- & $2.7 \times 10^{-5}$ \\
\hline DACRIN & $4.6 \times 10^{-6}$ & 0.40 & 3.3 & 2.3 & - & $1.4 \times 10^{-4}$ \\
\hline \multirow[t]{2}{*}{ CRAC-2 } & $1.2 \times 10^{-6}$ & $1.6 \times 10^{-2}$ & 0.62 & $4.1 \times 10^{-2}$ & -- & $2.9 \times 10^{-3}$ \\
\hline & $\left(4.6 \times 10^{-6}\right)^{b}$ & $\left(6.1 \times 10^{-2}\right)$ & $(2.4)$ & $(0.16)$ & --- & $\left(1.1 \times 10^{-2}\right)$ \\
\hline ICRP & $\left(4.5 \times 10^{-6}\right)^{b}$ & -- & $(6.3)$ & (3.7) & -- & $\left(1.8 \times 10^{-2}\right)^{d}$ \\
\hline INREM II $^{c}$ & $\left(4.5 \times 10^{-6}\right)^{b}$ & -- & $(6.0)$ & -- & -- & $\left(2.5 \times 10^{-2}\right)^{d}$ \\
\hline $\begin{array}{l}\text { 'This code use } \\
\text { bCode does (di } \\
\text { 'From INREN } \\
\text { d'Most of this }\end{array}$ & $\begin{array}{l}=10 \text { for } \\
\text { calculat } \\
\text { ose facto }\end{array}$ & $\begin{array}{l}\text { articles rathe } \\
\text { he standard } \\
\text { ted in Killou }\end{array}$ & $\begin{array}{l}\mathrm{QF}=20 . \\
\mathrm{n} \text { parenthes }\end{array}$ & used. & & \\
\hline
\end{tabular}

\section{REFERENCES}

Houston 1974: J. R. Houston, D. L. Strenge, and E. C. Watson, "DACRIN-A Computer Program for Calculating Organ Dose from Acute or Chronic Radionuclide Inhalation," Pacific Northwest Laboratories report BNWL-B-389 (December 1974).

Killough 1978A: G. G. Killough, D. E. Dunning, Jr., and J. C. Pleasant, "INREM II: A Computer Implementation of Recent Models for Estimating the Dose Equivalent to Organs of Man from an Inhaled or Ingested Radionuclide," US Nuclear Regulatory Commission report NUREG/CR-0114, ORNL/NUREG/TM-84 (1978).

Killough 1978B: G. G. Killough, D. E. Dunning, Jr., S. R. Bernard, and J. C. Pleasant, "Estimates of Internal Dose Equivalent to 22 Target Organs for Radionuclides Occurring in Routine Releases from Nuclear Fuel Cycle Facilities," US Nuclear Regulatory Commission report NUREG/CR-0150, ORNL/NUREG/TM-190 (June 1978).
NRC 1975: "Cálculation of Reactor Accident Consequences," Reactor Safety Study, US Nuclear Regulatory Commission report WASH-1400 (NUREG 75/014) (October 1975), App. VI.

Ritchie 1982: L. T. Ritchie, J. D. Johnson, and R. M. Blond, "CRAC2-Computer Code Users' Guide," Sandia National Latioratories report SAND 81-1994, NUREG/CR-2326 (1982).

Strenge 1981: D. L. Strenge and R. A. Peloquin, "HADOC-A Computer Code for Calculation of External and Inhalation Doses from Acute Radionuclides Releases," Pacific Northwest Laboraturies report PNL-3503 (1980).

Watson 1980: S. B. Watson and M. R. Ford, "A User's Manual to the ICRP Code-A Series of Computer Programs to Perfnrm Dosimetric Calculations for the ICRP Committee 2 Report," Oak Ridge National Laboratory report ORNL/TM-6980 (February 1980).

Wenzel 1982: D. R. Wenzel, "RSAC-3-Radiological Safety Analysis Computer Program," Exxon Nuclear Idaho report ENICO-1002 (April 1982). 


\section{APPENDIX G \\ ENVIRONMENTAL CONTAMINATION CONCERNS}

\section{INTRODUCTION}

Potential for dispersing radioactive material into the environment could affect both the site selection and major design features of a nuclear facility. Long-term radiation dose to the population in the region, major cleanup costs, and loss of production at nearby facilities are potential consequences. For the purposes of the Guide, it is assumed that contamination would be cleaned up to acceptable limits and long-term dose from residual contamination would not be a major concern. Loss of production at a nearby facility is a site-specific matter not easily handled in a generalized guidance document. Therefore, discussion has been limited to decontamination costs, which have received only minimal attention in most accident analyses. This appendix, although reflecting a general shortage of specific decontamination cost information, may be of help to the analyst when environmental contamination concerns are considered.

\section{DECONTAMINATION PARAMETERS}

\section{A. Radionuclide}

Determination of which radionuclides would be important if the environment were seriously contaminated by an accidental release depends on original amount, radioactive half-life, and dose conversion factor of the radionuclıde. Methods of determination are discussed in Section V.A.1. of the Guide.

\section{B. Source Strength}

The original source strength provides an indication of the severity of the spill or release. Decontamination costs are generally proportional to the contamination surface concentration, which is proportional to the amount released at the source (Finley 1979).

\section{Chemical Form}

The chemical form is important because decontamination methods depend on the decontamination factors. Ability to remove the radionuclide affects the cost of decontamination; that is, a surface could be decontaminated by physical or chemical cleaning or totally removed, such as removing a section of pavement with jackhammers.

\section{Dispersal Mechanism}

The dispersal mechanism determines the distribution of the concentration levels to be expected and the uniformity over the contaminated areas.

\section{E. Evacuation and Land Use Denial}

Short-term decisions on which areas to evacuate or restrict usage affect decontamination costs. Security needs and costs before, during, and perhaps after decontamination depend on the land use pattern and contamination levels involved. Even after extensive decontamination, some contamination will remain in the environment. Surveillance to follow long-term movement through the food chains may be needed. Land use before decontamination may be restricted. Certain crops, livestock, and produce (milk, for example) could be purchased and disposed of. Livestock foraging may be restricted from some areas.

\section{F. Decontamination Factors}

The decontamination factor is the amount of radionuclide per unit area before decontamination divided by the amount remaining after decontamination. A large variety of decontamination methods is available, ranging from careful hand scrubbing to wet sandblasting (Fore 1982, Chester 1981). Usually the simpler, inexpensive methods work for large areas. Removal and disposal of a surface may be more cost effective than its decontamination, as is the case for soil (Menzel 1971, James 1973). Decontamination data for radionuclide chemical forms encountered are needed for a variety of surfaces and liquids. Table G-I provides examples of decontamination factors developed for $\mathrm{PuO}_{2}$ (Wenzel 1982).

\section{G. Economic and Population Information for the Area}

The building replacement, land, and crop values can be obtained from US Department of Agriculture 


\begin{tabular}{lc}
\hline \hline TABLE G-I. DECONTAMINATION FACTORS FOR PuO \\
\hline General Description of Method \\
\hline Manual removal of vegetation & Decontamination Factor \\
Manual removal of 2 in. of soil & 2 \\
Vegetation removal with farm equipment & 100 \\
Removal of 4 in. soi! with road equipment (2 passes) & 2 \\
Manual decontamination of building interior & 300 \\
$\quad$ using detergants & 100 \\
Fire hosing, hard surfaced once (pavement and roofs) & 30 \\
Fire hosing, hard surfaced twice & 50 \\
Manual water hosing of vegetation & 10 \\
\hline 'Cobb 1973, Finley 1979, McGrath 1975, James 1973, Menzel 1971, Smith 1978, NRC 1975, and Wenzel \\
1982.
\end{tabular}

economists. Depending on the depth of the analysis, an economic activity assessment of the area would be needed to estimate evacuation and land use denial cost estimates. The accuracy of the analysis in general depends on the quality of the population density data for each contamination level and land use type chosen and the detail of monitoring performed before the operation.

\section{DECONTAMINATION TASKS AND COSTS PER UNIT AREA}

\section{A. Waste Disposal Methods}

Waste disposal is a major cost. Whether solid waste is retrievable ( $>100 \mathrm{nCi} / \mathrm{g}$ transuranic) or nonretrievable determines the waste disposal method. Liquid wastes will also be disposed of differently, depending on the level of contamination. Worker radiation dose is directly proportional to radionuclide concentration in the waste. Packaging and attendant cost is related to waste radionuclide concentration. The transport disrance for offsite disposal should be considered.

\section{B. Land Use Patterns}

The basic decontamination tasks and costs depend on land uses of the contaminated area. Table G-II is a generalized listing of typical land use types for agricultural areas, town, and central city. Tables G-III and G-IV give building parameter and land use fractions helpful for cost estimation. Detailed analysis would require site-specific data rather than the generalized data in Tables G-II through G-IV.

\section{Dacontamination Costs/Unit Area}

Decontamination cost/unit area or per capita tables for each land use pattern (agricultural, town, central city) and decontamination level should consider the following:

- initial radiological survey of entire contaminated area;

- land use denial and produce purchase;

- perimeter, urban, and long-term security;

- radiation surveys-precleanup, during cleanup, final certification, surveillance;

- decontamination tasks and costs for each land use area;

- restoration of topsoil and fertility, lawns, streets, buildings, property, and recreational potential; and

- onsite decontamination and restoration.

For illustration, Table G-V gives costs of three land use areas and three decontamination levels as DFs for $\mathrm{PuO}_{2}$ contamination.

\section{ACCIDENT DECONTAMINATION COST}

Once summary cost tables similar to Table G-VI for decontamination cost/unit area or per capita and land use have been developed, the costs for the entire accident decontamination can be estimated over the contamination levels and their area and land use patterns.

\section{A. Accident Radionuclide Contamination Levels}

A pufĩ dispersion model such as DIFOUT (Luna 1969) can be used to estimate the contamination levels 


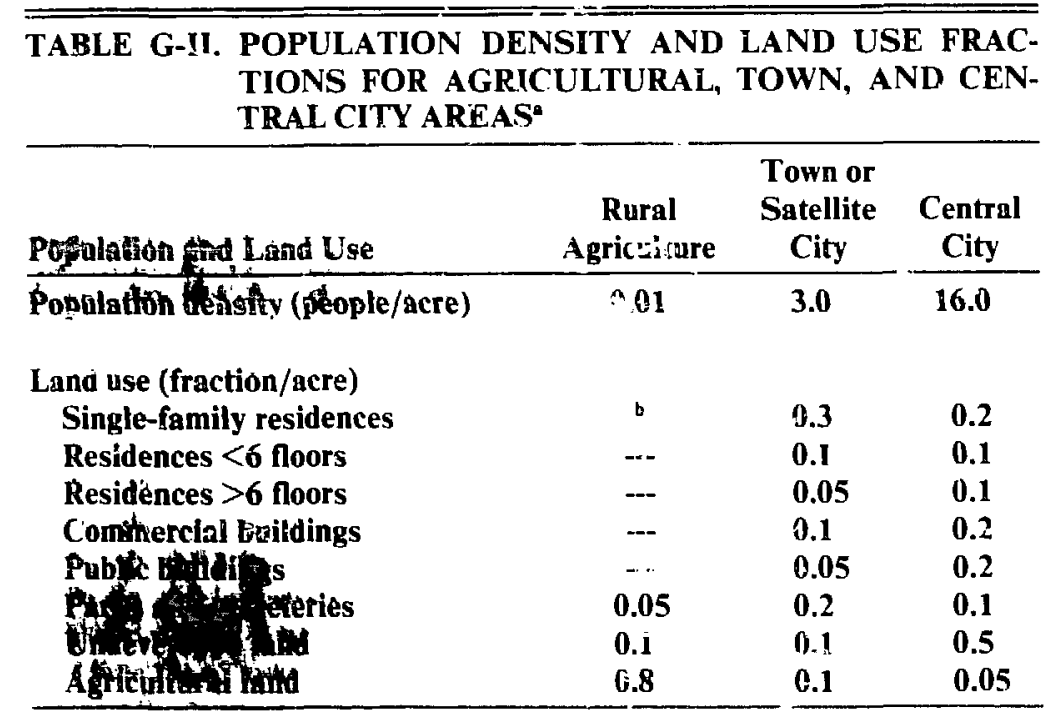

4See Finley 1979, NRC 1975, and Wenzel 1982.

bSingle-famlly residences in rural areas can be estimateci by dividing the population density by 3.2 people per family.

\begin{tabular}{|c|c|c|c|c|c|}
\hline Parameter & $\begin{array}{c}\text { Shifitinty } \\
\text { Rural } \\
\text { Residential }\end{array}$ & $\begin{array}{l}\text { Single-Family } \\
\text { Suburb́an } \\
\text { Residential }\end{array}$ & $\begin{array}{c}\text { Suburban } \\
\text { Apartment } \\
\text { (3 story) } \\
\end{array}$ & $\begin{array}{c}\text { Suivurban } \\
\text { Alartment } \\
\text { (i) story) }\end{array}$ & $\begin{array}{c}\text { Comniercial } \\
\text { 0. Public } \\
\text { Building }\end{array}$ \\
\hline Buildings/acre & 1 & 5 & 5 & 5 & 5 \\
\hline Familíes/acre & $\mathbf{I}$ & 5 & 39 & 60 & $\mathbf{0}$ \\
\hline Lot size $\left(\mathrm{ft}^{2}\right)$ & 40000 & 7260 & 7260 & 7260 & 7260 \\
\hline $\begin{array}{l}\text { Gutreet area }\left(\mathrm{ft}^{\hat{y}}\right) \\
\text { Livewày/parki. lot area }\end{array}$ & 3560 & 1450 & 1450 & 1450 & 1450 \\
\hline$\left(\mathrm{h}^{2}\right)$ & 1000 & 300 & 2660 & 3260 & 3260 \\
\hline Floor arĕá pet fhout $\left(\hat{r}^{2}\right)$ & 2560 & 2006 & 2600 & 2600 & 2600 \\
\hline Number of families/floor & 1 & 1 & $\overline{2}$ & 2 & 0 \\
\hline Open area and lawn $\left(\mathrm{ft}^{2}\right)$ & 36500 & 4960 & 2000 & 1000 & 1000 \\
\hline $\begin{array}{l}\text { Interiur horizontal } \\
\text { area }\left(\mathrm{ft}^{2}\right)\end{array}$ & 2500 & 2000 & 39000 & 78000 & 78000 \\
\hline
\end{tabular}

from particulate depơsition. Some assun̂ntions are needed for the nonhomugeneity of close-in deposition. This can be conservatively estimated by assuming the first or highest isopietn (line of similar concentration) to contain one-half of its area with hot spots set at the highest ground contamination level. The average concentration within an isopleth can be assumed to be one-half of the next isopleth line value.

\section{B. Isopletiı/Land Use Category}

The contamination isopleths and the $80-\mathrm{km}$ grid can be scaled and overiait on topographical or Landsai maps (see Stephon 1979) to estimate areas of undeveloped, agricultural, suburban, commercial, or other land use patterns. Once the fraction of each land use type is estimated for each isopleth, then population census data can be used to estimate the population in each land use fraction. 


\begin{tabular}{|c|c|c|c|c|}
\hline Land Use Type & $\begin{array}{l}\text { Area } \\
\left(\mathbf{m}^{2}\right) \\
\end{array}$ & $\begin{array}{c}\text { Fraction } \\
\text { of Street } \\
\text { Plus } \\
\text { Driveway } \\
\end{array}$ & $\begin{array}{c}\text { Fraction } \\
\text { of Open } \\
\text { Area Plus } \\
\text { Lawn } \\
\end{array}$ & $\begin{array}{c}\text { Fraction of Area } \\
\text { Occupied } \\
\text { by Building }\end{array}$ \\
\hline Rural single-family residence" & 4047 & 0.11 & 0.84 & 0.05 \\
\hline Suburban single-family residence & 809 & 0.20 & 0.57 & 0.23 \\
\hline$<6$-Story suburban apartment & 809 & 0.47 & 0.23 & 0.30 \\
\hline$>6$-Story surburban apartment & 809 & 0.54 & 0.12 & 0.34 \\
\hline Commercial or industrial area & - & 0.50 & 0.05 & 0.45 \\
\hline Public building area & -- & 0.50 & 0.20 & 0.30 \\
\hline Parks and cemeteries & -- & 0.05 & 0.90 & 0.05 \\
\hline Undeveloped and agricultural" & $\cdots$ & 0.025 & 0.95 & 0.025 \\
\hline
\end{tabular}

"Streets and driveways might not be paved or asphalted, which requires different decontamination methods and costs.

\section{Accident Decontamination Cost}

The total cost for the accident in dollars can be calculated by multiplying the area within an isopleth land use category $\left(\mathrm{m}^{2}\right)$ times the decontamination cost per unit area and contamination level for that land use category (dollars $/ \mathrm{m}^{2}$ ) and summing these for each land use category and isopleth. The total cost can then be adjusted for inflation for the year of concern.

\section{REFERENCES}

Chester 1981: C. V. Chester and E. A. Cristy, "Environmental Decontamination-Proceedings of the Workshop," December 4-5, 1979. Oak Ridge, Tennessee, CONF-791234 (February 1981)

Cobb 1973: F. C. Cobb and R. L. Van Hemert, "Source Book on Plutonium and its Decontamination," Defense Nuclear Agency, Kirtland Air Force Base, New Mexico, report DNA-3272T (September 1973).

Finley 1979: N. C. Finley, D. C. Aldrich, S. L. Daniel, D. M. Ericson, C. Henning-Sacks, P. C. Kaestner, N. R. Ortiz, D. D. Sheldon, J. M. Taylor, and S. F. Herreid, "Transportation of Radionuclides in Urban Environment: Draft Environmental Assessment," Sandia National Laboratories report SAND 79-0369 (NUREG/CR-0743) (July 1979).
Fore 1982: C. S. Fore, R. A. Faust, and R. H. Brewster, "Cleanup and Treatment of Radioactively Contaminated Land Including Areas Near Nuclear Facilities-A Selected Bibliography," Oak Ridge National Laboratory report ORNL/EIS-199 (September 1982).

James 1973: P. E. James and R. G. Menzel, "Research on Removing Radioactive Fallout from Farmland," Technical Bulletin No. 1464 (USDA, Agricultural Resez:ch Service, May 1973).

Luna 1969: R. E. Luna and H. W. Church, "DIFOUT: A Model for Computation of Aerosol Transport and Diffusion in the Atmosphere," Sandia National Laboratories report SC-RR-68-555 (January 1969).

McGrath 1975: P. E. McGrath, "Consequences of a Major Nuclear Reactor Accident After Initial Deposition of Released Radioactivit $;$;" Sandia National Laboratories draft report (Division 1721) (1975).

Menzel 1971: R. G. Menzel and P. E. James, "Treatments for Farmland Contaminated with Radioactive Material," Agriculture Handbook No. 395 (USDA, Agricultural Research Service, June 1971).

NRC 1975: "Calculation of Reactor Accident Consequences," Reactor Safety Study," US Nuclear Regulatory Commission report WASH 1400 (NUREG-75/014) (October 1975), App. VI. 


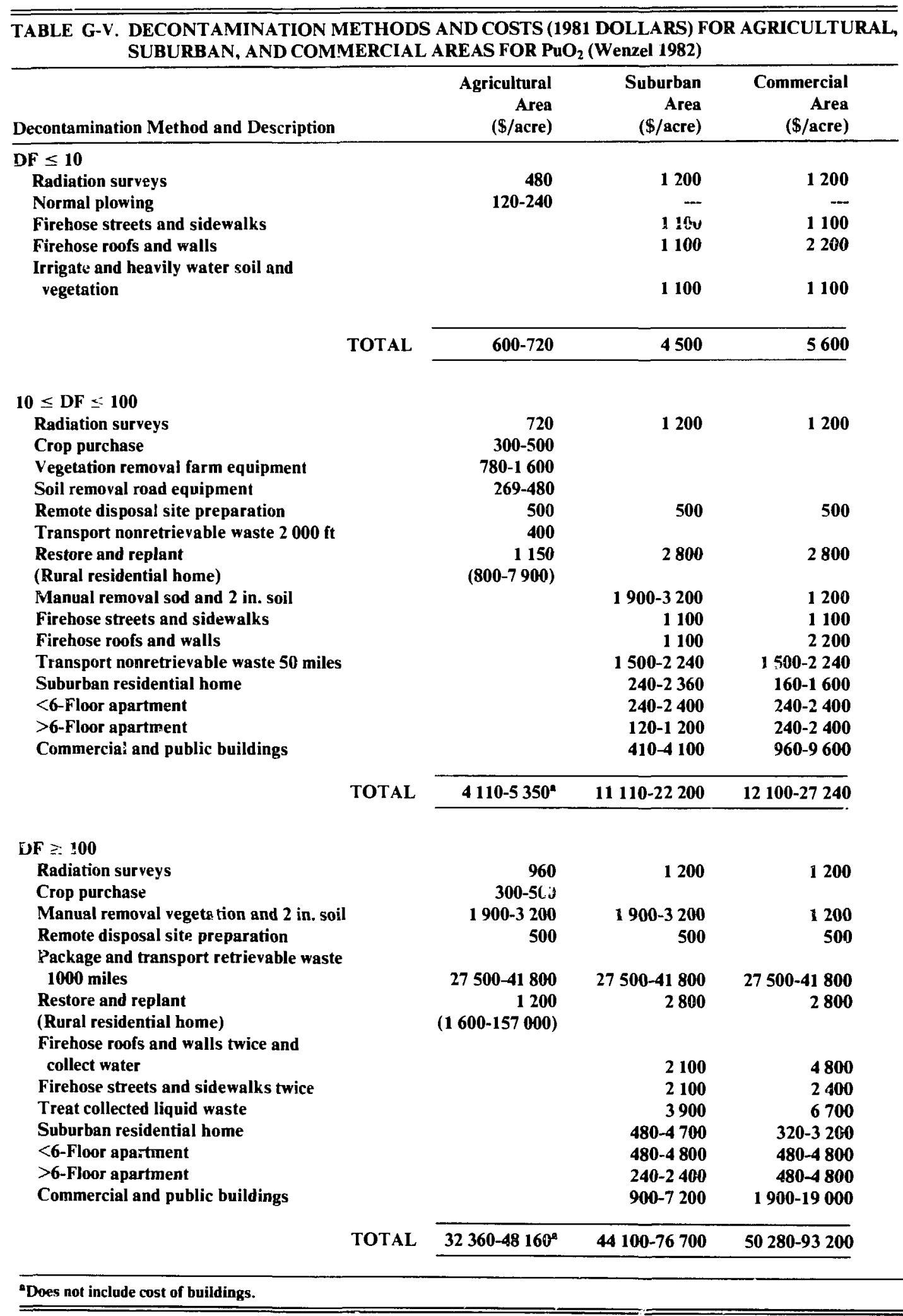




\begin{tabular}{|c|c|c|c|c|}
\hline Land Use & $\begin{array}{l}\text { Dollar Costs } \\
\text { (NRC 1975) }\end{array}$ & $\begin{array}{l}\text { Dollar Costs } \\
\text { (Smith 1978) }\end{array}$ & $\begin{array}{c}\text { Dollar Costs } \\
\text { (Finley 1979) }\end{array}$ & $\begin{array}{l}\text { Dollar Costs } \\
\text { (Wenzel 1982) }\end{array}$ \\
\hline \multicolumn{5}{|l|}{ Agriculture Land } \\
\hline $\begin{array}{c}D F \leq 10 \\
10 \leq D F \leq 100 \\
D F \geq 100\end{array}$ & $\begin{array}{c}\sim 230 / \text { acre } \\
- \\
-\end{array}$ & $\begin{array}{c}\sim 900-4900 / \text { acre } \\
\sim 3600-515000 / \text { acre } \\
-\end{array}$ & - & $\begin{array}{c}\sim 600-720 / \text { acre } \\
\sim 4100-5350 / \text { acre } \\
\sim 32360-48 \text { 160/acre }\end{array}$ \\
\hline \multicolumn{5}{|l|}{ Suburban Land } \\
\hline $\begin{array}{c}\mathrm{DF} \leq 10 \\
10 \leq \mathrm{DF} \leq 100 \\
\mathrm{DF} \geq 100\end{array}$ & $\begin{array}{c}\sim \text { 109-125/capita } \\
\sim \text { 84-93/capita } \\
-\end{array}$ & -- & 〜 185/capita & $\begin{array}{c}\sim 4500 / \text { acre } \\
\sim 11 \text { 100-22 } 000 / \text { acre } \\
\sim 44100-76700 / \text { acre }\end{array}$ \\
\hline \multicolumn{5}{|l|}{ Commercial Land } \\
\hline $\begin{array}{c}D F \leq 10 \\
10 \leq D F \leq 100 \\
D F \geq 100\end{array}$ & $\begin{array}{c}\sim 216-631 / \text { capita } \\
\sim 204-620 / \text { capita } \\
-\end{array}$ & $\begin{array}{l}-- \\
--\end{array}$ & $\begin{array}{l}\sim \text { 130/capita } \\
\sim 638 / \text { capita } \\
-\end{array}$ & $\begin{array}{c}\sim 5600 / \text { acre } \\
\sim 12100-27240 / \text { acre } \\
\sim 50280-93200 / \text { acre }\end{array}$ \\
\hline
\end{tabular}

Smith 1978: C. B. Srith and J. A. Lambert, "Technology and Costs for Cleaning Up Land Contaminated with Plutonium," in Selected Topics: Transuranic Effluents in the General Environment, Technical Note CSD-78-1 (US Environmental Protection Agency, Office of Radiation Programs, Washington, DC, April 1978).

Stephon 1979: J. Stephon, H. Foote, and V. Coburn, "Well Location and Land-Use Mapping in the Columbia Plateau Area," Rockwell Hanford Operations report RHO-BWI-C-61, PNL-3295 (October 1979).
Wenzel 1982: W. J. Wenzel and A. G. Gallegos, "Supplementary Documentation for an Environmental Impact Statement Regarding the Pantex Plant: Decontamination Methods and Cost Estimates for Postulated Accidents," Los Alamos National Laboratory report LA-9445-PNTX-N (1982). 
ATTACHMENT A

COMMENT SHEET

A GUIDE TO RADIOLOGICAL ACCIDENT CONSIDERATIONS FOR SITING AND DESIGN OF DOE NONREACTOR NUCLEAR FACILITIES

Los Alamos National Laboratory report LA-10294-MS

Conment Topic:

Commenter:

Affilistion:

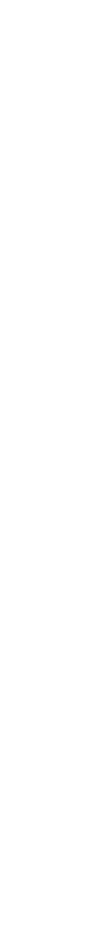

Date:

Address:

Phone:

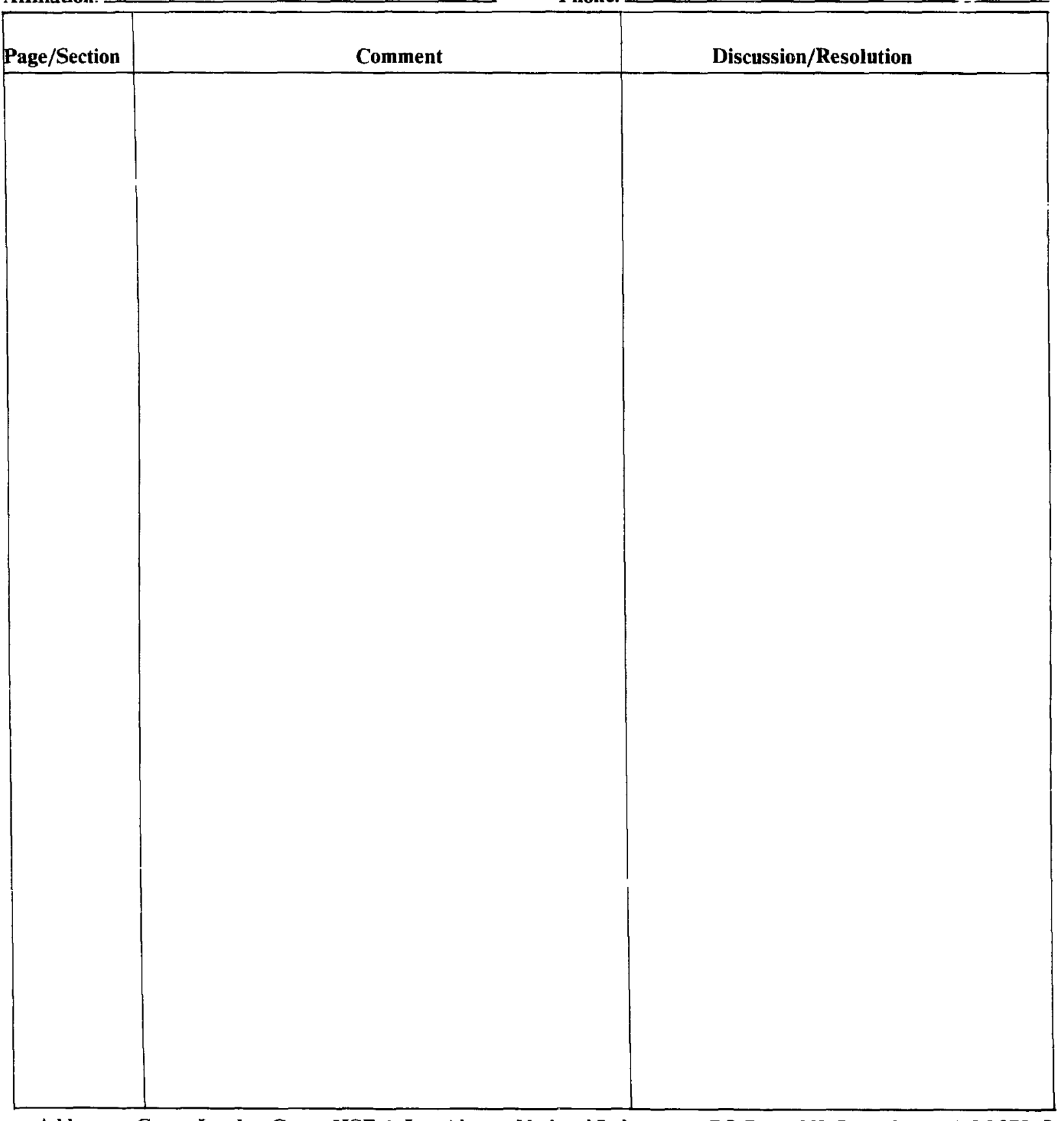

Addressee: Group Leader, Group HSE-1, Los Alamos National Laboratory, PO Box 1663, Los Alamos, NM 87545 